Working Paper in Economics No. 814

\title{
Harmful norms: \\ Can social convention theory explain the persistence of female genital cutting in Africa?
}

\section{Heather Congdon Fors, $\nmid$ Ann-Sofie Isaksson, $\ddagger$ Annika Lindskog}

Department of Economics, November 2021 


\title{
Harmful norms:
}

\section{Can social convention theory explain the persistence of female genital cutting in Africa? *}

\author{
Heather Congdon Fors, ${ }^{\dagger}$ Ann-Sofie Isaksson, ${ }^{\ddagger}$ Annika Lindskog ${ }^{\S}$
}

\begin{abstract}
This paper investigates the explanatory power of social convention theory for explaining the persistence of female genital cutting (FGC) in a broad sample of African countries. While influential in policy circles, the idea that FGC is best described as a bad equilibrium in a social coordination game has recently been challenged by quantitative evidence from selected countries. These studies have pointed towards the importance of private preferences. We use novel approaches to test whether FGC is social interdependent when decisions also depend on private preferences. We test implications of the simple fact that according to social convention theory mothers will sometimes cut their daughters even if they do not support the practice. The substantial regional variation in FGC practices warrants investigation in a broad sample. Empirical results drawing on Demographic and Health Survey data from 34 surveys performed between 1992-2018 in 11 African countries suggest that cutting behavior is indeed often socially interdependent, and hence that it can be understood as a social convention. Our findings indicate that even if social convention theory does not provide the full picture, it should not be dismissed. Accordingly, interventions that acknowledge the social interdependence of cutting behavior are likely to be more successful than interventions that do not.
\end{abstract}

Key words: Female genital cutting; social convention theory; norms; Africa

JEL codes: D71; D91; I15; O55

\section{Introduction}

In this paper we investigate the persistence of female genital cutting - a practice affecting an estimated 200 million women and girls in 30 countries worldwide (UNICEF, 2016). Female

\footnotetext{
*The authors are grateful for comments from Demic Getik, Andreas Kotsadam, Eva Ranehill, Nina Serdarevic, participants in the development economics seminar at the University of Gothenburg, and participants at the 2021 Nordic Conference in Development Economics. We also thank Chi Nguyen for her valuable research assistance. Funding from the Ragnar Söderberg Foundation is gratefully acknowledged. The usual disclaimer applies.

† University of Gothenburg, Department of Economics, heather.fors@economics.gu.se

₹ The Research Institute of Industrial Economics and University of Gothenburg, Department of Economics, ann-sofie.isaksson@economics.gu.se

$\S$ University of Gothenburg, Department of Economics, Annika.lindskog@economics.gu.se
} 
genital cutting ${ }^{5}$ refers to procedures involving partial or total removal of the external female genitalia or other injury to the female genital organs for non-medical reasons (WHO, 2008). On top of the immediate health risks involved, which include severe pain, excessive bleeding or even death (from, e.g., infections or haemorrhage), the practice can have severe long-term physiological and psychological effects (WHO, 2008), with consequences for the health, educational attainment, labor market outcomes, and productivity of women in societies where the practice is widespread (Bellemare et al., 2015).

Despite a significant anthropological literature on the existence of FGC in different countries around the world (Shell-Duncan et al. 2011), there is still little consensus about why it continues to be practiced. Until recently, the most influential theory to explain why FGC persists in spite of its harmful consequences has been social convention theory, according to which FGC is a bad equilibrium in a social coordination game (Mackie, 1996). Cutting is interpreted as a coordinated practice that families use to prepare their daughters for marriage, and individual parents who divert from local FGC norms harm their daughter's chances on the marriage market. As such, the prevalence of FGC in the community is critical to a family's decision about whether or not to cut their daughter. Hence, the FGC decision is socially interdependent, that is, it depends on what others in the community are doing (Bicchieri, 2017). Strictly interpreted ${ }^{6}$, social convention theory suggests that a critical threshold - or tipping point - exists such that, if the share of families who cut their daughters and demand cut wives for their sons is above the threshold, all families have an incentive to cut. If the share of families is below the threshold, however, the probability of finding husbands without cutting one's daughter is sufficiently high for families to reap the benefits of marriage without the health costs of cutting, and the rate of FGC should fall to zero (see the discussion in Hayford and Trinitapoli, 2011 and Efferson et al., 2015).

The over-arching aim of this paper is to investigate the explanatory power of social convention theory for explaining the persistence of female genital cutting in a broad sample of African countries, the broadest to date. We use novel empirical procedures to determine if

\footnotetext{
${ }^{5}$ Also known as female genital mutilation and female circumcision. Whereas the former, used by e.g. the WHO, is intended to emphasize the gravity of the act, the latter translates the terms used in African languages more accurately, but on the other hand signals that the practice is comparable with male circumcision (which it is not). The term female genital cutting, or FGC, which we use in this paper, can be seen as a middle way. 'Cutting' is a more neutral term than 'mutilation', but still does not downplay the gravity of the practice. For a discussion of the terminology, see e.g. Yoder et al. (2013).

${ }^{6}$ With strictly interpreted we mean an interpretation where the decision to cut or not to cut the daughter only depends on what others think and do.
} 
behavior is socially interdependent in a context where it may also depend on private preferences, where private preferences depend on the utility that the mother would get from cutting her daughter if there was no social consequences. ${ }^{7}$ That is, mothers may have varying preferences for the practice, depending on their beliefs about benefits and costs that are not of a social nature.

We present a simple model that incorporates both private and social utility of female genital cutting. It illustrates that interior equilibria are possible even in the presence of social interdependence and that corner solutions are possible also without social interdependence. Hence, we cannot test for social interdependence using only information about community FGC rates. As mentioned, the model captures the fact that social convention theory implies that people will sometimes act against their own convictions.

Our empirical approach builds on this simple fact: social convention theory implies that parents whose private preferences are not in favor of FGC will sometimes still cut their daughter if the community FGC rate is high enough. Conversely, parents whose private preferences are in favor of FGC may sometimes abstain from cutting their daughter if the community FGC rate is low enough, even if proponents of social convention theory has not emphasized this. To test implications of this fact, we use information about respondents' private preferences and the cutting of daughters. First, we test whether the community FGC rate remains a significant predictor of the decision to cut one's daughter when we account for mothers' private FGC preferences in a regression framework. Second, we compare the distributions of reported cutting of daughters and reported preferences for FGC in communities. If the cutting decision is socially interdependent, such that mothers who do not favour FGC do sometimes cut their daughter if FGC rates are high enough, the distribution of cutting behaviour should be more extreme than the distribution of private cutting preferences. Third, we compare the relationship between the community FGC rate and cutting of daughters for mothers who support FGC and mothers who do not support FGC. If the cutting decision is socially interdependent this relationship should be more concave for mothers who support FGC than for mothers who do not, again since mothers who do not favour FGC will sometimes still choice to cut their daughters when community FGC rates are high. Importantly the last two tests should be robust to misreporting (see the discussion in Section 5).

The analysis draws on Demographic and Health Survey data from 34 surveys performed between 1992-2018 in 11 African countries. The data consist in mother-daughter pairs with

\footnotetext{
${ }^{7}$ Gulesci et al. (2021) use the term intrinsic utility.
} 
information on the FGC status of both mothers and daughters as well as on a wide range of covariates. We find that the community cut rate, measured among co-ethnics from the same region born 1-6 years before the daughter, remains a strong predictor of the daughters' FGC status even when we control for mothers' private preferences in a regression framework. Furthermore, the distribution of cutting behavior is indeed more extreme than the distribution of private preferences in the pooled sample and in the majority of separate country samples. Also suggestive of social interdependence, the relationship between the community cut rate and the cutting of daughters is more concave for mothers' who support FGC than for mothers' who do not in the pooled sample and in the majority of the individual country samples.

Taken together, our results thus suggest that cutting behavior is often socially interdependent, and hence that it can be understood as a social convention. Even if, as earlier studies have shown, social convention theory does not provide the full picture, it should not be dismissed. This implies that interventions which acknowledge the social interdependence of cutting behavior are likely to be more successful than interventions that do not.

In complementary analysis, we first endogenize mothers' private preferences by considering the intergenerational transmission of values. We test whether the community FGC rate remains a significant predictor of the FGC of daughters when we account for mothers' own FGC status. We find that it does, even if mothers' own FGC status is in itself a strong predictor of whether or not the daughter is cut. In a subsample of mother-daughter pairs where the mother has moved between regions and we have information about where she lived before, we also control for the influence of the FGC rate in the community where the mother grew up. The vertical transmission channel appear to be influential, but the community cut rate remains an important predictor when we control for it. In the subsample of "movers", in addition to mothers' FGC status, both the FGC rate in the current community and that in the community where the mother grew up predict whether or not daughters are cut. Hence, both intergenerational transmission of values and beliefs and social conventions theory have explanatory power.

Second, and along the lines of earlier studies, we investigate the distributions of FGC rates across communities and over time for our broader sample of African countries. This analysis can be seen as a test of a strict version of social convention theory, not allowing for variation in private preferences. Since we only need respondents' own FGC status for this analysis, we can use an even broader sample than in the main analysis. Specifically, we i) investigate the extent to which community FGC rates are close to zero or one with a sharp discontinuity at some threshold value of the community FGC rate and ii) for large ethnic 
groups we investigate whether there appear to be stable internal equilibria where some girls are cut and other girls are not. The distribution of community FGC rates is in line with a strict interpretation of social convention theory in a few countries, but in the pooled sample and in most individual country samples, it is not. Following communities over time shows that most have stable extreme FGC rates (close to zero or one) or steadily declining ones, but some appear to have stable interior FGC rates.

Social convention theory has had a major influence on the efforts of key development agencies to end FGC (see e.g. UNICEF, 2010; UNICEF, 2013; WHO, 2008). As formulated in the UN interagency statement on female genital mutilation (WHO, 2008, p. 13), the conventional nature of FGC "requires a significant number of families within a community to make a collective, coordinated choice to abandon the practice". Efferson et al. (2015) describe a typical intervention as consisting in development workers trying to convince families in a community to abandon cutting. Once they estimate that they have enough families to cross the critical threshold, they organize a public declaration. The hope is that this will lead the remaining families to realize that abandoning the practice is now in their own interest. Hence, whether or not FGC is socially interdependent is highly policy relevant. If there is an important element of social interdependence, community level interventions that bring people together to discuss and agree to abandon the practice are likely to be more efficient than interventions that lack a social component, which are less likely to affect expectations about the FGC decisions of others.

However, recent quantitative evidence from selected countries has challenged the explanatory power of social convention theory in the case of FGC (Bellemare et al., 2015; Efferson et al., 2015; Novak, 2020). Efferson et al. (2015) find in their Sudanese sample that community level cutting rates vary continuously along the full spectrum, rather than being extremely high or extremely low and displaying a clear discontinuity suggestive of coordination, leading them to state that "Female genital cutting is not a social coordination norm". Novak (2020) investigates the variation in FGC rates within communities over time in Burkina Faso to search for either universal tipping points, as would be suggested by social convention theory strictly interpreted, or stable interior equilibria where some members in the community cut their daughters while others do not. She finds that while some communities appear to have tipping points after which the FGC rate falls to zero, others display stable interior equilibria. Bellemare et al. (2015) find that attitudes to female genital cutting in West Africa depend more on household- and individual-level determinants than on village-level factors. However, their study focuses on attitudes rather than behavior, and is not designed to 
evaluate the explanatory power of social convention theory for FGC. Mackie (1996) argues that a defining feature of the convention is that in communities where it is practiced, it is practiced even by those who oppose it. Indeed, Akinsanya and Gbadebo (2011), who study FGC practices in Nigeria, find that many of the respondents who claimed they did not approve of FGC still practiced the act (and correspondingly, those who did not cut their daughters did not necessarily do so because of non-approval). A key question, according to Mackie and LeJeune (2009), is how FGC can persist even in areas where attitudes have turned against it. As outlined above, our model and empirical analysis capture the fact that social convention theory implies that people will act against their own convictions to avoid costs of deviating from the social convention.

In summary, both Efferson (2015) and Novak (2020) reject a strict version of social convention theory, where the cutting decision depends only on what others in the community are doing. Rather, they suggest that the private preferences for FGC is important for the decision of whether or not to cut one's daughter. However, it is difficult to separate social interdependence from community level correlation in private preferences, and previous studies have not been able to empirically test the extent to which FGC is also socially interdependent.

We make several contributions to the literature. We make an immediate contribution to the literature evaluating the explanatory power of social convention theory for FGC (Bellemare et al., 2015; Efferson et al., 2015; Novak, 2020) originally developed by Mackie (1996). Earlier studies have demonstrated that individual private preferences appear to matter. We test implications of social convention theory when decisions depend on private utility in addition to social utility. We also contribute by using the largest sample to date (namely all African countries engaging in the practice and for which data is available). This is important considering the substantial regional variation in FGC practices (see the discussion in Section 2), and the multiple potential mechanisms involved.

We also contribute to the emerging literature on interventions to eradicate FGC (see e.g. Shell-Duncan et al., 2011, 2013; Camilotti, 2015; Vogt et al., 2016; García-Hombrados and Salgado, 2019). Our study provides insights about whether or not it is beneficial to organize interventions collectively in communities.

In more general terms, the study contributes to the literature exploring factors (not related to social convention theory specifically) affecting FGC practices (see e.g. Poyker, 2016, on the role of regime stability; Vogt et al., 2016, on the impact of information campaigns; Becker, 2019, on the role of pastoralism and paternal uncertainty; Harari, 2019, on the impact of 
inheritance rights, Diabate and Mesple-Somps, 2019, on the role of return migrants for norm transmission, and Corno et al., 2020, on the impact of slave trade), as well as the persistence of other deeply rooted harmful practices (Alesina et al., 2021).

Last but not least, we contribute to the general social norms literature (e.g. Bénabou and Tirole, 2006; Tabellini, 2008; Acemoglu and Jackson, 2015, 2017; Bicchieri, 2017; Ali and Bénabou, 2020; Bursztyn et al., 2020) by providing novel procedures to test for social interdependence using data on attitudes and behaviors

\section{Background on FGC practices}

The term female genital cutting describes a broad range of practices performed on girls, mostly before the age of 15 and often in infancy or early childhood (UNICEF, 2013). The long-term health risks include chronic pain, infections, excessive scar tissue, urinary and menstrual problems, painful sexual intercourse, an increased risk for HIV infection due to bleeding during intercourse, birth complications, dangers to the newborn, and psychological consequences such as anxiety and post-traumatic stress disorder (WHO, 2008). The World Health Organization (2018) classifies FGC into four types. In the first type, clitoridectomy, the clitoris is partially or totally removed. In the second type, excision, both the clitoris and the labia are partially or totally removed. In the third and most extreme type, infibulation, the vaginal opening is narrowed by cutting, repositioning and sometimes stitching together the labia. The fourth type includes all other harmful procedures to the female genitalia for nonmedical purposes, e.g. pricking, piercing, incising, scraping and cauterizing the genital area.

Historically, FGC is thought to have originated as a custom to constrain women's sexuality. Anthropological studies suggest that customs restricting female sexuality serve the function of reducing paternity uncertainty, and thus disproportionately tend to appear in environments where mate guarding is difficult (Mackie, 1996; Becker, 2019; Corno et al., 2020).

Laws banning FGC have been passed in the majority of African countries (see Table A1), but vary significantly in terms of their degree of restriction and enforcement (see the discussion in Shell-Duncan et al., 2013). Perhaps most notably, even in countries where FGC is illegal, it is still often widely practiced.

There is substantial regional variation in prevalence and type of FGC practiced (see Table A1). The concentration of FGC is particularly high in northern East Africa; in Somalia (not in our sample), Egypt and Sudan estimated prevalence rates range between 87 and 98 percent 
(Orchid Project, 2021). Furthermore, the rate of infibulation is much higher here than elsewhere. FGC is also concentrated in some West African countries - Burkina Faso, the Gambia, Guinea, Liberia, Mali and Sierra Leone - with estimated prevalence rates ranging from 50 (Liberia) to 97 percent (Guinea).

While accounts of variation in FGC practices commonly cite cultural variables, such as ethnicity and religion, it is worth emphasizing that an ethnic or religious explanation of FGC is not sufficient (Mackie and LeJeune, 2009). First, FGC is practiced in a wide variety of ethnic and religious groups, and second, the practice is often not universal within the broader group, but rather focused within certain subgroups. With respect to religion, there are both Christian and Muslim communities who practice FGC, often believing that the practice is required by the holy book. Yet, nearby communities of the same religion may not engage in the practice, and worldwide most Christians and most Muslims clearly do not.

Justifications offered for practicing FGC differ across groups, but marriageability is still perhaps the most common reason offered across practicing communities, irrespective of ethnicity, religion and severity of cutting (Mackie and LeJeune, 2009). In line with this idea, Chesnokova and Vaithianathan (2010) model FGC as a pre-marital investment. Similarly, García-Hombrados and Salgado (2019) suggest that education and FGC work as substitutes in the marriage market and that educational investments are affected by the cost of alternative pre-marital investments, such as FGC. Empirical findings from Senegal support this view. Based on DHS data from 13 African countries, Wagner (2015) shows that conditional on e.g. ethnic group, village and age, women who have undergone FGC are more likely to be married. In the next section, we will present a simple model where parents' decision regarding whether or not to cut their daughter depends on both private preferences and social forces.

\section{Theoretical framework}

Below we sketch a simple model to illustrate our argument of an interplay between private and social utility in the decision of whether or not to cut a daughter. The model, which is inspired by Novak (2020) and Gulesci et al. (2021), shows that investigating the distribution of community FGC rates is not enough to test social convention theory; all types of distributions are theoretically possible regardless of whether households respond to the behavior of other households in the community or not. The model also demonstrates how households may go against their private preferences if social norms (either for or against FGC) are sufficiently strong, and how this can be used to test social convention theory. 
We refer to mothers as the primary unit of analysis and abstract from intra-household bargaining. ${ }^{8}$ Mothers can choose between two actions $A=\{0,1\}$, where 0 is not to cut her daughter and 1 is to cut her daughter. Mothers choose the action that maximizes her utility, where the utility function consists of one private and one social component. The private component captures utility from doing what the mother personally believes is right for the daughter if there were no social consequences of the decision. The social component captures social utility, which depends on reactions of others to the decision, i.e. marriage market consequences and other types of social rewards or punishments.

Let $\gamma_{i c}^{A}$ be the private utility associated with cutting or not cutting the daughter for mother $i$ in community c. $\gamma_{i c}^{A}$ will depend on the mother's values and beliefs about (nonsocial) costs and benefits of female genital cutting. For example, it will matter whether she believes that cutting is an important religious or ceremonial act, possible beliefs about adverse consequences at childbirth, perceptions of health costs, etc. We allow values and beliefs, and thus private preferences, to be correlated within communities, but also to display withincommunity variation. ${ }^{9}$ Without loss of generality, we normalize the private utility of not cutting the daughter to 0 . Thus, $\gamma_{i c}^{1}$ is the perceived private net benefit of cutting the daughter, which can be either positive or negative.

Let $r_{c}$ be the cut rate in the community, where $0 \leq r_{c} \leq 1$. Let $s^{A}\left(r_{c}\right)$ be the social benefit of cutting or not cutting daughters. The social benefits include for example differences in expected marriage outcomes and other possible social rewards. In line with Novak (2020), we make a number of simplifying assumptions about the nature of the social utility. First, we assume that the community cut rate is observable and that mothers are norm-takers, i.e. they accept the prevailing norms in the community, rather than trying to shape the norms themselves. ${ }^{10}$ Second, we assume that the social benefit of cutting daughters is increasing in the community cut rate, while the social benefit of not cutting daughters is decreasing in the

\footnotetext{
${ }^{8}$ Gulesci et al. (2021) identify mothers as the main decision-makers regarding daughters FGC in their Somalian sample. According to their argument, fathers sometimes participate in the decision, while extended family members rarely do so. This is also in line with the general finding from the anthropological literature that women are typically the primary decision-makers when it comes to FGC (see e.g. Mackie, 1996; Shell_Duncan et al., 2011).

${ }^{9}$ In models of cultural transmission of values and beliefs there will often be convergence in communities. But heterogeneity may exist both as a stable equilibria and along the convergence process (Bisin and Verdier, 2000; 2001; Giavazzi et al., 2019).

${ }^{10}$ In many cultures, the FGC procedure involves ceremony and celebration (see e.g. Wagner, 2015). In the communities Efferson et al. (2015) study in Sudan, for instance, henna is applied to a girl's feet when she is cut, and in Sierra Leone and Liberia, FGC is practiced as part of an initiation into a secret society for women (Yoder et al., 2013).
} 
community cut rate, $r_{c}$. More specifically we assume $s^{1}\left(r_{c}\right)=0$ and $s^{0}\left(r_{c}\right)>0$ when $r_{c}=0$ while $s^{1}\left(r_{c}\right)>0$ and $s^{0}\left(r_{c}\right)=0$ when $r_{c}=1$. Moreover, we assume that households and communities can vary in their sensitivity to social norms, captured by a sensitivity parameter $\alpha_{i c}{ }^{11}$

Given the above, the utility function for a mother that chooses to cut her daughter is $V^{1}=$ $\gamma_{i c}^{1}+\alpha_{i c} s^{1}\left(r_{c}\right)$ while the utility function for a mother that chooses not to cut her daughter is $V^{0}=\alpha_{i c} s^{0}\left(r_{c}\right)$. Taken together, this implies that a mother will choose to cut her daughter if

$$
V^{1}-V^{0}=\gamma_{i c}^{1}+\alpha_{i c}\left(s^{1}\left(r_{c}\right)-s^{0}\left(r_{c}\right)\right)>0
$$

From equation 1 we can see that in the extreme case where there is no individual household variation in the parameters, we should observe community cutting rates of either $r_{c}=0$ or $r_{c}=1$ for the following reasons:

1) If $\alpha_{c}>0$, then there will be a unique threshold value of $r_{c}$ above which all mothers will choose to cut their daughters and below which no one will choose to cut their daughters. This threshold value $r_{c}^{*}$, or tipping point, is the value of $r_{c}$ where $\gamma_{c}^{1}+$ $\alpha_{c} s^{1}\left(r_{c}\right)=\alpha_{c} s^{0}\left(r_{c}\right)$. In this case, the theory predicts that within a given community, if $r_{c}<r_{c}^{*}$ then no household should choose to cut their daughters while if $r_{c}>r_{c}^{*}$ then all households should choose to cut their daughters.

2) If $\alpha_{c}=0$, then the community cut rate is irrelevant to the household's decision to cut their daughters or not, and only the identical private utility will matter, i.e. $\gamma_{c}^{1} \gtreqless 0$. Here we would observe either $r_{c}=0$, when $\gamma_{c}^{1}<0$, or $r_{c}=1$, when $\gamma_{c}^{1}>0$. The difference from the scenario above is that there is no threshold level of $r_{c}$ that would induce households to change their cutting behavior.

However, with individual variation in the parameters of equation 1 , it is no longer certain that we will only observe community cutting rates of either $r_{c}=0$ or $r_{c}=1$. Again, there are two potential scenarios:

\footnotetext{
${ }^{11}$ Realistically, social benefits are likely to vary between communities for a given $r_{c}$ since the relative social importance of the practice may vary between communities, implying that $s^{0}$ and $s^{1}$ would vary between communities. However, given that we assume $\alpha$ varies between communities, we choose to adopt a more general functional form for social benefits for the sake of simplicity.
} 
1) In the case where $\alpha_{i c}>0$, there will no longer be a unique threshold level of $r_{c}^{*}$, but rather each mother will potentially have her own threshold value $r_{i c}^{*}$. This individual threshold level will be determined where $\gamma_{i c}^{1}+\alpha_{i c} s^{1}\left(r_{c}\right)=\alpha_{i c} s^{0}\left(r_{c}\right)$.

2) If on the other hand $\alpha_{i c}=0$, then each mother will decide whether or not to cut her daughters based solely on her private preferences, i.e. whether $\gamma_{i c}^{1} \gtreqless 0 .{ }^{12}$

Both of the scenarios above raise the possibility of intermediate levels of cutting within the community, $r_{c} \in(0,1)$, rather than separating equilibria. As shown by for example Schelling (1978), Granovetter (1978) and Novak (2020), heterogeneous thresholds within the community imply the possible existence of one or more stable internal equilibria where some community members cut and others do not. In the second scenario, the community cut rate does not play a role in household cutting behaviour, and we would therefore expect a stable internal equilibrium with no tipping points.

From the above discussion, it is clear that all types of equilibrium behavior are theoretically possible regardless of the role of private- and social utility, while social convention theory is only relevant in the cases where $\alpha>0$. For social convention theory to be useful to understand the persistence of FGC, and for designing interventions to encourage abandonment of the practise, households should respond to what other households are doing and thinking, i.e. to the community cut rate. We thus need a way to disentangle the individual motivations from the social ones. To do so we will make use of information regarding mothers' private preferences. In particular, $\alpha>0$ implies the following:

Testable implication 1: There will be a positive association between households' cutting behaviour and community cut rates when we control for mothers' private preferences.

If mothers respond to the community cut rate, we should observe a positive association between cutting behaviour and community cut rates when we control for mothers' private preferences (a related implication is that in general we cannot distinguish between an impact of community cut rates and correlated values and beliefs within the community unless we control for private preferences).

If both private preferences and social norms play a role, some households will go against their own preferences when the social benefits of doing so are sufficiently high. According to the

\footnotetext{
${ }^{12}$ If $\alpha_{i c}>0$ for some households and $\alpha_{i c}=0$ for others, then some households decide to cut or not according to scenario 1) and some according to scenario 2).
} 
model, households who oppose the practise will cut their daughter if $\alpha_{i c}\left(s^{1}\left(r_{c}\right)-s^{0}\left(r_{c}\right)\right)>$

$\left|\gamma_{i c}^{1}\right|$, which is more likely the higher $r_{c}$ is. Correspondingly, some households who support the practise will abstain from cutting their daughter if $\left|\alpha_{i c}\left(s^{1}\left(r_{c}\right)-s^{0}\left(r_{c}\right)\right)\right|>\gamma_{i c}^{1}$, which is more likely the lower $r_{c}$ is. In other words, mothers who do not support FGC sometimes cut their daughters when the community FGC rate is high enough, and mothers who support FGC sometimes abstain from cutting their daughter when the community FGC rate is low enough. This has two implications that we will test in the empirical analysis:

Testable implication 2: The community cut rates of daughters will take more extreme values than the community rate of support for FGC.

Testable implication 3: The relationship between the community FGC rate and the decision of whether to cut one's daughter will be more concave among mothers who support FGC than among mothers who do not support the practice. Put differently, cut rates among households who oppose and among households who agree with the practise will be closer at very high and very low community cut rates than at intermediate community cut rates.

\section{Data and sample construction}

In order to investigate the explanatory power of social convention theory for FGC in a wide sample, we use data from the Demographic and Health Survey (DHS, 2021). We compile 49 cross-sectional datasets collected in 15 African countries between 1990 and 2019 that have information about FGC status of respondents and daughters: Benin, Burkina Faso, Chad, Cote d'Ivoire, Egypt, Ethiopia, Guinea, Kenya, Mali, Mauretania, Nigeria, Senegal, Sierra Leone, Sudan and Tanzania.

Information about the FGC status of daughters was collected differently in different surveys. The oldest surveys (1990-2003) asked about the oldest daughter. In between surveys (1995-2013) asked if any daughter was cut, and then specific questions on the most recently cut daughter. The later surveys (2005 and later) asked about FGC status of all daughters up until an age cut-off, usually 15 but sometimes 16 or 17. Table A2 shows the availability of data on daughters' FGC status and how this information was collected for each survey. To get a measure that is comparable across countries and survey rounds, we focus on the FGC status of the oldest daughter. In most survey rounds, we thus assume that the oldest daughter is cut if any daughter is reported to be so. There is support for this assumption in the finding that it 
is very rare that some daughter(s) are cut and other daughter(s) are not, given the younger daughters are old enough (Hayford and Trinitapoli, 2011).

Cut ages vary across (as well as within) countries. We only use observations where the oldest daughter is above the age at which $95 \%$ of cut women in the country are reported to have been so. For the latest surveys where we only know FGC status of daughters below some cut-off age, the oldest observed daughter has to be above the $95 \%$ cut-age. In some countries, such as Kenya, Nigeria, Sierra Leone, and Tanzania where it is common to have the procedure during adolescence, this removes nearly all observations from the latest surveys. Column 3 in Table A3 shows the sample size of mother-daughter pairs from each country.

We measure mothers' private preferences, $\gamma_{i c}^{1}$, using the answer to a question on whether the respondent thinks that FGC should continue or be stopped. If the respondent answers that FGC should continue she is coded as supporting FGC, if she answers that it should be stopped or that she does not know she is coded as not supporting the practice. A possible concern is that reported support for the practice is prone to social desirability bias. Relatedly, the respondent may express preferences that are in line with own past behavior (in particular, whether she has let a daughter undergo FGC in the past) rather than ex ante private preferences, to avoid cognitive dissonance. We will discuss these issues, and how they affect the interpretation of our findings, further below. In the remainder of the paper, we will use the terms private preferences for and support for FGC interchangeably.

Other important variables are those used to define the community to which the respondent and her daughter belong. As noted, social convention theory suggests that the prevalence of FGC in the community, or local marriage market, is critical to a household's decision about whether or not to cut their daughter. How to delineate 'the community' is not evident, however. Ideally, we should have information about social networks constituting marriage market of observed households. Since marriage markets are likely to be defined by ethnicity and geographical proximity we define communities by region, ethnicity and birth year in our main analysis. ${ }^{13}$ In robustness analysis we also i) restrict the analysis to rural areas of the region, ii) define communities only by region and year of birth and iii) use communities defined by sample clusters. Independent of community definition, there is likely to be some

\footnotetext{
${ }^{13}$ See e.g. Isiugo-Abanihe and Fayehun (2017), who study homogamy in Nigeria and find that 9 out of 10 couples marry within their ethnic and religious groups.
} 
measurement error in the community FGC rates, since they are not likely to correspond exactly to the relevant marriage markets.

Our main analysis uses 33 surveys from 11 countries that has information on ethnicity: Benin, Burkina Faso, Chad, Cote d'Ivoire, Ethiopia, Guinea, Kenya, Mali, Nigeria, Senegal, and Sierra Leone. In the robustness analysis, when we use alternative definitions of the community, not based on ethnicity, we can also include Egypt, Mauretania, Sudan and Tanzania. When we investigate the distributions of community cut rates across communities and over time in a broader sample than in earlier studies we can use the data on respondents' own cut status, which enables us to also include the Central African Republic, Gambia and Liberia.

Due to the data restrictions described above, the exact estimation sample varies across specifications. In the baseline estimations in Tables 1-3, the estimation sample consists of 52,750 mother-daughter pairs. Table A4 shows availability of key variables for each survey round. Table A5 show summary statistics for mother-daughter pairs.

\subsection{Measuring FGC in the survey}

The FGC data is based on self-reporting. Women report their own FGC status as well as the FGC status of their daughters. They also report their support for the practice. These accounts are potentially prone to reporting bias. As discussed in De Cao and Lutz (2018), eliciting honest answers in surveys is challenging, especially when studying sensitive issues such as sexual and reproductive health. In particular, a fair concern is that social desirability bias may lead respondents to underreport FGC and FGC support, not least because FGC is, in fact, illegal in many countries (see Table A1).

It seems reasonable to assume that reported support of the practice is more susceptible to social desirability bias than reports of actual behaviors, since attitude questions as opposed to questions on actual behaviors lack a clear-cut true answer. In a study of attitudes towards FGC in Ethiopia, De Cao and Lutz (2018) compare the outcomes of a list experiment designed to elicit truthful answers about FGC support ${ }^{14}$ with the answers given to a direct question about

\footnotetext{
${ }^{14}$ As described by the authors, the method involves presenting respondents with a list of items and asking them to indicate the total number of items with which they agree. The control group receives a list of non-sensitive items. The treatment group receives the same list of non-sensitive items plus one sensitive item. The proportion of the respondents who agree with the sensitive item is estimated by computing the difference in the mean response between the two groups.
} 
the same. ${ }^{15}$ Their results suggest that answers to direct questions underestimated the FGC support by about 10 percentage points.

There are also studies on reporting bias with regard to actual FGC. Comparing the FGC prevalence rate obtained from gynecological exams in two provinces of Burkina Faso in 1998 (Jones et al., 1999) with the FGC rate obtained from the DHS in the same provinces and year, Novak (2019) finds relatively small differences. The gynecological exams suggest an FGC rate of 93 percent. The rate obtained from the DHS data is slightly lower: 89 percent. While the difference is small to begin with, Novak argues that it may in fact be even smaller since the gynecological sample was slightly older (and FGC has declined over time), and since women visiting the clinics are likely to have more health complications than the average woman in these areas (and some of these complications may be the result of having undergone FGC). Similarly, in a study comparing self-reported FGC with results from clinical examinations in Sudan, Elmusharaf et al. (2006) found that while respondents were sometimes confused about which type of FGC they had undergone, there was no misreporting about whether they had undergone FGC or not.

To minimize reporting bias, DHS enumerators are instructed to use the local term for female circumcision (Demographic and Health Survey, 2016). Importantly, then, they do not use the term 'female genital mutilation/cutting', which emphasizes the harmfulness of the practice and as such might have discouraged respondents from answering truthfully. Furthermore, it is worth noting that FGC is relatively common in most of the countries that we study. Figure A1 gives the country sample share of respondents that report to have undergone FGC. It ranges from 15 percent in Tanzania to 97 percent in Guinea. In 11 of our sample countries, more than half of the respondents report to have gone through the procedure. It seems reasonable to assume that in contexts where the practice is this common, underreporting should be less of a concern (see the reasoning in Askew, 2005). ${ }^{16}$ However, respondents may be more prone to underreport FGC in contexts where the practice is rare.

For the reasons described above, we will at all times recognize potential social desirability bias whenever we use self-reported support for FGC in our analysis, while we will regard reported FGC status as more reliable.

\footnotetext{
${ }^{15}$ In particular, they ask respondents 'Do you agree on the following statement? A girl should be circumcised'. ${ }^{16}$ Indeed, we cannot rule out over-reporting in countries where FGC is very widespread.
} 


\section{Empirical strategy}

Our aim is to investigate the extent to which mothers respond to the community FGC rate in their decision about whether or not to cut their daughter, that is whether $\alpha>0$. In the main analysis we test implications of the fact that according to social convention theory mothers will sometimes act against their private preferences to comply with the social convention. Throughout, we will perform the analysis for the pooled sample and for each country separately.

First, we test the predictive power of community FGC rates on the FGC status of daughters in a regression that control for the mother's private FGC preferences:

(1) $Y_{i c j t}=\alpha \cdot r_{c j t}+\gamma \cdot$ support $_{i c j t}+\beta \cdot \mathbf{X}_{i c j t}+\delta_{j t}+\varepsilon_{i c j t}$

where $Y$ is a dummy specifying if daughter $i$ from community $c$ in country $j$ born in year $t$ has undergone $\mathrm{FGC}$, and $r$ refers to the share in the community that has undergone FGC, support is a dummy which equal 1 if the mother support the continuation of FGC, $\mathbf{X}$ is a vector of other individual-level variables (urban, Muslim, Christian, the daughter's age and the mother's education), and $\delta$ are country-specific birth year fixed effects. We cluster the standard errors $\varepsilon_{i c j t}$ at the region level. In line with Novak (2020), we define the relevant community as girls of the same ethnicity and region who were born one to six years prior to the birth of the daughter ${ }^{17}$. This is because it is reasonable to assume that mothers are able to observe the extent to which the procedure is performed on girls born a few years before the daughter in question when making the decision for their daughter. This should also help minimize the reflection problem (Manski, 1993). We use observations of both respondents and daughters to compute community cut rates. ${ }^{18}$

If mothers respond to the community FGC rate, $\alpha$ should be positive and statistically significant even when we control for the mother's private preferences. However, there can be measurement error for both private preferences and community FGC rates, and if private preferences are less precisely estimated than community FGC rates, community FGC rates

\footnotetext{
${ }^{17}$ The exception is robustness regressions where the community is defined by the sampling cluster, which should correspond to a village. In these cases the community rate is computed on everyone in the cluster older than the daughter (respondents and daughters).

${ }^{18}$ Typically the number of observed respondents exceed the number of observed daughters substantially, since not all respondents are mothers, not all mothers have daughters, and not all daughters are within the relevant age range. In total we have 851,708 observations of FGC status of respondents in the eleven countries in the main sample, while we only have 45,877 observations of mother-daughter pairs, where the daughter is in the relevant age-range.
} 
could pick up some correlation in perceived net benefits of FGC in the community even when we control for private preferences. Hence, to add private preferences to the regression in equation 2 might not be enough to claim that parents respond to the community cut rate. Our next two procedures should be robust to measurement error.

Second, we investigate whether the cutting rates of daughters are more extreme than mothers' private preferences. We do so by plotting the distributions of the community rate of support for FGC and the community cut rate of daughters in the same graph. We order communities from the lowest to highest support for FGC and from the lowest to highest cut rate of daughters. In the main analysis, we define communities by ethnicity, region and survey year. As noted, if mothers who do not support FGC sometimes still cut their daughters when the community FGC rate is high enough, and conversely, mothers who support FGC sometimes abstain from cutting their daughter when the community FGC rate is low enough, then the community cut rates of daughters should be more extreme than the community rate of support. That is, we expect more bunching close to zero or one of actual cut rates than of community rates of support. The actual cut rate will then display a more discontinuous pattern, and it may cross the community support rate (being higher at high rates and lower at low rates). Note, however, that proponents of social convention theory tend to focus on the impact at high rates rather than low rates. They are less clear about possible costs of cutting your daughter when few others in the community do so, both in terms of marriage prospects and other possible social costs. Hence the curves may only approach each other at low rates and not cross.

Last, we test if the relationship between the cutting of daughters and the community cut rate is more concave for mothers who support the practice than for mothers who do not support it. If mothers who do not support FGC sometimes cut their daughters when the community FGC rate is high enough and mothers who support FGC sometimes abstain from cutting when the community FGC rate is low enough, this should be the case. We use binned scatter plots with a quadratic fit to illustrate the relationships for each country. To formally test if the relationship between the cutting of daughters and the community cut rate is more concave for mothers who support the practice than for mothers who do not, we run the following regressions:

$$
Y_{i c j t}=\alpha_{0}+\alpha_{1} \cdot r_{c j t}+\alpha_{2} \cdot \text { support }_{i c j t}+\alpha_{3} \cdot r_{c j t} \cdot \operatorname{support}_{i c j t}+\alpha_{4} \cdot r_{-} s q_{c j t}+
$$




$$
\alpha_{5} \cdot r_{-} s q_{c j t} \cdot \text { support }_{i c j t}+\beta \cdot \mathbf{X}_{i c j t}+\delta_{j t}+\varepsilon_{i c j t}
$$

If the relationship is more concave for mothers who support FGC then $\alpha_{5}<0$ and statistically significant.

Importantly, these last two procedures should be valid tests of whether mothers respond to the community cut rate even with misreporting. General under-reporting of support of FGC would not bias these tests. Alternatively, if social desirability bias is systematically related to the community FGC rate, we should expect it to increase the tendency to report more favorable views on FGC when the community FGC rate is high, and less favorable views when it is low. This would work against a pattern where cutting is more extreme than private preferences. It would also work against a pattern where more mothers who report opposing FGC cut their daughters at high rather than at lower community FGC rates.

Relatedly, if mothers report private preferences in line with past behavior to avoid cognitive dissonance, it should be harder to find the hypothesized patterns in the data, since fewer respondents would appear to go against their private preferences.

\section{Results}

In this section, we present the main results, using private preferences to test the relevance of social convention theory. Next, we present the results of complementary analyses, exploring the role of intergenerational transmission of preferences, and the distributions of community cut rates - at a point in time for a broad sample of countries, as well as over time in specific ethnic groups.

\subsection{Main results}

Our main analysis uses private preferences to test the relevance of social convention theory. We first run regressions to estimate the predictive power of community FGC rates when we control for mothers' private preferences. The community FGC rate is for women/girls who belong to the same ethnic group, live in the same region and who were born 1 to 6 years before the daughter. Comparing r-squared in the different specifications in Table 1 shows the high predictive power of in particular community FGC rates but also of private preferences. All specifications include country-specific year of birth effects, thus controlling for country-specific changes over time (say, due to legal reforms, information campaigns etc.) 
Including community FGC rates increases r-squared from 0.306 to 0.526 (Column 1 versus Column 6), while private preferences (Column 2) increases it to 0.446 . Including both of these variables (Column 3) increases r-squared to 0.570. Also adding standard individual-level factors, namely religion, age, urban residence and mother's education, (Column 4) only changes the explanatory power of the model marginally; r-squared increases to $0.573,{ }^{19}$ and adding region dummies (Column 5) increases it to 0.573 .

If the community FGC rate goes from 0 to 1 , the probability that the daughter is cut increases by around 90 percentage points (Column 1). When we control for mothers' private preferences, the community FGC rate coefficient is reduced by a fifth, to 0.734 (Column 3 versus Column 1 in Table 1), suggesting that the community FGC rate to some extent captures correlated beliefs that determine the perceived net benefits of the procedure. However, the coefficient remains both statistically significant and large. If the mother supports the continuation of FGC, the daughter is about 27 percentage points more likely to be cut. Introducing individual controls (Column 4) ${ }^{20}$ and sub-national region dummies (Column 5), does not change this picture markedly.

Table 1: Predictive power of the community FGC rate and mother's support for FGC for daughters' FGC status (LPM coefficients)

\begin{tabular}{|c|c|c|c|c|c|c|}
\hline & $(1)$ & $(2)$ & (3) & (4) & (5) & $(6)$ \\
\hline Community FGC rate & $\begin{array}{c}0.902^{* * *} \\
(0.018)\end{array}$ & & $\begin{array}{c}0.734^{* * *} \\
(0.018)\end{array}$ & $\begin{array}{c}0.724^{* * *} \\
(0.018)\end{array}$ & $\begin{array}{c}0.672 * * * \\
(0.023)\end{array}$ & \\
\hline Private preference & & $\begin{array}{c}0.457 * * * \\
(0.037)\end{array}$ & $\begin{array}{c}0.279 * * * \\
(0.022)\end{array}$ & $\begin{array}{c}0.270 * * * \\
(0.022)\end{array}$ & $\begin{array}{c}0.265^{* * *} \\
(0.023)\end{array}$ & \\
\hline Individual controls & & & & Yes & Yes & \\
\hline $\begin{array}{l}\text { Country\#Year ot birth } \\
\text { effects } \\
\text { Region effects }\end{array}$ & Yes & Yes & Yes & Yes & $\begin{array}{l}\text { Yes } \\
\text { Yes }\end{array}$ & Yes \\
\hline Observations & 52,750 & 52,750 & 52,750 & 52,592 & 52,592 & 52,750 \\
\hline R-squared & 0.526 & 0.446 & 0.570 & 0.573 & 0.579 & 0.306 \\
\hline Mean of outcome & 0.504 & 0.504 & 0.504 & 0.504 & 0.504 & 0.504 \\
\hline
\end{tabular}

\footnotetext{
${ }^{19}$ To only add individual level controls only increase r-squared from 0.306 to 0.334 .

${ }^{20}$ Table A6 show the individual level control coefficients. They are all of the expected sign, but modest in size in comparison to the community FGC rate and the mother's private preference.
} 
Table 2 presents the coefficients on the community FGC rate and the mother's private preference from individual country estimations. Overall, the community parameters are large and statistically significant, most of them falling into the 0.6 to 0.8 range. The parameter on mother's support for the practice is statistically significant at the 5 percent level for all countries except Benin and Sierra Leone. For Sierra Leone it is so at the 10 percent level. Coefficients generally fall within the 0.2 to 0.3 range.

Table 2: Predictive power of the community cut rate and the mother's expressed preference for FGC for daughters' FGC status by country

\begin{tabular}{|c|c|c|c|c|c|}
\hline \multirow[b]{2}{*}{ Benin } & \multicolumn{2}{|c|}{ Community FGC rate } & \multicolumn{2}{|c|}{ Private preferences } & \multirow{2}{*}{$\frac{N}{4094}$} \\
\hline & $0.684^{* * *}$ & $(0.0810)$ & 0.161 & $(0.0925)$ & \\
\hline Burkina Faso & $0.614^{* * *}$ & $(0.0720)$ & $0.293 * * *$ & $(0.0173)$ & 6573 \\
\hline Chad & $0.769 * * *$ & $(0.0427)$ & $0.266^{* * *}$ & $(0.0411)$ & 2020 \\
\hline Cote d'Ivoire & $0.558 * * *$ & $(0.0692)$ & $0.265^{* * *}$ & $(0.0335)$ & 468 \\
\hline Ethiopia & $0.670 * * *$ & $(0.0544)$ & $0.191^{* * *}$ & $(0.0454)$ & 6391 \\
\hline Guinea & $1.175^{* * *}$ & $(0.148)$ & $0.0615^{* *}$ & (0.0209) & 2770 \\
\hline Kenya & $0.765^{* * *}$ & (0.0659) & $0.258 * * *$ & $(0.0602)$ & 2226 \\
\hline Mali & $0.789 * * *$ & $(0.0408)$ & $0.239 * * *$ & $(0.0545)$ & 10558 \\
\hline Nigeria & $0.677 * * *$ & $(0.0496)$ & $0.482 * * *$ & $(0.0592)$ & 3243 \\
\hline Senegal & $0.648^{* * *}$ & $(0.0363)$ & $0.397 * * *$ & $(0.0388)$ & 11623 \\
\hline Sierra Leone & $0.765^{* *}$ & $(0.186)$ & $0.143^{*}$ & $(0.0554)$ & 2626 \\
\hline
\end{tabular}

In sum, the regression results suggest that the community FGC rate is highly predictive of individual-level FGC status, also when we control for mothers' private preferences. Hence, they are in line with social convention theory, which emphasizes the role of social interdependence. However, mother's private preferences could be imprecisely measured. If there is more measurement error in the preference variable than in the community FGC rate variable, the community variable may capture some unobserved variation across communities in perceived private net benefits of FGC.

Next we investigate implications regarding the relationship between private preferences and cut rates that would be hard to explain by alternative factors. First, we compare the distribution of community FGC rates and community rates of support for FGC. Figures 1 and 2 show the distribution of shares of mothers who agree that FGC should continue and the share of mothers who have cut their daughter in the same graph. The community consists of mother-daughter pairs who belong to the same ethnicity, live in the same region and are observed in the same survey year. Communities are ordered from highest to lowest support 
and highest to lowest FGC rate. A pattern where FGC rates are more extreme (closer to zero or one) than private preferences is in line with social convention theory.

Figure 1: The distribution of preferences for FGC and actual cutting of daughters in communities, pooled sample

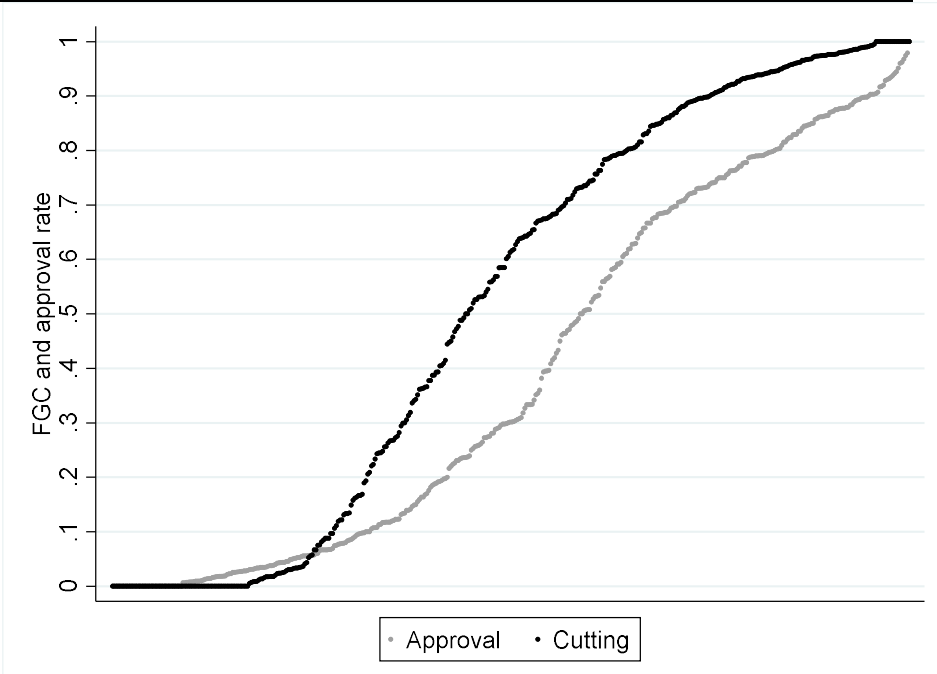

We can note that in general, the distribution of FGC rates is above the distribution of preferences. This is consistent with mothers cutting their daughters against their own private preference because of possible expected marriage market benefits or other social benefits. In particular it is consistent with so called pluralistic ignorance where people hold on to the practice because they believe that support for it is higher than it actually is (Bursztyn et al., 2020). However, it is also consistent with social desirability bias if respondents believe that the right answer to the FGC support question is that it should stop. ${ }^{21}$

Is the distribution of cut rates more extreme than the distribution of preferences? In the pooled sample (Figure 1) this is the case, and the two distributions cross as suggested by social convention theory. Turning to the individual country samples (Figure 2), the two distributions clearly cross in Chad and Senegal, and somewhat less clearly so in Kenya, Nigeria and Sierra Leone. In Guinea and Mali, even though the distributions do not cross, the cutting distribution

\footnotetext{
${ }^{21}$ It is also consistent with mothers having changed their minds since they cut their daughter. However, empirical evidence does not suggest this to be common. At least it is very rare that some daughter(s) are cut and other daughter(s) are not if the younger daughters have reached cut-age (Hayford and Trinitapoli, 2011). It is also consistent with mothers opposing the practise but not being the ones making the decision. Unfortunately we are not able to investigate this possibility with our data. However, Gulesci et al. (2021) identify mothers as the main decision-makers regarding daughters FGC in their Somalian sample.
} 
is more extreme and more discontinuous than the distribution of private preferences. In Benin, Burkina Faso and Ethiopia this is not the case.

Last we compare how cut rates of daughters vary depending on community FGC rates (again among girls 1-6 years older than the daughter who belong to the same ethnic group and live in the same region) for mothers who support FGC and for mothers who do not. Again, we investigate implications of the fact that according to social convention theory mothers who oppose the practice will sometimes still cut their daughter if the community FGC rate is high enough. Similarly mothers who support the practice may sometimes abstain from cutting their daughter if the community FGC rate is low enough. This implies that the relationship between community FGC rates and cutting of daughters should be more concave for mothers who support the practice than for mothers who do not. Put differently, cut rates of daughters to mothers who support and to mothers who do not should be closer at high than at intermediate community FGC rates, and possibly they are also closer at low than at intermediate community FGC rates. 
Figure 2: Distribution of preferences for FGC and cutting of daughters in communities, by country
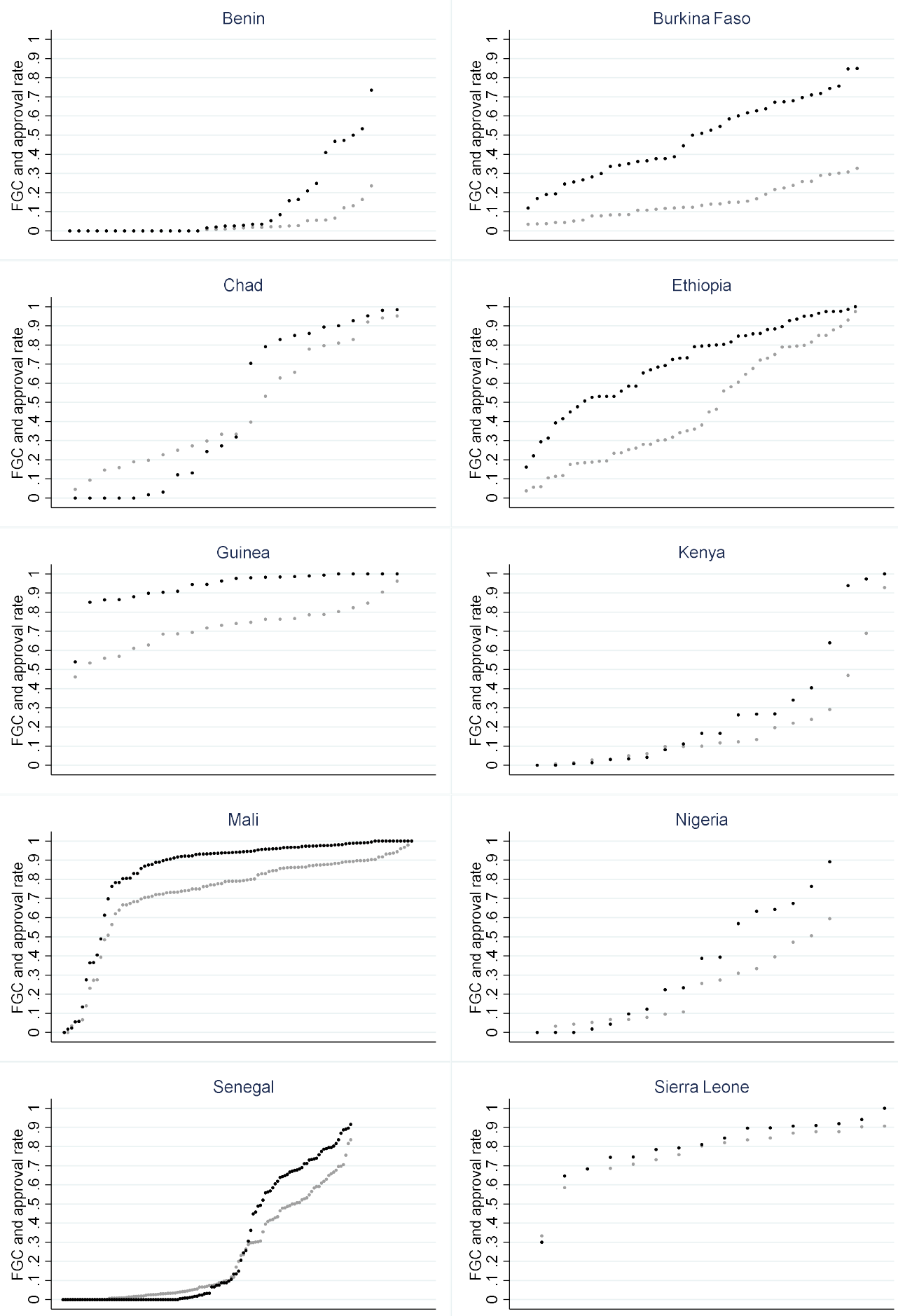

Approval

- Cutting

Note: Cote d'Ivoire is excluded in this analysis, as the region-ethnic groups are not sufficiently large. 
Figures 3 and 4 show bin scatter plots with a quadratic fit of the relationship between previous community FGC rates and the cutting of daughters to mother who support FGC and to mothers who don't in the pooled sample and in different countries. Table 3 shows the coefficient of the term $r_{c}^{2}$ support from regressions of equation 2 in different countries. If the relationship between cut rates of daughters and community cut rates is more concave for mothers who support FGC than for mothers who do not this coefficient should be negative and statistically significant.

Figure 3: Daughters cut rate by community cut rates for mothers who agree with or oppose the practise, pooled sample.

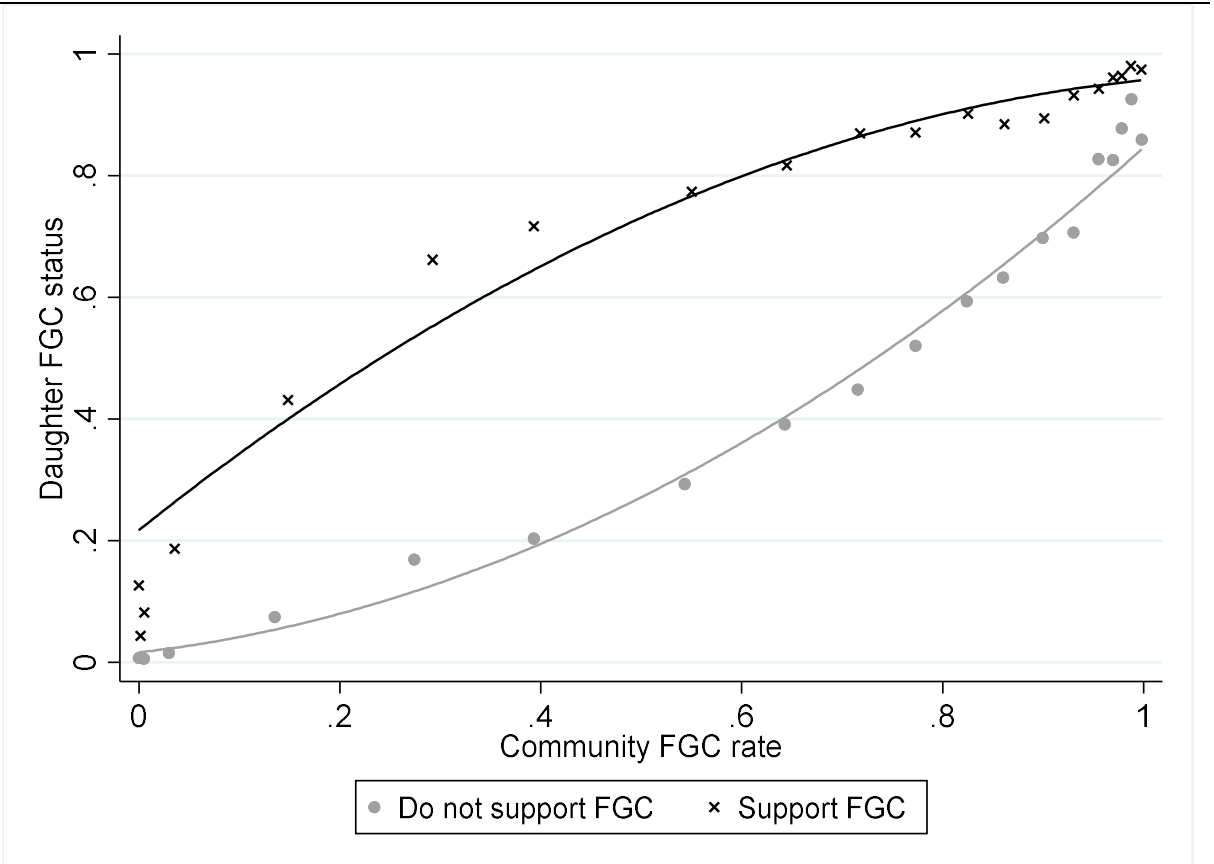

Note: Bin scatter plots with a quadratic fit; The community FGC refers to girls from the same ethnic-region group who were born 1-6 years earlier than the daughter.

Starting with Figure 3, the two curves are indeed closer at both high and low levels of community cut rates than at intermediate ones. Turning to the individual countries (Figure 4), this same pattern is visible in Chad, Cote d'Ivoire, Kenya, Mali, Nigeria and Senegal. Furthermore, in Burkina Faso, Ethiopia, Guinea and Sierra Leone, the two curves are closer at high than at intermediate levels of community cut rates, but do not approach again at low levels. The only country where the two curves are not closer at high than at intermediate levels of community cut rates is Benin. In Table 3, we can see that the relationship is statistically significantly more concave among mothers who support FGC than among mothers who do not it in the pooled sample and in six of the eleven separate country samples: Burkina Faso, 
Chad, Cote d'Ivoire, Guinea, Kenya, and Senegal. In Nigeria the relationship is weakly significant, at the ten percent level.

Figure 4: Daughters cut rate by community cut rates for mothers who agree with or oppose the practise, by country.
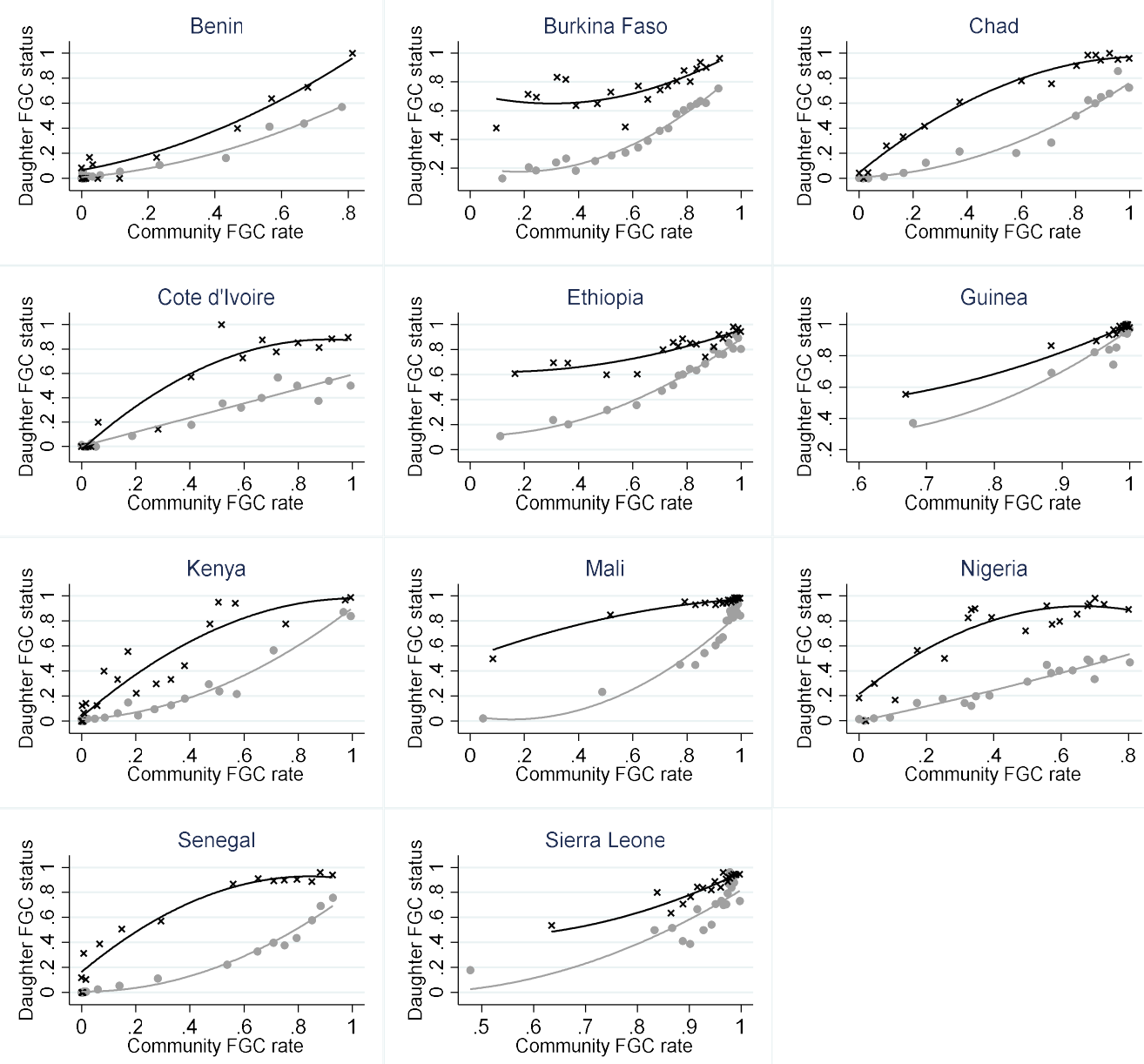

Do not support FGC $\quad \times \quad$ Support FGC

Notes: Bin scatter plots with a quadratic fit.The community FGC refers to girls from the same ethnicregion group who were born 1-6 years earlier than the daughter. 
Table 3: Testing if the relationship between FGC rate of daughter's and the community cut rate is more concave for mothers who support the practice than for mothers who oppose it by country

\begin{tabular}{|c|c|c|c|}
\hline & Community FGC ra & her supports FGC & N \\
\hline Pooled & $-1.316 * * *$ & $(0.141)$ & 52,592 \\
\hline Benin & 0.107 & $(0.354)$ & 4094 \\
\hline Burkina Faso & -0.427 & $(0.250)$ & 6573 \\
\hline Chad & $-1.483 * * *$ & (0.209) & 2020 \\
\hline Cote d'Ivoire & $-1.202^{* *}$ & $(0.500)$ & 468 \\
\hline Ethiopia & -0.280 & (0.459) & 6391 \\
\hline Guinea & -1.644 & (1.256) & 2770 \\
\hline Kenya & $-1.661 * * *$ & $(0.224)$ & 2226 \\
\hline Mali & $-1.787 * * *$ & $(0.211)$ & 10558 \\
\hline Nigeria & $-1.784^{*}$ & $(0.786)$ & 3243 \\
\hline Senegal & $-1.871 * * *$ & $(0.223)$ & 11623 \\
\hline Sierra Leone & -0.137 & $(0.585)$ & 2626 \\
\hline \multicolumn{4}{|c|}{$\begin{array}{l}\text { Notes: Standard errors clustered at the subnational region in parentheses. }{ }^{* * *} p<0.01,{ }^{*} p<0.05,{ }^{*} p<0.1 \text {; } \\
\text { Social convention theory predicts a more concave relationship between FGC rate of daughters and the } \\
\text { community cut rate for mothers who support the practice than for mothers who oppose the practise. If so the } \\
\text { coefficient on the 'community FGC rate squared times support FGC' variable should be negative. The } \\
\text { community FGC rate refers to girls of the same ethnic-region group who were born } 1-6 \text { years earlier than the } \\
\text { daughters. The full model also includes the community FGC rate, the community FGC rate squared, a support } \\
\text { FGC dummy, the community FGC rate times support FGC, the daughter's year of birth and age, religion, level } \\
\text { of education, and urban residence. }\end{array}$} \\
\hline
\end{tabular}

In sum, social convention theory implies that individuals will sometimes diverge from their individual private preferences to gain social or marriage market rewards. In line with this idea, we find that even when we control for mother's private preferences, community FGC rates strongly predict the decision to cut the daughter. Furthermore, consistent with mothers cutting their daughters against their own preferences, the distribution of FGC rates is generally above the distribution of preferences. In most, but not all, countries, the cutting distribution is indeed more extreme and more discontinuous than the distribution of preferences, as expected from social convention theory, and in two countries, Chad and Senegal, the two distributions clearly do cross. With respect to the final prediction, that cut rates of daughters of mothers who agree with and mothers who do not support the practice should be closer at high than at intermediate community FGC rates, this pattern is confirmed in 9 out of 11 countries, but it is only statistically significant at the 5 percent level for 6 of these countries. 
Table 4: Summary of the tests of social convention theory including private preferences

\begin{tabular}{|c|c|c|c|c|}
\hline Test of SCT & Support & Not Support & Mixed results & Not part of test \\
\hline Figure 2 & $\begin{array}{l}\text { Chad, Guinea, } \\
\text { Mali, Kenya, } \\
\text { Nigeria, } \\
\text { Senegal, Sierra } \\
\text { Leone. }\end{array}$ & $\begin{array}{l}\text { Benin, Burkina } \\
\text { Faso, Ethiopia }\end{array}$ & & Cote d'Ivoire \\
\hline Figure 4 and Table 3 & $\begin{array}{l}\text { Burkina Faso, } \\
\text { Chad, Cote } \\
\text { d'Ivoire, Kenya, } \\
\text { Mali, Nigeria*, } \\
\text { Senegal }\end{array}$ & $\begin{array}{l}\text { Benin, Sierra } \\
\text { Leone }\end{array}$ & Ethiopia, Guinea & \\
\hline In sum & $\begin{array}{l}\text { Chad, Cote } \\
\text { d'Ivoire }^{+} \text {Kenya, } \\
\text { Mali, Nigeria, } \\
\text { Senegal }\end{array}$ & Benin, Ethiopia & $\begin{array}{l}\text { Burkina Faso, } \\
\text { Guinea, Sierra } \\
\text { Leone }\end{array}$ & \\
\hline
\end{tabular}

Notes: *At the $10 \%$ level ${ }^{+}$Not included in Figure 2.

Looking at individual countries (see Table 4), all results are in line with social convention theory for Chad, Cote d'Ivoire, Kenya, Mali, Nigeria and Senegal. ${ }^{22}$ Evidence from Benin and Ethiopia are not supportive of social convention theory: the coefficient on the community cut rate is statistically significant even when we control for preferences, but this could be because of measurement errors in preferences. Evidence from Burkina Faso, Guinea, and Sierra Leone is mixed.

We carry out a wide range of robustness tests (see Appendix II). In Tables A7-A8 (and Figures A3-A4), we restrict our analysis to rural areas. Results are extremely similar to in the main analysis.

In Tables A9-A12 (and Figures A5-A8), we use alternative definitions of community. To be able to use also surveys without information on ethnicity, and thus include more countries in the analysis, we define communities using only information on region and birth year. We also define communities by sampling cluster. Given the smaller number of observations from a cluster, we compute community cut rates among everyone in the community older than the daughter in question. Hence, while we increase geographic precision, we lose precision over time. When comparing the distributions of private preferences and cutting of daughters in communities, we decrease the minimum number of observations per community from 30 to 10. The overall patterns remain similar to in the main analysis.

${ }^{22}$ Evidence from Cote d'Ivoire is in line with social convention theory, but the country is not in the analysis where we investigate if community cutting rates are more extreme than preferences, since region-ethnic groups are not large enough. 
In Tables A13-A14 and Figures A9-A10 we restrict the analysis to mother-daughter pairs where the daughter is at most five years older than the $95 \%$ cut age in the country, such that the time in-between the decision to cut the daughter or not and the mother's expressed support for FGC in the survey should not be too long. Results are very similar to in the main analysis.

\subsection{Endogenizing private preferences:The role of intergenerational transmission}

Mothers' private preferences depend on their beliefs and values. Theories of transmission of values and beliefs typically model these to be transmitted vertically within the family and horizontally from interactions with other members of the surrounding society during childhood and adolescence (Bisin and Verdier, 2001; 2011; Doepke and Zilibotti, 2017; Giavazzi et al., 2019). Assume the simplest form possible and let the mother's private utility parameter, $\gamma_{i c}^{1}$ be a weighted average of her mother's private utility parameter $\gamma_{i c}^{v}$ and the average in the society where she grew up, $\gamma_{i c}^{h} \gamma_{i c}=\pi \gamma_{i c}^{v}+(1-\pi) \gamma_{i c}^{h}$, where $\pi \in[0,1]$ is the weight of vertical transmission. The mother will then decide to cut her daughter if: $V^{1}-$ $V^{0}=\pi \gamma_{i c}^{v}+(1-\pi) \gamma_{i c}^{h}+\alpha_{i c}\left(s^{1}\left(r_{c}\right)-s^{0}\left(r_{c}\right)\right)>0$. While we do not directly observe $\gamma_{i c}^{v}$ and $\gamma_{i c}^{h}$, we can use the mother's own cut-status as a measure of $\gamma_{i c}^{v}$ (her mother once took the decision to cut or not to cut her). Similarly we can use the community cut rate where and when the mother grew up as a measure of $\gamma_{i c}^{h}$. In Table 5 we present the results of estimations exploring whether there is a positive association between cutting of daughters and community cut rates when we control for the intergenerational transmission of beliefs and values.

We begin by adding the mother's cut status to the regression in equation 2 . We first do so without controlling for mothers' private preferences and then add the control for mothers' preferences. Note that we expect the intergenerational transmission to work through private preferences. However, we do not expect the mother's expressed private preferences and mothers' cut status to capture exactly the same thing. First, the mother's cut status may be more precisely estimated. However, it is also a less complete measure since it only captures vertical transmission of values and beliefs, not horizontal transmission.

When we add the mother's FGC status to the model that does not control for the mother's preferences, the coefficient on the community FGC rate declines to 0.435 , which is a reduction of more than $50 \%$ and larger than the reduction when we added the mother's private preference to the model. Moreover, the coefficient on mother's FGC status is at least as large 
as the community FGC rate coefficient. When we also control for the mother's private preference for FGC, the coefficients on the community FGC rate and on the mother's FGC status decline to 0.383 and 0.368 , respectively. The coefficient on the mother's expressed preferences is around 0.212. All three coefficients are statistically significant at the one percent level. Separate regressions for each country are presented in Appendix III.

Table 5: Predictive power of the community cut rate and the mother's FGC status for FGC for daughters' FGC status (LPM coefficients)
(1)
(2)
(3)
(4)

VARIABLES

\begin{tabular}{|c|c|c|c|c|}
\hline Mother is cut & $\begin{array}{c}0.437 * * * \\
(0.035)\end{array}$ & $\begin{array}{c}0.464 * * * \\
(0.032)\end{array}$ & $\begin{array}{c}0.383^{* * *} \\
(0.029)\end{array}$ & $\begin{array}{c}0.409 * * * \\
(0.027)\end{array}$ \\
\hline Community cut rate & $\begin{array}{c}0.435 * * * \\
(0.033)\end{array}$ & $\begin{array}{c}0.383^{* * *} \\
(0.029)\end{array}$ & $\begin{array}{c}0.368 * * * \\
(0.030)\end{array}$ & $\begin{array}{c}0.342^{* * *} \\
(0.029)\end{array}$ \\
\hline Mother support FGC & & & $\begin{array}{c}0.212 * * * \\
(0.017)\end{array}$ & $\begin{array}{c}0.198^{* * *} \\
(0.016)\end{array}$ \\
\hline Country\#Year of birth effects & Yes & Yes & Yes & Yes \\
\hline Region effects & No & Yes & No & Yes \\
\hline Observations & 52,462 & 52,462 & 52,462 & 52,462 \\
\hline R-squared & 0.596 & 0.609 & 0.620 & 0.629 \\
\hline
\end{tabular}

According to our model, we should also add a measure of the community cut rate where and when the mother grew up. In general, these are strongly correlated with current community cut rates, not least since we control for country-specific year of birth effects. However, we have information about the previous region of residence for respondents who have moved in the most recent surveys of four countries that also contain ethnicity data, Ethiopia, Mali, Guinea and Nigeria. For the sub-sample of mother-daughter pairs where the mother grew up in a different region than the one where they currently live, we can thus compare the relative importance of community cut rates in the region where the mother grew up to that in the region where they are currently living. The community cut rate when and where the mother grew up is measured by the FGC rate among women of the same ethnicity who were born from five years before to five years after the mother in her previous region of residence. We argue that this should reflect values and beliefs that were transmitted to the mother when she grew up. The community cut rate in the current region is measured by the FGC rate among the youngest cohort with available data, or, if this is available, among girls 1-6 years older than the daughter. We argue that this would be the relevant community to consider if the 
family is concerned about marriage prospects of the daughter or the social rewards and costs that they can expect related to FGC.

Our outcome variable in these regressions is equal to 1 if the daughter is either cut or if the mother states an intention to cut all of her daughters. We use this outcome variable instead of actual cutting to increase the sample size, since the latest surveys only contain information on FGC status of daughters' who are up to age 15 and we need to restrict the sample to the 95\% cut age when we consider actual FGC status (which is age 13 in Ethiopia, age 14 in Guinea, age 11 in Mali, and age 16 in Nigeria ${ }^{23}$ ). This leaves few daughters within the possible age-span (none from Nigeria). Table 6 presents the regression coefficients.

Table 6: Comparing the influence of the community cut rate in the mother's previous region to the one in the current region on actual cutting or intentions to cut

\begin{tabular}{lccc}
\hline & $(1)$ & $(2)$ & $(3)$ \\
\hline Cut rate in mother's & $0.335^{* * *}$ & $0.174^{*}$ & 0.114 \\
previous region & $(0.092)$ & $(0.088)$ & $(0.090)$ \\
Cut rate in current region & $0.299^{* * *}$ & $0.228^{* *}$ & 0.127 \\
& $(0.105)$ & $(0.091)$ & $(0.086)$ \\
Mother is cut & & $0.287^{* * *}$ & $0.219^{* * *}$ \\
& & $(0.061)$ & $(0.050)$ \\
Mother support FGC & & $0.273^{* * *}$ \\
& & & $(0.042)$ \\
Individual controls & Yes & Yes & Yes \\
Country*yob FEs & Yes & Yes & Yes \\
\hline$R^{2}$ & 0.44 & 0.47 & 0.52 \\
$N$ & 1,205 & 1,205 & 1,204 \\
\hline
\end{tabular}

Standard errors clustered at region level in parenthesis.

Column 1 in Table 6 controls for individual-level characteristics and country-specific birthyear effects. Our preferred specification is Column 2, which includes the mother's FGC status (capturing vertical transmission). Column 3 also add the mother's private preference for FGC. When we do not include mothers' cut status the coefficients of both community variables are statistically significant, in spite of the small sample size, and they are comparable in magnitude. When we control for vertical transmission with the mother's cut status, the coefficient of the community where the mother grew up shrink and lose in significance, but is still statistically significant at the ten percent level. When we also add mother's private preference, none of the community variables remain statistically significant, but this may be

\footnotetext{
${ }^{23}$ It is age 18 in Tanzania, which we can also include when we define communities only by region and birth year in Appendix II.
} 
due to the small sample size. Table A17 presents the coefficients from country-specific regressions.

In sum, our empirical estimations suggest that both social convention theory and intergenerational transmission of FGC norms are important to explain the decision of whether or not to cut one's daughter.

\subsection{Investigating the distributions of community cut rates in a broad sample of countries.}

As has been demonstrated by e.g. Efferson et al. (2015) and Novak (2020), community cut rates will be either close to zero or one only in the case where there is little to no individual variation in possible private preferences. The empirical analysis in Efferson et al. (2015) and Novak (2020) focused on Sudan and Burkina Faso, respectively. Following these studies we investigate the distribution of community FGC rates and how these evolve over time in a broad sample of countries. This can be seen as a test of a strict version of social convention theory, not allowing for variation in private preferences.

We first investigate the extent to which community FGC rates are close to zero or one with a sharp discontinuity at some threshold value of the community FGC rate, as would be predicted by social convention theory if there was no individual variation in parameter values. That is, along the lines of Efferson et al. (2015), we order communities by their FGC rate, and explore whether the share that has undergone FGC varies smoothly across the full spectrum or whether there is bunching at very low and very high cut rates (with few at intermediate levels), indicative of coordination. A community consists of women who belong to the same ethnicity, live in the same region and were born in the same year. We use the FGC rate of the respondents since this sample is much larger than that of mother-daughter pairs. ${ }^{24}$ Not the least, it allow us to also include Gambia and Liberia. Figure 5 displays the resulting distributions of community cut rates.

We can note that community FGC rates do indeed display a pattern consistent with coordination in some countries. In the Central African Republic, the Gambia, Guinea, Mali and possibly Benin, Senegal and Sierra Leone there is bunching at high and low cut rates, with relatively few communities displaying intermediate FGC rates. But in other countries the

\footnotetext{
${ }^{24}$ To also include daughters for whom we have data on FGC status does not change the general pattern in any country (not reported but available on request)
} 
distribution varies continuously across the full spectrum: Burkina Faso, Ethiopia, Kenya, Liberia and Nigeria. In the remaining countries, the pattern is more difficult to interpret. In some cases there are few communities large enough to see any patterns.

Figure 5: Distribution of community cut rates by country
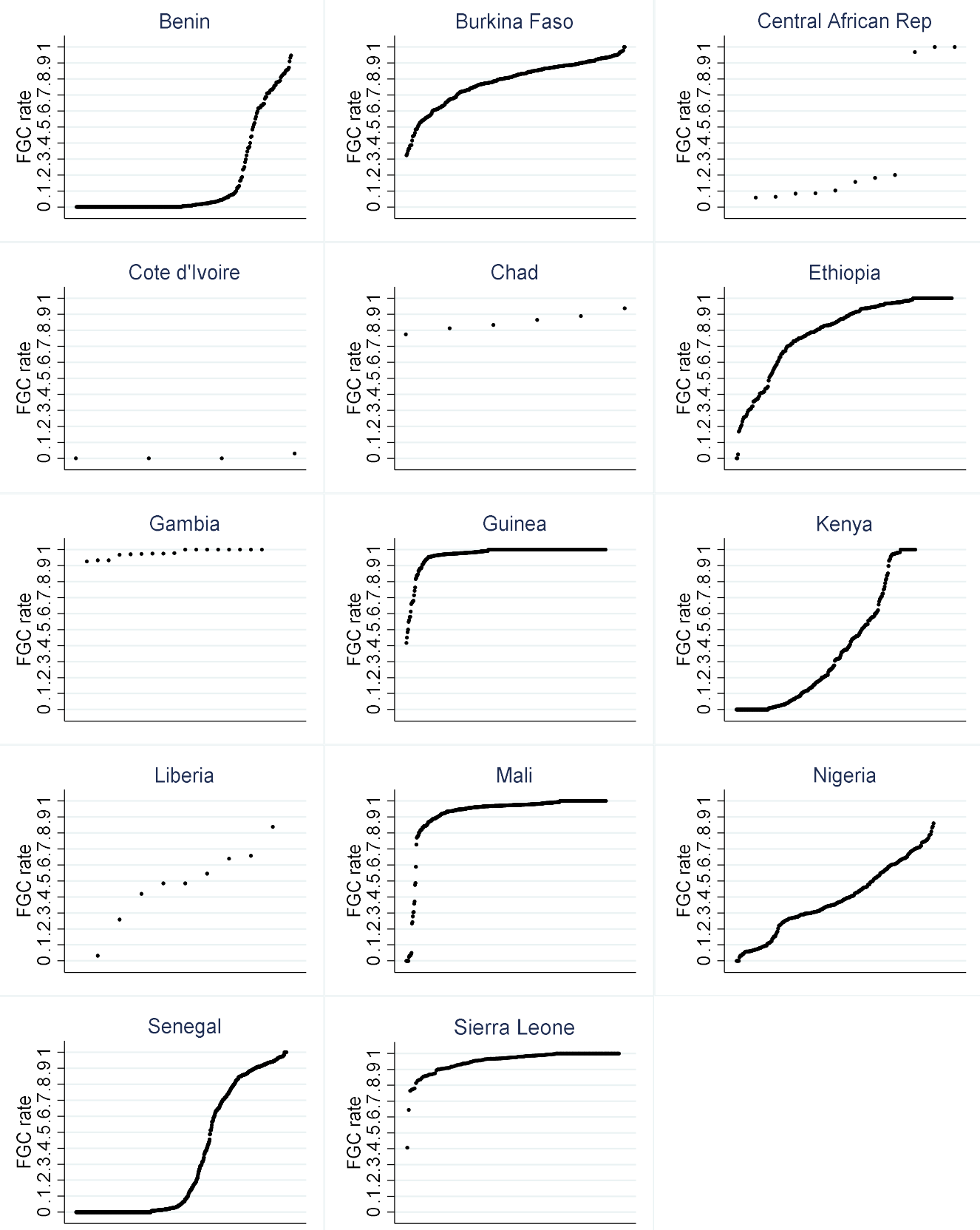

Notes: Communities consist of women of the same ethnicity, living in the same region and born in the same year Include respondents above the age at which $95 \%$ of cut women in the country were cut. Liberia does not include information on cut age in the data. The literature suggest that most women were cut at age 18. 
Importantly, however, Figure 5 does not capture changes over time. Yet there is a dynamic aspect to the model; if some exogenous change makes enough households shift strategy, there will be a sustained change towards a new equilibrium. ${ }^{25}$ Therefore, if we observe a community with $r_{c} \in(0,1)$ only once, we do not know if this is an internal equilibrium or movement along a path from one equilibrium to another. In a stable equilibrium $r_{c, t}=r_{c, t-1}$. Therefore, it is necessary to observe the same community at different points in time to be able to determine if internal equilibria are stable, or if they reflect a process of change over time.

Figure 6: FGC rates in ethnicity-region communities over time, illustration of the four typical patterns

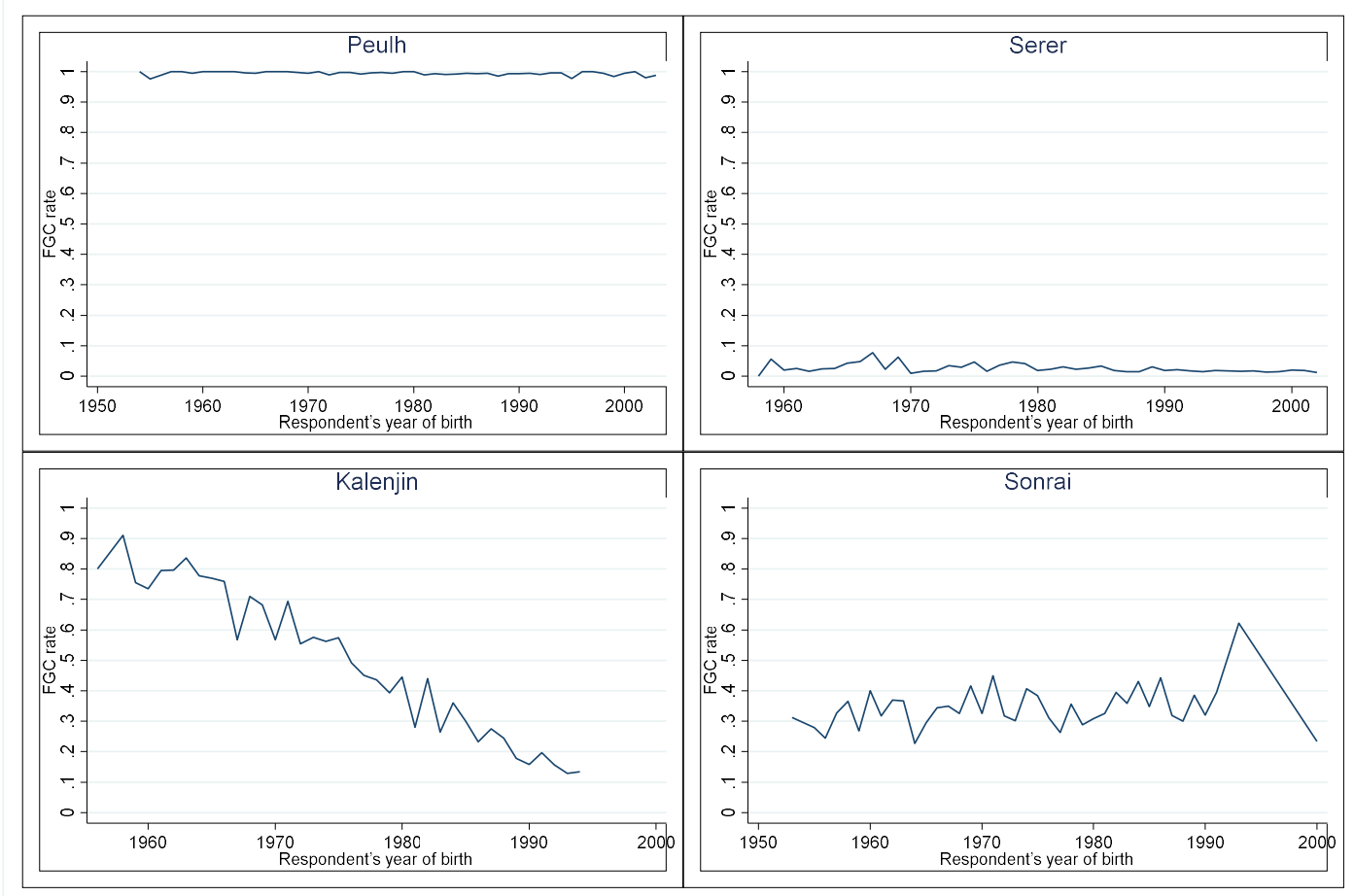

Next, in the spirit of Novak (2020), we therefore investigate whether there appear to be stable internal equilibria where some girls are cut and other girls are not, or if internal community FGC rates are observations of communities during a process of abandonment of the procedure. We do this in a very straightforward way, by plotting the FGC rate over time (with the time dimension given by the birth year of the respondent), in all large enough country-

\footnotetext{
${ }^{25}$ As is standard in models with multiple stable equilibria (whether these are internal or at the 'everyone cut' or 'no one cut' extremes), there will also be (one or more) tipping points (Granovetter, 1978; Zhang, 2011; Centola et al., 2018).
} 
ethnic groups. ${ }^{26} \mathrm{We}$ consider country-ethnic groups with at least 2000 observations and estimate the FGC rate for all birth years where we have observations for at least 30 women. ${ }^{27}$ In total, we have data on 55 such ethnic groups from 13 countries. In Appendix III (Figures A11-A22) we present graphs showing FGC trends over time in these ethnic groups. We use visual inspection to classify the trajectories over time as stable high, stable low, falling, or stable internal equilibria (summarized in Table A18). In Figure 6, we show examples from four ethnic groups that illustrate the main patterns: the Peulh in Guinea have a stable FGC rate close to 1, the Serer in Senegal a stable rate close to 0, The Kalenjin in Kenya a falling pattern, and the Sonrai in Mali a stable internal rate.

In total there are 20 ethnic groups with stable rates close to 0 (10) or 1 (10). Ethnic groups who are abandoning the practise over time tend to do so gradually. There are no rapid transitions from high to low rates for any ethnic group. In total 23 ethnic groups display declining trends. Most of these have started from high FGC rates, and as far as the data allow us to observe the process, the decline appears to continue until the practise is abandoned. However, there are also 12 ethnic groups who display a stable interior FGC rate. In summary, the results in the second complementary analysis are in line with a more general model of social convention theory, where heterogeneity in perceived net benefits slows down abandonment processes and where internal equilibria are possible.

\section{Conclusions}

In this paper, we use a wide sample of data from the Demographic and Health Survey to investigate the relevance of social convention theory in explaining the persistence of female genital cutting. We show that the relevance of the theory cannot be tested using only distributions of community cut rates if private preferences matter in addition to social utility. We further show how it can be tested using information about private preferences. In particular, we test implications of the fact that social convention theory implies that mothers will sometimes go against their private preferences to comply with the social convention.

Taken together our results suggest that FGC is to a significant extent socially interdependent. Even if mothers' individual values and beliefs also matter for the decision to

\footnotetext{
${ }^{26}$ Novak (2020) uses a more involved approach where she aims to estimate the empirical relationship between cutting of daughters and the community cut rate to search for stable internal equilibria or tipping points.

${ }^{27}$ If we also include daughters with data on FGC status the general pattern remains the same. This is not reported but available on request.
} 
cut or not to cut their daughter, they also appear to respond to the FGC-rate in the community that should be relevant for expected marriage market benefits and social rewards. Hence, social convention theory seems relevant for understanding the persistence of FGC, and should be considered when designing policies to end the practice. Our results also suggest that there is great variation in the extent to which FGC is socially interdependent. This implies that results that challenge or support social convention theory in one particular setting are not necessarily relevant in another. Indeed, while previous results for Sudan and Burkina Faso have challenged social convention theory as an explanation for FGC, our findings, based on a broad sample, suggest that the approach has strong explanatory power in the majority of countries. This in turn means that policies need to take into account local conditions in order to be effective.

When behavior is socially interdependent, it depends on expectations of what others in the relevant community will do. When it comes to changing expectations of others' behavior, collective interventions that bring together community members are arguably more effective than interventions without an explicit social component. 


\section{References}

Acemoglu, D. and M. O. Jackson (2015) "History, Expectations, and Leadership in the Evolution of Social Norms", Review of Economic Studies, 82, pp. 423-456.

Acemoglu, D. and M. O. Jackson (2017) "Social Norms and the Enforcement of Laws", Journal of the European Economic Association, 15 (2), pp. 245-95.

Akinsanya, O. and B. Gbadebo (2011) "Intergenerational Attitude Changes Regarding Female

Genital Cutting in Nigeria”, Journal of Women's Health, 20(11), pp. 1655-1661.

Alesina, A., Brioschi, B. and E. La Ferrra (2021) "Violence Against Women: A Cross-cultural Analysis for Africa", Economica, vol. 88, pp. 70-104.

Ali, S. N. and R. Bénabou (2020) "Image versus Information: Changing Societal Norms and Optimal Privacy”, American economic journal: Microeconomics, 12 (3), pp.116-164.

Askew, I. (2005) "Methodological Issues in Measuring the Impact of Interventions against Female Genital Cutting", Culture, Health and Sexuality, vol. 7, no. 5, pp. 463-477.

Becker, A. (2019) “On the Economic Origins of Restrictions on Women's Sexuality”, CESifo Working Papers 7770, July 2019.

Bellemare M. F., Novak, L. and, T. L. Steinmetz (2015) "All in the family: Explaining the persistence of female genital cutting in West Africa, Journal of Development Economics, vol. 116, pp. 252-265.

Bénabou, R. and J. Tirole (2006) "Incentives and prosocial behavior", American Economic Review, 96 (5), pp.1652-78.

Bicchieri, C. (2017) Norms in the Wild: How to Diagnose, Measure, and Change Social Norms, New York: Oxford University Press.

Bisin, A., \& Verdier, T. (2001) "The economics of cultural transmission and the dynamics of preferences", Journal of Economic theory, 97(2), pp. 298-319.

Bisin, A., \& Verdier, T. (2011), "The economics of cultural transmission and socialization", In Handbook of social economics (Vol. 1), North-Holland, pp. 339-416.

Bursztyn, L., González, A. L. and D. Yanagizawa-Drott (2020) "Misperceived Social Norms: Women Working Outside the Home in Saudi Arabia", American Economic Review, 110(10), pp. 2997-3029.

Camilotti, G. (2015) "Interventions to stop female genital cutting and the evolution of the custom: evidence on age at cutting in Senegal", Journal of African Economies, 25 (1), pp. $133-158$.

Centola, D., Becker, J., Brackbill, D. and A. Baronchelli (2018) "Experimental evidence for tipping points in social convention", Science, vol. 360, pp. 1116-1119.

Chesnokova, T. and R. Vaithianathan (2010) "The Economics of Female Genital Cutting," The B.E. Journal of Economic Analysis \& Policy, 10(1), Article 64, pp. 1-26. 
Corno, L., La Ferrara, E. and A. Voena (2020) "Female Genital Cutting and the Slave Trade", CEPR Working Paper DP15577, Centre for Economic Policy Research.

De Cao, E. and G. La Mattina (2019) "Does Maternal Education Decrease Female Genital Cutting?", AEA Papers and Proceedings, vol. 109, pp. 100-104.

De Cao, E. and C. Lutz (2018) "Sensitive survey questions: Measuring attitudes regarding female genital cutting through a list experiment", Oxford Bulletin of Economics and Statistics, 80(5), pp. 871-892.

Demographic and Health Survey (2021) “Data”, available at: https://dhsprogram.com/data/

Diabate, I. and Mesple-Somps, S., (2019) "Female Genital Mutilation and Migration in Mali; Do Return Migrants Transfer Social Norms?”, Journal of Population Economics, 32(4), pp. 1125-1170.

Doepke, M. and F. Zilibotti, (2017) "Parenting with style: Altruism and paternalism in intergenerational preference transmission", Econometrica, vol. 85, pp. 1331-1371.

Efferson,C., Vogt, S., Elhadi, A., Hilal El Fadil, A. and E. Fehr (2015) "Female genital cutting is not a social coordination norm", Science, 349 (6255), pp. 1446-1447.

Elmusharaf, S., Elhadi, N., Almroth, L. (2006) "Reliability of self-reported form of female genital mutilation and WHO classification: cross-sectional study", British Medical Journal, 333 (7559), pp. 124-127.

García-Hombrados, J. and E. Salgado (2019) "Female genital cutting and education: theory and causal evidence from Senegal", Social Policy Working Paper 10-19. London: LSE Department of Social Policy.

Giavazzi, F., Petkov, I. and F. Schiantarelli (2019) "Culture: persistence and evolution", Journal of Economic Growth, 24(2), pp. 117-154.

Granovetter, M. (1978) "Threshold models of collective behavior", American journal of sociology, 83(6), 1420-1443.

Gulesci, S., Jindani, S., La Ferrara, E., Smerdon, D., Sulaiman, M. and H. A. Young (2021) "A stepping stone approach to understanding harmful norms" CEPR Discussion Paper No. DP15776, available at SSRN: https://ssrn.com/abstract=3784002.

Harari, M. (2019) "Women's Inheritance Rights and Bargaining Power: Evidence from Kenya”, Economic Development and Cultural Change, 68(1), pp. 189-238.

Hayford. S. and J. Trinitapoli (2011) "Religious Differences in Female Genital Cutting: A Case Study from Burkina Faso", Journal for the Scientific Study of Religion, 50(2), pp. $252-271$.

Isiugo-Abanihe and Fayehun (2017) "Ethnic, religious and educational homogamy in Nigeria", African Population Studies, 31(1), pp. 3510-3518.

Jackson, E.F., Akweongo, P., Sakeah, E., Hodgson, A., Asuru, R., Phillips, J.F. (2003) "Inconsistent reporting of female genital cutting status in Northern Ghana: explanatory factors and analytical consequences”, Studies in Family Planning, 34 (3), 200-210. 
Jones, H., N. Diop, I. Askew, and I. Kabore (1999) "Female genital cutting practices in Burkina Faso and Mali and their negative health outcomes", Studies in Family Planning, 3(30), pp. 219-230.

Kanter, R. M. (1977) "Some effects of proportions on group life: Skewed sex ratios and responses to token women" American Journal of Sociology, vol. 82, pp. 965-990.

Mackie, G. (1996) "Ending Footbinding and Infibulation: A Convention Account”, American Sociological Review, 61(6), pp. 999-1017.

Mackie, G. and J. LeJeune (2009) "Social dynamics of abandonment of harmful practices: A new look at the theory", Innocenti Working Paper 2009-06, UNICEF Innocenti Research Centre, Florence, Italy, 2009.

North, D.C. (1990) Institutions, Institutional Change, and Economic Performance. Cambridge University Press, Cambridge.

Novak, L. (2020) "Persistent Norms and Tipping Points: The case of Female Genital Cutting”, Journal of Economic Behavior and Organization, vol. 177, pp. 433-474.

Orchid Project (2021) "Where does FGC happen", available at: https://www.orchidproject.org/about-fgc/where-does-fgc-happen/

Poyker, M. (2020) "Regime Stability and the Persistence of Traditional Practices", Columbia Business School Research Paper.

Shell-Duncan, B., Hernlund, Y., Wander, K. and A. Moreau (2011) "Dynamics of change in the practice of female genital cutting in Senegambia: Testing predictions of social convention theory", Social Science \& Medicine, vol. 73, pp. 1275-1283.

Shell-Duncan, B., Hernlund, Y., Wander, K. and A. Moreau (2013) "Legislating Change? Responses to Criminalizing Female Genital Cutting in Senegal”, Law \& Society Review, 47(4), pp. 803-834.

Schelling, T. C. (1978) Micromotives and macrobehavior, New York: WW Norton \& Co.

Tabellini, G. (2008) “The scope of cooperation: values and incentives”, Quarterly Journal of Economics, 123, 905-950.

The Atlantic (2018) “The Tipping Point When Minority Views Take Over”, E. Yong for The Atlantic, June $7,2018.2$ Available at: https://www.theatlantic.com/science/archive/2018/06/the-tipping-point-when-minorityviews-take-over/562307/

UNICEF (2016) "Female Genital Mutilation/Cutting: A global concern", United Nations Children's Fund, New York.

UNICEF (2013). Female genital mutilation/cutting: A statistical overview and exploration of the dynamics of change. United Nations Children's Fund, New York. 
UNICEF (2010) "The Dynamics of Social Change: Towards the abandonment of female genital mutilation/cutting in five African countries", Innocenti Insight, UNICEF Innocenti Research Centre, Florence.

Vogt, S., Zaid, N. A. M., El Fadil Ahmed, H., Fehr, E. and C. Efferson (2016) "Changing cultural attitudes towards female genital cutting”, Nature, 538, pp. 506-509.

Wagner, N. (2015) "Female genital cutting and long-term health consequences-nationally representative estimates across 13 countries", Journal of Development Studies, 51 (3),226-246

World Health Organization (2018) "Female genital mutilation", updated 31 January 2018, available at: (accessed 2019-06-11).

World Health Organization (2008) "Eliminating Female Genital Mutilation: An interagency statement UNAIDS, UNDP, UNECA, UNESCO, UNFPA, UNHCHR, UNHCR, UNICEF, UNIFEM, WHO”, WHO Press, Geneva.

Yoder, P.S., Wang, S. and E. Johansen (2013) "Estimates of Female Genital Mutilation/Cutting in 27 African Countries and Yemen", Studies in Family Planning, 44(2), pp. 189-204.

Zhang, J. (2011). Tipping and residential segregation: a unified Schelling model. Journal of Regional Science, 51(1), 167-193. 


\section{Appendix I: Background information and summary statistics}

Table A1: FGC practice and legal status in sample countries

\begin{tabular}{|c|c|c|c|}
\hline Country & $\begin{array}{r}\text { Laws passed against } \\
\text { FGC }\end{array}$ & $\begin{array}{r}\text { FGC types most } \\
\text { practiced }\end{array}$ & $\begin{array}{r}\text { Estimated prevalence } \\
\text { among women 15-49 (\%) }\end{array}$ \\
\hline Benin & 2003 & II & $\begin{array}{ll}9 \\
\end{array}$ \\
\hline Burkina Faso & 1996 & ॥ & 68 \\
\hline $\begin{array}{l}\text { Central African } \\
\text { Republic }\end{array}$ & 1966, 1996, 2006 & I, II & 24 \\
\hline Cote d'Ivoire & 1998, 2008, 2010 & II & 37 \\
\hline Egypt & 2008 & I, II & 87 \\
\hline Ethiopia & 2004 & I, II & 65 \\
\hline Gambia & 2015 & I, II & 75 \\
\hline Guinea & 1965, 2000, 2016 & II & 97 \\
\hline Kenya & 2011 & I, II & 21 \\
\hline Liberia & None (legal) & II & 50 \\
\hline Mali & None (legal) & I, II & 83 \\
\hline Mauretania & 2005,2017 & I, II & 67 \\
\hline Nigeria & $\begin{array}{r}\text { Legal status varies } \\
\text { across states }\end{array}$ & $\begin{array}{r}\text { I, II in the south, III in } \\
\text { the north }\end{array}$ & 19 \\
\hline Senegal & 1999 & II & 23 \\
\hline Sierra Leone & None (legal) & I, II & 90 \\
\hline Sudan & $\begin{array}{r}\text { Illegal in } 4 \text { out of } 18 \\
\text { states }\end{array}$ & III & 87 \\
\hline Tanzania & 1998 & II & 10 \\
\hline Chad & 2002 (never enforced) & ॥ & 38 \\
\hline
\end{tabular}

Notes: Information obtained from the Orchid Project (2021)

Table A2: Data on FGC status of daughters in each survey.

\begin{tabular}{|c|c|c|c|c|c|}
\hline Country & Year & $\begin{array}{c}\text { Eldest } \\
\text { daughter }\end{array}$ & $\begin{array}{c}\text { Any } \\
\text { daughter }\end{array}$ & $\begin{array}{l}\text { Any daughter } \\
\text { up to } 15\end{array}$ & $\begin{array}{c}\text { Intention to } \\
\text { cut }\end{array}$ \\
\hline Benin & 2001 & & $x$ & & \\
\hline Benin & 2006 & & $x$ & & $x$ \\
\hline Benin & 2012 & & & $x$ & \\
\hline Burkina Faso & 1999 & $x$ & & & \\
\hline Burkina Faso & 2003 & & $x$ & & $x$ \\
\hline Burkina Faso & 2010 & & & $\mathrm{x}$ & \\
\hline $\begin{array}{l}\text { Central African } \\
\text { Republic }\end{array}$ & 1995 & \multicolumn{4}{|c|}{ No information on daughters } \\
\hline Chad & 2004 & & $x$ & & $x$ \\
\hline Chad & 2015 & & & $x$ & \\
\hline Cote d'Ivoire & 1999 & $x$ & & & \\
\hline Cote d'Ivoire & 2012 & & & $x$ & \\
\hline Egypt* & 1995 & & $x$ & & $x$ \\
\hline Egypt* & 2000 & & $x$ & & $x$ \\
\hline Egypt*a) & 2005 & & & $x$ & $x$ \\
\hline Egypt*b) & 2008 & & & $x$ & $x$ \\
\hline
\end{tabular}




\begin{tabular}{|c|c|c|c|c|c|}
\hline Egypt* & 2014 & & & $x$ & $x$ \\
\hline Ethiopia & 2000 & & $x$ & & \\
\hline Ethiopia & 2005 & & $x$ & & \\
\hline Ethiopia & 2016 & & & $x$ & \\
\hline Gambia & 2013 & \multicolumn{4}{|c|}{ No direct question about daughters } \\
\hline Guinea & 1999 & & $\mathrm{X}$ & & $\mathrm{x}$ \\
\hline Guinea & 2005 & & $x$ & & $\mathrm{X}$ \\
\hline Guinea & 2012 & & $x$ & & \\
\hline Guinea & 2018 & & & $x$ & \\
\hline Kenya & 1998 & $x$ & & & $\mathrm{X}$ \\
\hline Kenya & 2003 & $\mathrm{x}$ & & & $\mathrm{x}$ \\
\hline Kenya & 2008 & & $x$ & & $\mathrm{X}$ \\
\hline Kenya & 2014 & & & $x$ & \\
\hline Liberia & 2007 & \multicolumn{4}{|c|}{ No information on daughters } \\
\hline Liberia & 2013 & \multicolumn{4}{|c|}{ No information on daughters } \\
\hline Mali & 1996 & $x$ & & & \\
\hline Mali & 2001 & & $\mathrm{x}$ & & \\
\hline Mali & 2006 & & $\mathrm{x}$ & & $x$ \\
\hline Mali & 2013 & & & $x$ & \\
\hline Mali & 2018 & & & $x$ & \\
\hline Mauritania & 2001 & & $x$ & & $x$ \\
\hline Nigeria & 2003 & & $x$ & & $x$ \\
\hline Nigeria & 2008 & & $x$ & & $x$ \\
\hline Nigeria & 2013 & & & $x$ & \\
\hline Nigeria & 2018 & & & $x$ & \\
\hline Senegal & 2005 & & $x$ & & $x$ \\
\hline Senegal & 2010 & & & $x$ & \\
\hline Senegal & 2014 & & & $x$ & \\
\hline Senegal & 2015 & & & $x$ & \\
\hline Senegal & 2017 & & & $x$ & \\
\hline Senegal & 2019 & & & $x$ & \\
\hline Sierra Leone & 2008 & & $x$ & & $x$ \\
\hline Sierra Leone & 2013 & & $x$ & & $x$ \\
\hline Sudan & 1990 & $x$ & & & $x$ \\
\hline Tanzania & 1996 & $x$ & & & \\
\hline Tanzania & 2005 & & $x$ & & $x$ \\
\hline Tanzania & 2010 & & $x$ & & $x$ \\
\hline Tanzania & 2015 & & & $x$ & \\
\hline
\end{tabular}

Notes: *Sample of ever-married women age 15-49 a) Up to age 17 b) up to age 19 
Table A3: The age at which $95 \%$ of cut respondents in each country were cut, and number of mother-daughter pairs where the daughter is above that age

\begin{tabular}{lcc}
\hline & $95 \%$ cut age & Sample size \\
\hline Benin & 14 & 4,563 \\
Burkina Faso & 12 & 7,635 \\
The Central African Republic & 15 & No daughter info \\
Chad & 13 & 2,619 \\
Cote d'Ivoire & 15 & 886 \\
Egypt & 13 & 21,992 \\
Ethiopia & 13 & 6,691 \\
Gambia & 10 & No daughter info \\
Guinea & 14 & 4,672 \\
Kenya & 18 & 3,420 \\
Liberia & $18^{\text {b }}$ & No daughter info \\
Mali & 11 & 11,919 \\
Mauretania & $1^{\text {a }}$ & 3,490 \\
Nigeria & 16 & 3,470 \\
Senegal & 10 & 15,974 \\
Sierra Leone & 18 & 2,897 \\
Sudan & $13^{c}$ & 1,817 \\
Tanzania & 18 & 6,891 \\
\hline a 95\% of cut respondents were cut at age 0, but since there are still many uncut infants we restrict the the \\
age to 1. \\
bThe age at which respondents are cut is not available in the data. According to Yoder (2013) girls are ususally \\
cut after puberty as part of initiation rituals. We therefore set the $95 \%$ cut age to 18. \\
cThe age at which respondents are cut is not available in the data. According to Efferson et al. (2015) girls are \\
ususally cut before entering primary school. We therefore set the 95\% cut age to 13.
\end{tabular}

Table A4: Respondents birth year and availability of key variables for each survey round.

\begin{tabular}{|l|c|c|c|c|c|c|c|}
\hline Country & Year & $\begin{array}{c}\text { Respondent's } \\
\text { birth year }\end{array}$ & $\begin{array}{c}\text { Suppor } \\
\text { t FGC }\end{array}$ & Ethnicity & $\begin{array}{c}\text { Religio } \\
\mathbf{n}\end{array}$ & Region $^{\text {a }}$ & $\begin{array}{c}\text { Previous } \\
\text { region }\end{array}$ \\
\hline Benin & 2001 & $1951-1986$ & $\mathrm{X}$ & $\mathrm{X}$ & $\mathrm{X}$ & $\mathrm{X}$ & \\
\hline Benin & 2006 & $1956-1991$ & $\mathrm{X}$ & $\mathrm{X}$ & $\mathrm{X}$ & $\mathrm{X}$ & \\
\hline Benin & 2012 & $1962-1997$ & $\mathrm{X}$ & $\mathrm{X}$ & $\mathrm{X}$ & $\mathrm{X}$ & \\
\hline Burkina Faso & 1999 & $1948-1984$ & $\mathrm{X}$ & $\mathrm{X}$ & $\mathrm{X}$ & $\mathrm{X}$ & \\
\hline Burkina Faso & 2003 & $1953-1988$ & $\mathrm{X}$ & $\mathrm{X}$ & $\mathrm{X}$ & $\mathrm{X}$ & \\
\hline Burkina Faso & 2010 & $1960-1995$ & $\mathrm{X}$ & $\mathrm{X}$ & $\mathrm{X}$ & $\mathrm{X}$ & \\
\hline $\begin{array}{l}\text { Central } \\
\text { African } \\
\text { Republic }\end{array}$ & 1995 & $1944-1980$ & & $\mathrm{X}$ & $\mathrm{X}$ & $\mathrm{X}$ & \\
\hline Chad & & & & & & & \\
\hline Chad & 2004 & $1954-1989$ & $\mathrm{X}$ & $\mathrm{X}$ & $\mathrm{X}$ & $\mathrm{X}$ & \\
\hline Cote d'Ivoire & 1999 & $1948-1984$ & $\mathrm{X}$ & $\mathrm{X}$ & $\mathrm{X}$ & $\mathrm{X}$ & \\
\hline Cote d'Ivoire & 2012 & $1962-1997$ & $\mathrm{X}$ & $\mathrm{X}$ & $\mathrm{X}$ & $\mathrm{X}$ & \\
\hline Egypt* & 1995 & $1945-1980$ & $\mathrm{X}$ & & $\mathrm{X}$ & $\mathrm{X}$ & \\
\hline Egypt* & 2000 & $1950-1985$ & $\mathrm{X}$ & & & $\mathrm{X}$ & \\
\hline
\end{tabular}




\begin{tabular}{|c|c|c|c|c|c|c|c|}
\hline Egypt*a) & 2005 & $1955-1990$ & $x$ & & $x$ & $x$ & \\
\hline Egypt*b) & 2008 & 1958-1993 & $x$ & & $x$ & $x$ & \\
\hline Egypt* & 2014 & 1964-1999 & $x$ & & $x$ & $x$ & \\
\hline Ethiopia & 2000 & 1942-1977 & $x$ & $x$ & $x$ & $x$ & \\
\hline Ethiopia & 2005 & 1947-1982 & $x$ & $x$ & $x$ & $x$ & \\
\hline Ethiopia & 2016 & 1958-1993 & $x$ & $x$ & $x$ & $x$ & $x$ \\
\hline Gambia & 2013 & 1963-1998 & $x$ & $x$ & $x$ & $x$ & \\
\hline Guinea & 1999 & 1949-1984 & $x$ & $x$ & $x$ & & \\
\hline Guinea & 2005 & $1955-1990$ & $x$ & $x$ & $x$ & $x$ & \\
\hline Guinea & 2012 & 1962-1997 & $x$ & $x$ & $x$ & $x$ & \\
\hline Guinea & 2018 & $1968-2003$ & $x$ & $x$ & $x$ & $x$ & $x$ \\
\hline Kenya & 1998 & 1948-1983 & $x$ & $x$ & $x$ & $x$ & \\
\hline Kenya & 2003 & 1953-1988 & & $x$ & $x$ & $x$ & \\
\hline Kenya & 2008 & 1958-1994 & $x$ & $x$ & $x$ & $x$ & \\
\hline Kenya & 2014 & 1964-1999 & $x$ & $x$ & $x$ & $x$ & \\
\hline Liberia & 2007 & 1957-1992 & & & $x$ & $x$ & \\
\hline Liberia & 2013 & 1963-1998 & & $x$ & $x$ & $x$ & \\
\hline Mali & 1996 & $1946-1981$ & $x$ & $x$ & $x$ & $x$ & \\
\hline Mali & 2001 & 1951-1986 & $x$ & $x$ & $x$ & $x$ & \\
\hline Mali & 2006 & 1956-1991 & $x$ & $x$ & $x$ & $x$ & \\
\hline Mali & 2013 & 1963-1997 & $x$ & $x$ & $x$ & $x$ & \\
\hline Mali & 2018 & $1968-2003$ & $x$ & $x$ & $x$ & $x$ & $x$ \\
\hline Mauritania & 2001 & 1950-1986 & $x$ & & & $x$ & \\
\hline Nigeria & 2003 & 1953-1988 & $x$ & $x$ & $x$ & $x$ & \\
\hline Nigeria & 2008 & 1958-1993 & $x$ & $x$ & $x$ & $x$ & \\
\hline Nigeria & 2013 & 1963-1998 & $x$ & $x$ & $x$ & $x$ & \\
\hline Nigeria & 2018 & $1968-2003$ & $x$ & $x$ & $x$ & $x$ & $x$ \\
\hline Senegal & 2005 & $1955-1990$ & $x$ & $x$ & $x$ & $x$ & \\
\hline Senegal & 2010 & 1960-1996 & $x$ & $x$ & $x$ & $x$ & \\
\hline Senegal & 2014 & 1962-1999 & $x$ & $x$ & $x$ & $x$ & \\
\hline Senegal & 2015 & $1965-2001$ & $x$ & $x$ & $x$ & $x$ & \\
\hline Senegal & 2017 & $1967-2002$ & $x$ & $x$ & $x$ & $x$ & \\
\hline Senegal & 2019 & $1968-2003$ & $x$ & $x$ & $x$ & $x$ & \\
\hline Sierra Leone & 2008 & 1958-1993 & $x$ & $x$ & $x$ & $x$ & \\
\hline Sierra Leone & 2013 & 1963-1998 & $x$ & $x$ & $x$ & $x$ & \\
\hline Sudan & 1990 & 1940-1975 & $x$ & & $x$ & $x$ & \\
\hline Tanzania & 1996 & 1946-1981 & & $x$ & $x$ & $x$ & \\
\hline Tanzania & 2005 & 1954-1990 & $x$ & & $x$ & $x$ & \\
\hline Tanzania & 2010 & 1960-1995 & $x$ & & & $x$ & \\
\hline Tanzania & 2015 & $1965-2001$ & $x$ & & & $x$ & $x$ \\
\hline
\end{tabular}


Table A5: Summary statistics of mother-daughter pairs

\begin{tabular}{lrrrrr}
\hline Variable & Obs & \multicolumn{1}{c}{ Mean } & Std. Dev. & Min & Max \\
\hline & & & & & \\
Mother's age & 52,750 & 39.321 & 5.798 & 20 & 49 \\
Mother's birth year & 52,750 & 1966.122 & 9.869 & 1942 & 1996 \\
Mother has primary education & 52,750 & 0.151 & 0.358 & 0 & 1 \\
Mother has secondary education & 52,750 & 0.068 & 0.252 & 0 & 1 \\
Mother has higher education & 52,750 & 0.011 & 0.104 & 0 & 1 \\
Mother's FGC status & 52,620 & 0.680 & 0.466 & 0 & 1 \\
Age at which mother cut & 28,764 & 5.010 & 5.456 & 0 & 33 \\
Mother's private preference & 52,750 & 0.396 & 0.489 & 0 & 1 \\
Urban & 52,750 & 0.300 & 0.458 & 0 & 1 \\
Muslim & 52,592 & 0.680 & 0.466 & 0 & 1 \\
Christian & 52,702 & 0.262 & 0.440 & 0 & 1 \\
Daughter's age & 52,750 & 17.942 & 5.318 & 10 & 38 \\
Daughter's birth year & 52,750 & 1987.523 & 10.153 & 1955 & 2007 \\
Daughter's FGC status & 52,750 & 0.531 & 0.503 & 0 & 9 \\
\hline
\end{tabular}

Figure A1: Share of respondents that are cut in each sample country

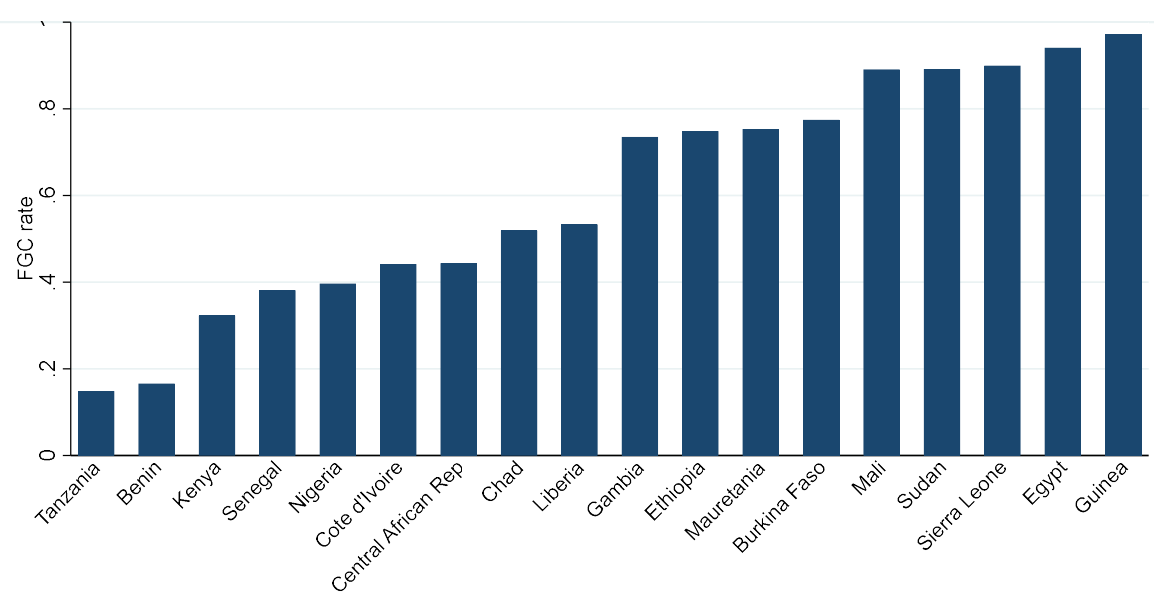




\section{Appendix II: Robustness}

Table A6: Complete regression results table 1

\begin{tabular}{|c|c|c|c|c|c|c|}
\hline & (1) & (2) & (3) & (4) & (5) & (6) \\
\hline Community FGC rate & $\begin{array}{c}0.902 * * * \\
(0.018)\end{array}$ & & $\begin{array}{c}0.734^{* * *} \\
(0.018)\end{array}$ & $\begin{array}{c}0.724^{* * *} \\
(0.018)\end{array}$ & $\begin{array}{c}0.672^{* * *} \\
(0.023)\end{array}$ & \\
\hline Private preference & & $\begin{array}{c}0.457 * * * \\
(0.037)\end{array}$ & $\begin{array}{c}0.279 * * * \\
(0.022)\end{array}$ & $\begin{array}{c}0.270 * * * \\
(0.022)\end{array}$ & $\begin{array}{c}0.265 * * * \\
(0.023)\end{array}$ & \\
\hline Age & & & & $\begin{array}{c}0.004^{* *} \\
(0.002)\end{array}$ & $\begin{array}{c}0.004^{* *} \\
(0.002)\end{array}$ & \\
\hline Urban & & & & $\begin{array}{l}-0.011^{*} \\
(0.006)\end{array}$ & $\begin{array}{c}-0.015^{* * *} \\
(0.006)\end{array}$ & \\
\hline Muslim & & & & $\begin{array}{l}0.031^{*} \\
(0.016)\end{array}$ & $\begin{array}{c}0.046 * * * \\
(0.015)\end{array}$ & \\
\hline Christian & & & & $\begin{array}{l}-0.011 \\
(0.012)\end{array}$ & $\begin{array}{l}-0.016 \\
(0.012)\end{array}$ & \\
\hline Primary & & & & $\begin{array}{c}-0.023 * * * \\
(0.007)\end{array}$ & $\begin{array}{c}-0.028 * * * \\
(0.006)\end{array}$ & \\
\hline Secondary & & & & $\begin{array}{c}-0.063 * * * \\
(0.013)\end{array}$ & $\begin{array}{c}-0.069 * * * \\
(0.013)\end{array}$ & \\
\hline Higher & & & & $\begin{array}{c}-0.135 * * * \\
(0.025)\end{array}$ & $\begin{array}{c}-0.143^{* * *} \\
(0.024)\end{array}$ & \\
\hline Community FGC rate & $\begin{array}{c}0.902 * * * \\
(0.018)\end{array}$ & & $\begin{array}{c}0.734 * * * \\
(0.018)\end{array}$ & $\begin{array}{c}0.724^{* * *} \\
(0.018)\end{array}$ & $\begin{array}{c}0.672 * * * \\
(0.023)\end{array}$ & \\
\hline Private preference & & $\begin{array}{c}0.457 * * * \\
(0.037)\end{array}$ & $\begin{array}{c}0.279 * * * \\
(0.022)\end{array}$ & $\begin{array}{c}0.270 * * * \\
(0.022)\end{array}$ & $\begin{array}{c}0.265^{* * *} \\
(0.023)\end{array}$ & \\
\hline $\begin{array}{l}\text { Country\#Year of birth } \\
\text { effects } \\
\text { Region effects }\end{array}$ & Yes & Yes & Yes & Yes & $\begin{array}{l}\text { Yes } \\
\text { Yes }\end{array}$ & Yes \\
\hline Observations & 52,750 & 52,750 & 52,750 & 52,592 & 52,592 & 52,750 \\
\hline R-squared & 0.526 & 0.446 & 0.570 & 0.573 & 0.579 & 0.306 \\
\hline Mean of outcome & 0.504 & 0.504 & 0.504 & 0.504 & 0.504 & 0.504 \\
\hline
\end{tabular}


Table A7: Predictive power of the community cut rate among girls and the mother's expressed preference for FGC for daughters' FGC status by country- rural sample

\begin{tabular}{llllll}
\hline & \multicolumn{2}{c}{ Community FGC rate } & \multicolumn{2}{c}{ Mother supports FGC } & $\mathrm{N}$ \\
\hline Pooled & $0.728^{* * *}$ & $(0.020)$ & $0.263^{* * *}$ & $(0.025)$ & 36,820 \\
\hline Benin & $0.695^{* * *}$ & $(0.079)$ & $0.186^{*}$ & $(0.091)$ & 2,446 \\
Burkina Faso & $0.580^{* * *}$ & $(0.034)$ & $0.307^{* * *}$ & $(0.011)$ & 5,179 \\
Chad & $0.748^{* * *}$ & $(0.058)$ & $0.285^{* * *}$ & $(0.058)$ & 1,238 \\
Cote d'Ivoire & $0.580^{* * *}$ & $(0.058)$ & $0.230^{* * *}$ & $(0.054)$ & 228 \\
Ethiopia & $0.718^{* * *}$ & $(0.069)$ & $0.176^{* * *}$ & $(0.055)$ & 4,764 \\
Guinea & $1.113^{* * *}$ & $(0.052)$ & $0.049^{*}$ & $(0.025)$ & 2,030 \\
Kenya & $0.754^{* * *}$ & $(0.056)$ & $0.271^{* * *}$ & $(0.06)$ & 1,865 \\
Mali & $0.780^{* * *}$ & $(0.054)$ & $0.241^{* *}$ & $(0.071)$ & 7,753 \\
Nigeria & $0.675^{* * *}$ & $(0.06)$ & $0.465^{* * *}$ & $(0.072)$ & 2,006 \\
Senegal & $0.646^{* * *}$ & $(0.038)$ & $0.400^{* * *}$ & $(0.041)$ & 7,671 \\
Sierra Leone & $1.056^{* *}$ & $(0.262)$ & $0.090^{*}$ & $(0.032)$ & 1,640 \\
\hline
\end{tabular}

Notes: Standard errors clustered at the subnational region in parentheses. ${ }^{* * *} p<0.01,{ }^{* *} p<0.05, * p<0.1 ;$ The community cut rate refers to the FGC rate among women in the same ethnic group and region who were born 1-6 years earlier than the respondent.

Figure A3: Distribution of support for FGC and cutting of daughters in rural communities

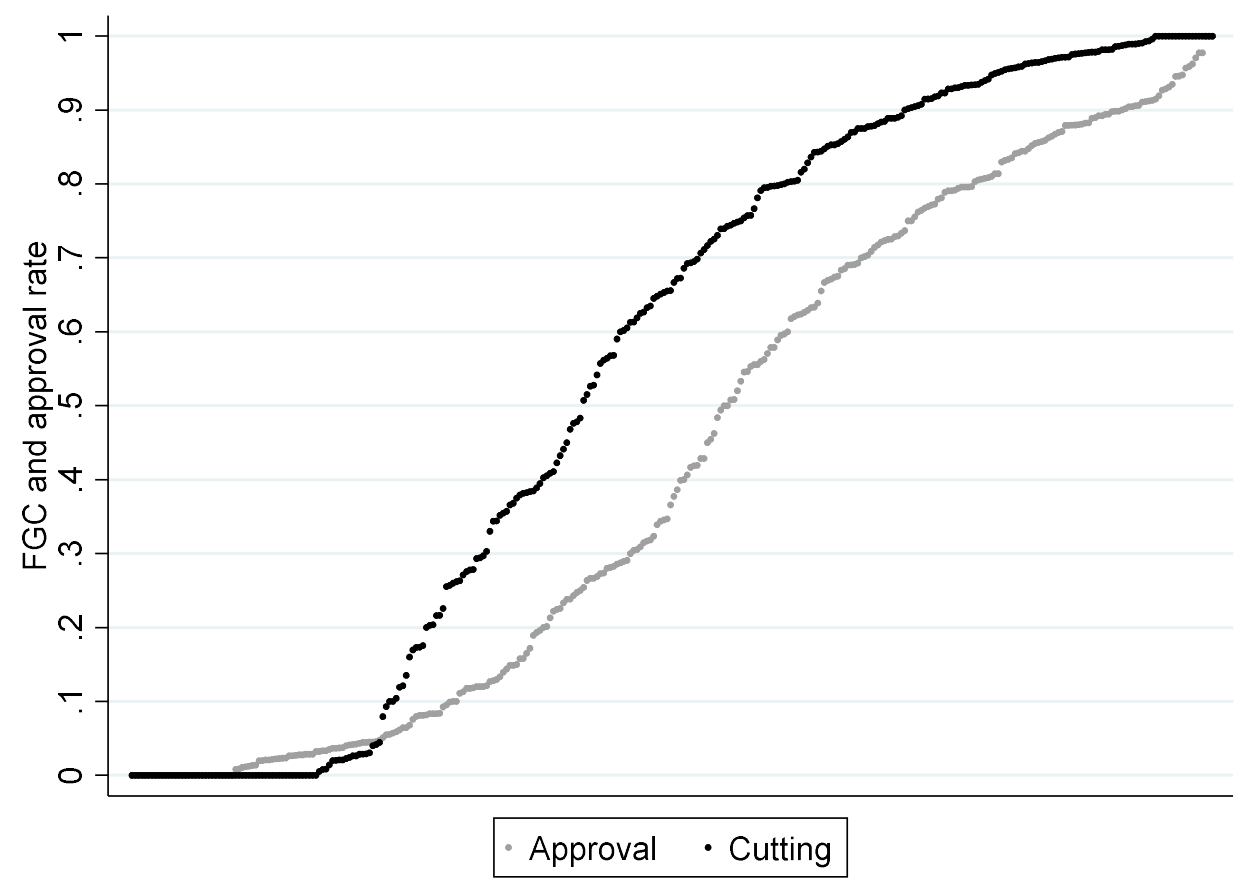


Figure A4: The distribution of preferences for FGC and actual cutting of daughters in rural communities, by country

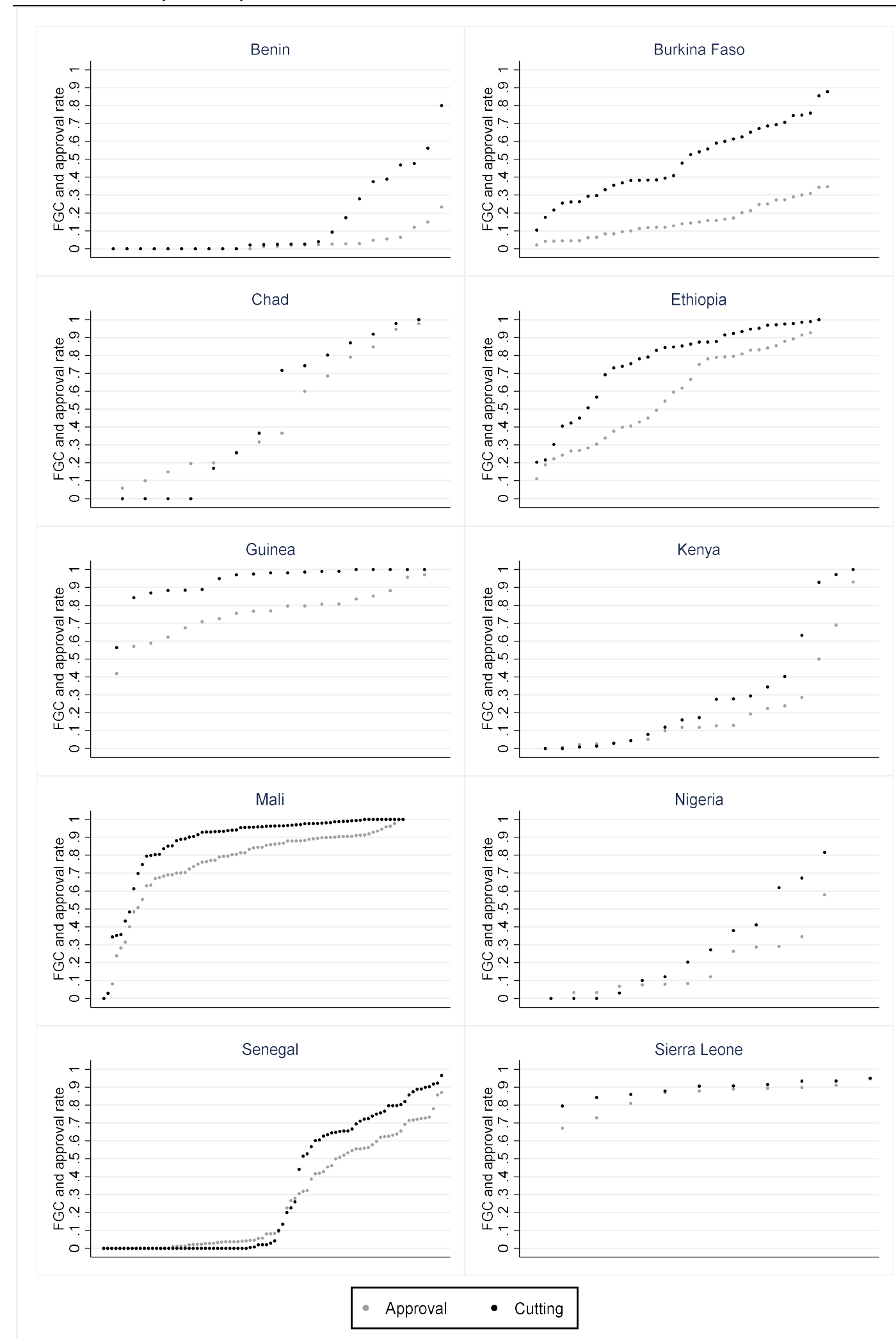

Note: Cote d'Ivoire is excluded in this analysis, as the region-ethnic groups are not sufficiently large. 
Table A8: Testing if the relationship between FGC rate of daughter's and the community cut rate is more concave for mothers who support the practice than for mothers who oppose it in rural communities by country

\begin{tabular}{|c|c|c|c|}
\hline \multirow{2}{*}{ Pooled } & \multicolumn{2}{|c|}{ Community FGC rate squared* Mother supports FGC } & \multirow{2}{*}{$\begin{array}{c}\mathrm{N} \\
36,820 \\
\end{array}$} \\
\hline & $-1.286 * * *$ & $(0.156)$ & \\
\hline Benin & 0.096 & $(0.468)$ & 2,446 \\
\hline Burkina Faso & $-0.409 *$ & (0.179) & 5,179 \\
\hline Chad & $-1.763 * * *$ & $(0.334)$ & 1,238 \\
\hline Cote d'Ivoire & -1.312 & $(0.851)$ & 228 \\
\hline Ethiopia & -0.296 & $(0.476)$ & 4,764 \\
\hline Guinea & $-2.829 *$ & $(1.362)$ & 2,030 \\
\hline Kenya & $-1.639 * * *$ & $(0.236)$ & 1,865 \\
\hline Mali & $-1.726 * * *$ & $(0.298)$ & 7,753 \\
\hline Nigeria & -1.384 & $(0.852)$ & 2,006 \\
\hline Senegal & $-1.738 * * *$ & $(0.261)$ & 7,671 \\
\hline Sierra Leone & 0.413 & $(2.631)$ & 1,640 \\
\hline \multicolumn{4}{|c|}{$\begin{array}{l}\text { Notes: Standard errors clustered at the subnational region in parentheses. }{ }^{* * *} p<0.01,{ }^{* *} p<0.05,{ }^{*} p<0.1 \text {; } \\
\text { Social convention theory predicts a more concave relationship between FGC rate of daughters and the } \\
\text { community cut rate for mothers who support the practice than for mothers who oppose the practise. If so the } \\
\text { coefficient on the 'community FGC rate squared times support FGC' variable should be negative. The } \\
\text { community FGC rate refers to girls of the same ethnic-region group who were born } 1-6 \text { years earlier than the } \\
\text { daughters. The full model also includes the community FGC rate, the community FGC rate squared, a support } \\
\text { FGC dummy, the community FGC rate times support FGC, the daughter's year of birth and age, religion, level } \\
\text { of education, and urban residence }\end{array}$} \\
\hline
\end{tabular}

Table A9: Predictive power of the community cut rate and the mother's expressed preference for FGC for daughters' FGC status by country- community defined by region and birth-year

\begin{tabular}{|c|c|c|c|c|c|}
\hline \multirow[b]{2}{*}{ Pooled } & \multicolumn{2}{|c|}{ Community FGC rate } & \multicolumn{2}{|c|}{ Mother supports FGC } & \multirow{2}{*}{$\frac{N}{1^{74,23}}$} \\
\hline & $0.692^{* * *}$ & (0.024) & $0.354 * * *$ & $(0.024)$ & \\
\hline Benin & $0.533 * * *$ & $(0.057)$ & $0.207^{*}$ & $(0.088)$ & 4,277 \\
\hline Burkina Faso & $0.818 * * *$ & $(0.104)$ & $0.303^{* * *}$ & $(0.018)$ & 6,875 \\
\hline Chad & $0.756 * * *$ & $(0.062)$ & $0.340 * * *$ & $(0.042)$ & 2,204 \\
\hline Cote d'Ivoire & $0.394 * * *$ & $(0.075)$ & $0.380 * * *$ & $(0.024)$ & 623 \\
\hline Egypt & $0.652 * * *$ & $(0.120)$ & $0.455^{* * *}$ & $(0.054)$ & $8^{15,46}$ \\
\hline Ethiopia & $0.542 * * *$ & $(0.068)$ & $0.226 * * *$ & $(0.041)$ & 6,466 \\
\hline Guinea & $0.987^{* * *}$ & $(0.107)$ & $0.068 * *$ & $(0.022)$ & 2,817 \\
\hline Kenya & $0.606 * * *$ & $(0.076)$ & $0.423^{* * *}$ & $(0.064)$ & 2,313 \\
\hline Mali & $0.828 * * *$ & $(0.051)$ & $0.254^{* * *}$ & $(0.056)$ & $7^{11,35}$ \\
\hline Mauretania & $0.570 * * *$ & $(0.102)$ & $0.452 * * *$ & $(0.055)$ & 3,485 \\
\hline Nigeria & $0.811^{* * *}$ & $(0.036)$ & $0.528 * * *$ & (0.049) & 3,448 \\
\hline Senegal & $0.618^{* * *}$ & $(0.045)$ & $0.471 * * *$ & $(0.044)$ & $0^{12,69}$ \\
\hline Sierra Leone & $1.129 * *$ & $(0.244)$ & $0.149 *$ & $(0.062)$ & 2,871 \\
\hline
\end{tabular}




\begin{tabular}{llllll} 
Sudan & $0.469 * *$ & $(0.147)$ & $0.454^{*}$ & $(0.189)$ & 1,734 \\
\cline { 2 - 6 } Tanzania & $0.692 * * *$ & $(0.081)$ & $0.493^{* * *}$ & $(0.070)$ & 2,371 \\
\hline
\end{tabular}

Notes: Standard errors clustered at the subnational region in parentheses. ${ }^{* * *} p<0.01,{ }^{* *} p<0.05,{ }^{*} p<0.1$; The community cut rate refers to the FGC rate among women in the same ethnic group and region who were born 1-6 years earlier than the respondent; religion controls not included in Egypt and Tanzania

Figure A5: Distribution of support for FGC and cutting of daughters - community defined by region and birth-year

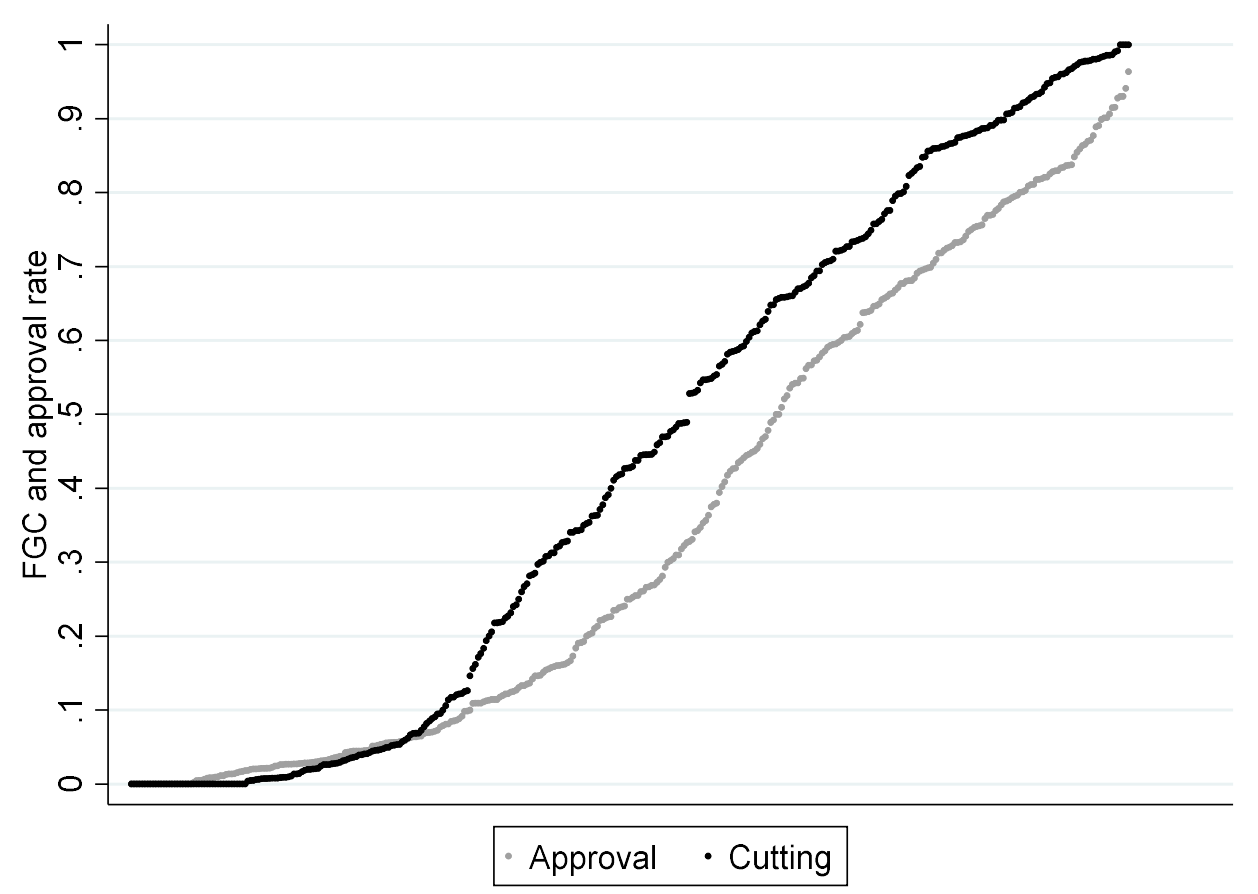


Figure A6: Distribution of support for FGC and cutting of daughters by country - community defined by region and birth-year
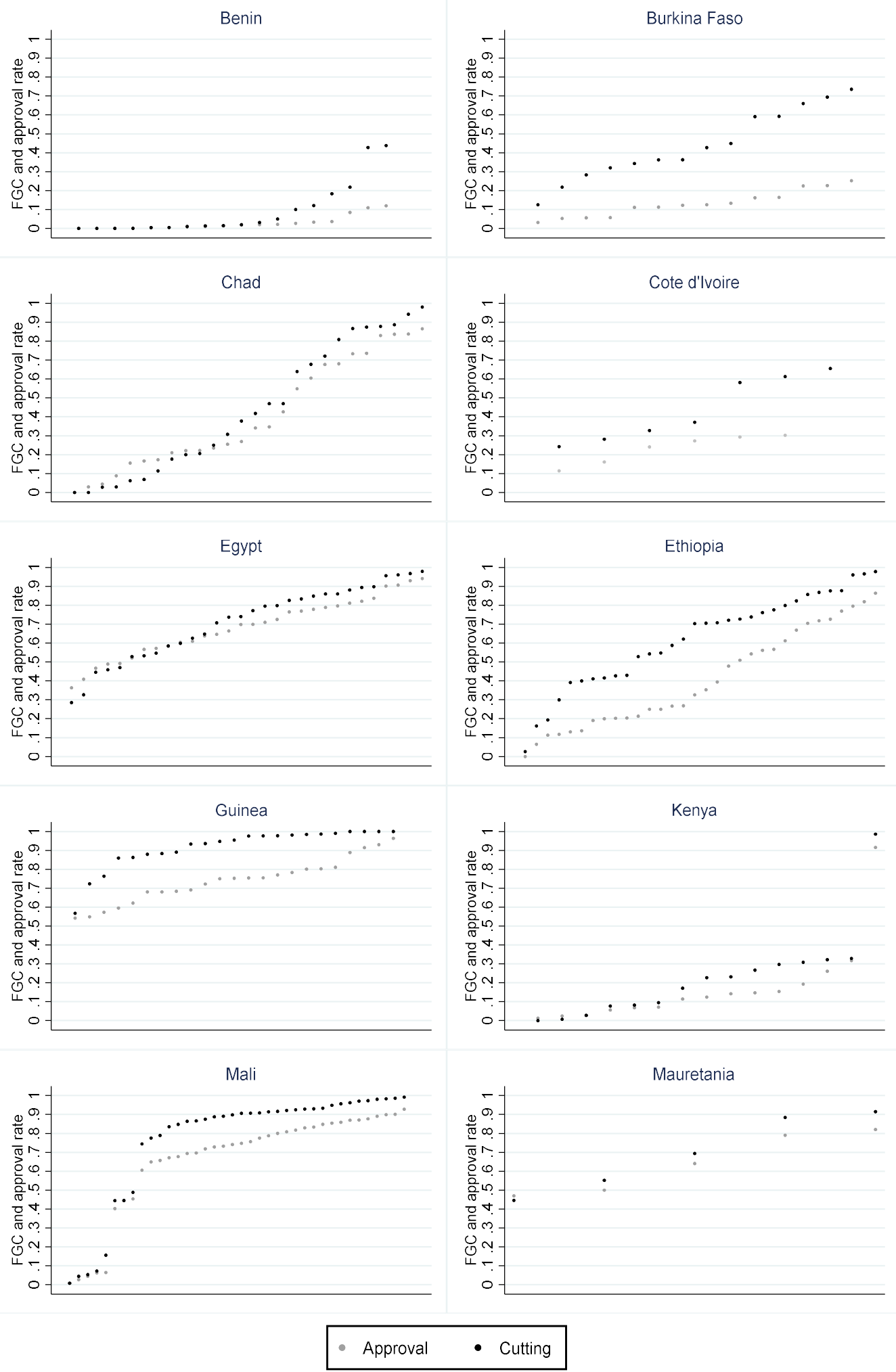

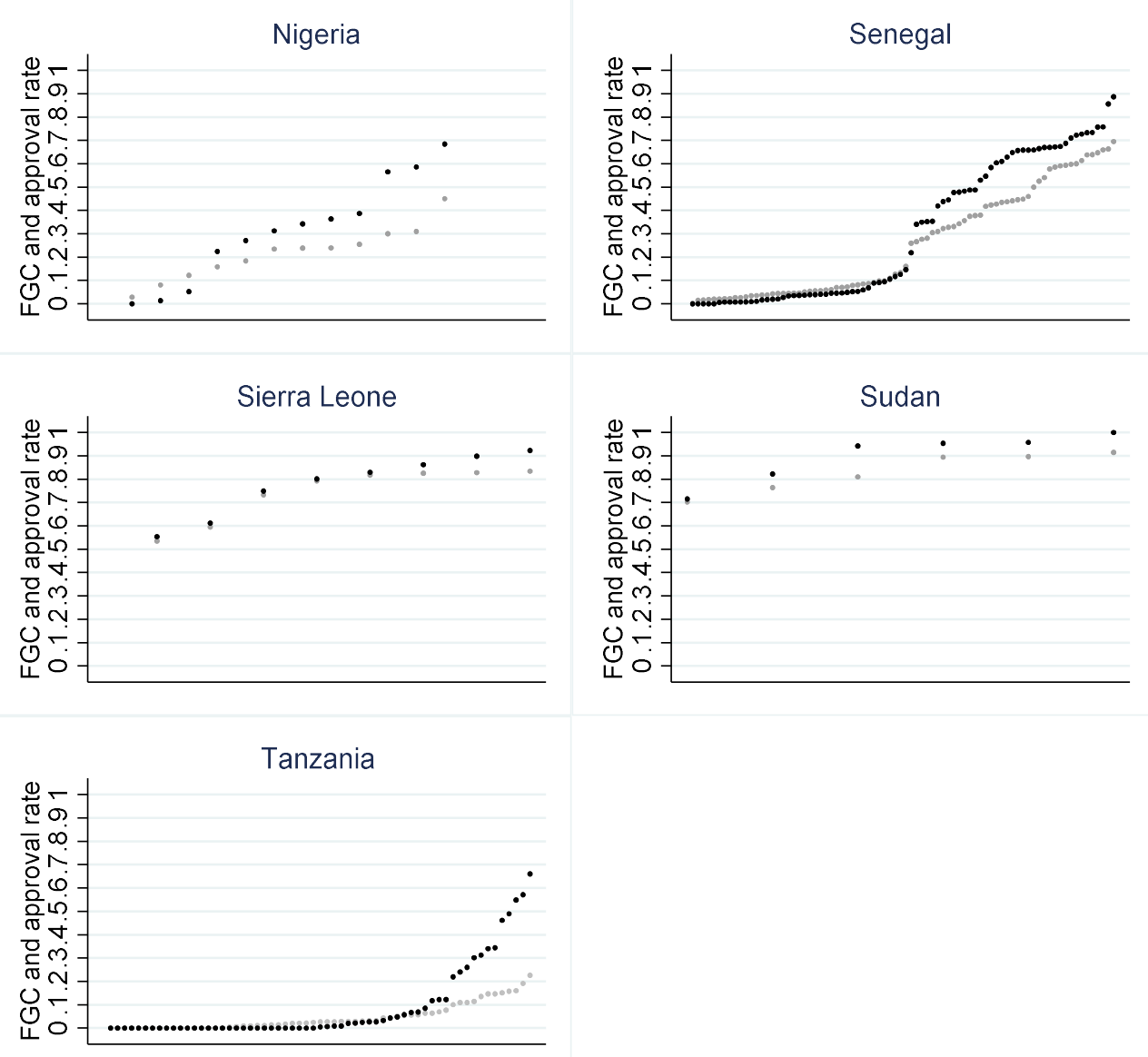

- Approval - Cutting 
Table A10: Testing if the relationship between FGC rate of daughter's and the community cut rate is more concave for mothers who support the practice than for mothers who oppose the practice by country - community defined by region and birth-year

\begin{tabular}{|c|c|c|c|}
\hline & Community FGC ra & her supports FGC & $\mathrm{N}$ \\
\hline Pooled & $-0.570 * * *$ & $(0.122)$ & 72,497 \\
\hline Benin & $3.144^{* * *}$ & $(0.632)$ & 4,277 \\
\hline Burkina Faso & 0.537 & $(0.345)$ & 6,875 \\
\hline Chad & $-0.755^{* *}$ & $(0.286)$ & 2,204 \\
\hline Cote d'Ivoire & -1.153 & (0.879) & 623 \\
\hline Egypt & -0.422 & $(0.379)$ & 15,468 \\
\hline Ethiopia & 0.044 & (0.599) & 6,466 \\
\hline Guinea & -1.354 & $(2.257)$ & 2,817 \\
\hline Kenya & $-1.248^{* *}$ & (0.411) & 2,313 \\
\hline Mali & $-0.610 *$ & $(0.322)$ & 11,357 \\
\hline Mauretania & $-1.287^{* *}$ & $(0.377)$ & 3,485 \\
\hline Nigeria & $-1.893 * *$ & $(0.722)$ & 3,448 \\
\hline Senegal & $-1.376 * * *$ & $(0.241)$ & 12,690 \\
\hline Sierra Leone & 2.431 & $(1.503)$ & 2,871 \\
\hline Sudan & -0.197 & $(0.710)$ & 1,734 \\
\hline Tanzania & $-2.083^{* *}$ & $(0.821)$ & 2,371 \\
\hline \multicolumn{4}{|c|}{$\begin{array}{l}\text { Notes: Standard errors clustered at the subnational region in parentheses. }{ }^{* * *} p<0.01,{ }^{* *} p<0.05,{ }^{*} p<0.1 \text {; } \\
\text { Social convention theory predicts a more concave relationship between FGC rate of daughters and the } \\
\text { community cut rate for mothers who support the practice than for mothers who oppose the practise. If so the } \\
\text { coefficient on the 'community FGC rate squared times support FGC' variable should be negative. The } \\
\text { community FGC rate refers to girls of the same ethnic-region group who were born 1-6 years earlier than the } \\
\text { daughters. The full model also includes the community FGC rate, the community FGC rate squared, a support } \\
\text { FGC dummy, the community FGC rate times support FGC, the daughter's year of birth and age, religion, level } \\
\text { of education, and urban residence; Religion dummies not in Tanzania and Mauretania. So few Tanzania } \\
\text { observations and no Mauretania in the pooled. }\end{array}$} \\
\hline
\end{tabular}


Table A11: Predictive power of the community cut rate and the mother's expressed preference for FGC for daughters' FGC status by country - Community defined by sample cluster

\begin{tabular}{|c|c|c|c|c|c|}
\hline & \multicolumn{2}{|c|}{ Community FGC rate } & \multicolumn{2}{|c|}{ Mother supports FGC } & \multirow{2}{*}{$\frac{N}{69,528}$} \\
\hline & $0.650 * * *$ & $(0.023)$ & $0.287^{* * *}$ & $(0.021)$ & \\
\hline Benin & $0.443^{* * *}$ & $(0.044)$ & $0.186^{* *}$ & $(0.072)$ & 4,267 \\
\hline Burkina Faso & $0.621 * * *$ & (0.029) & $0.260 * * *$ & $(0.014)$ & 6,287 \\
\hline Chad & $0.766 * * *$ & $(0.047)$ & $0.233 * * *$ & $(0.042)$ & 2,203 \\
\hline Cote d'Ivoire & $0.471^{* * *}$ & $(0.073)$ & $0.334 * * *$ & $(0.023)$ & 622 \\
\hline Egypt & $0.608 * * *$ & $(0.101)$ & $0.376 * * *$ & $(0.052)$ & 14,533 \\
\hline Ethiopia & $0.765^{* * *}$ & $(0.052)$ & $0.147^{* * *}$ & $(0.035)$ & 6,391 \\
\hline Guinea & $1.281 * * *$ & (0.192) & $0.059 * *$ & $(0.018)$ & 2,802 \\
\hline Kenya & $0.641 * * *$ & $(0.067)$ & $0.299 * * *$ & $(0.047)$ & 2,309 \\
\hline Mali & $0.862 * * *$ & $(0.023)$ & $0.172 * * *$ & $(0.024)$ & 11,335 \\
\hline Mauretania & $0.637 * * *$ & $(0.076)$ & $0.379 * * *$ & $(0.036)$ & 3,324 \\
\hline Nigeria & $0.676 * * *$ & $(0.033)$ & $0.343 * * *$ & $(0.02)$ & 3,445 \\
\hline Senegal & $0.626 * * *$ & (0.029) & $0.379 * * *$ & (0.029) & 12,525 \\
\hline Sierra Leone & $-0.060 * * *$ & (0.009) & $0.157^{*}$ & $(0.065)$ & 1,723 \\
\hline Sudan & $0.630 * * *$ & $(0.080)$ & $0.296 * *$ & $(0.107)$ & 1,799 \\
\hline Tanzania & $0.575^{* * *}$ & $(0.065)$ & $0.393 * * *$ & $(0.058)$ & 2,365 \\
\hline
\end{tabular}

Notes: Standard errors clustered at the subnational region in parentheses. ${ }^{* * *} p<0.01,{ }^{* *} p<0.05,{ }^{*} p<0.1$; The community cut rate refers to the FGC rate among women in the same ethnic group and region who were born 1-6 years earlier than the respondent.

Figure A7: Distribution of support for FGC and cutting of daughters - Community defined by sample cluster

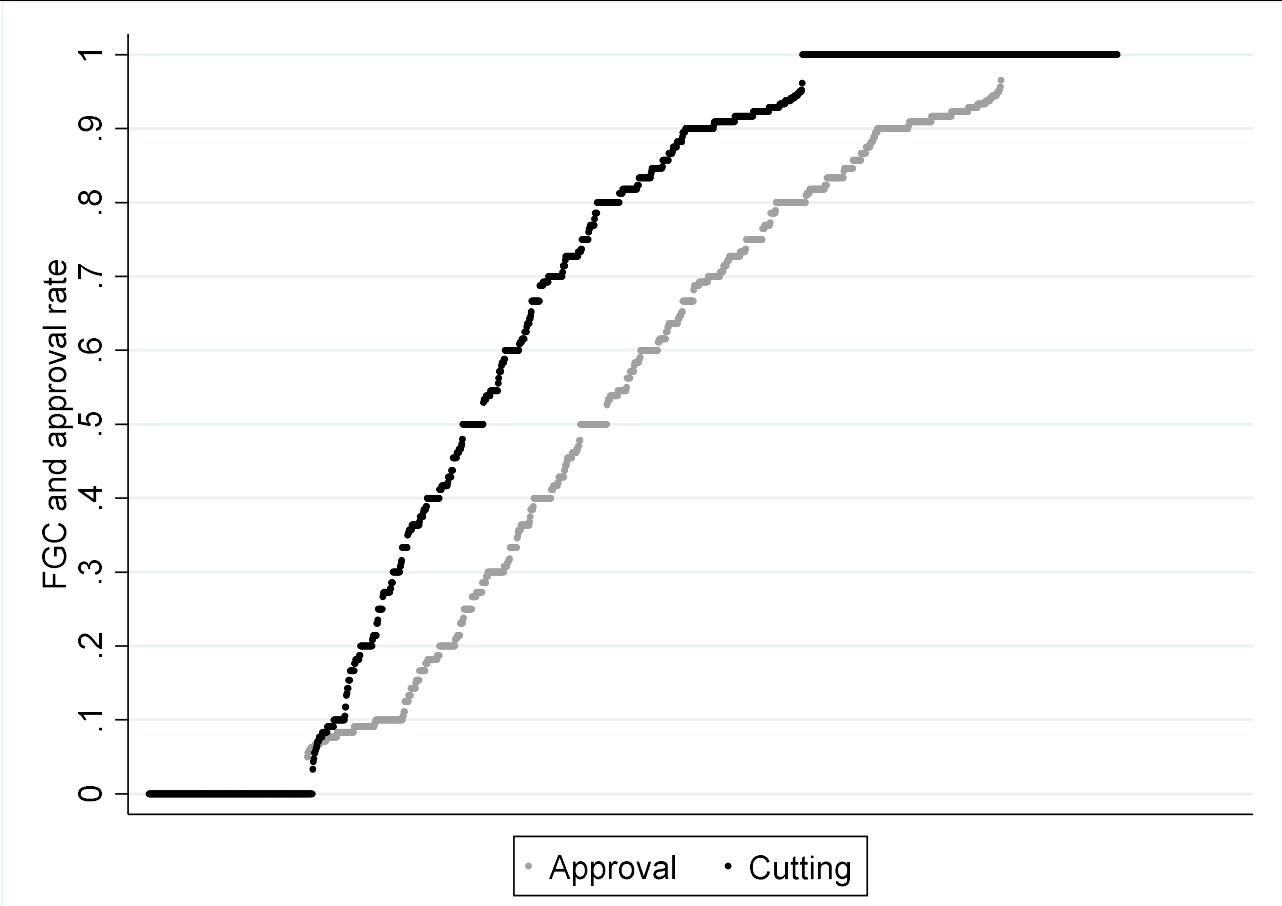

Note: Computed for clusters with a minimum of 10 observations 
Figure A8: Distribution of support for FGC and cutting of daughters by country - Community defined by sample cluster
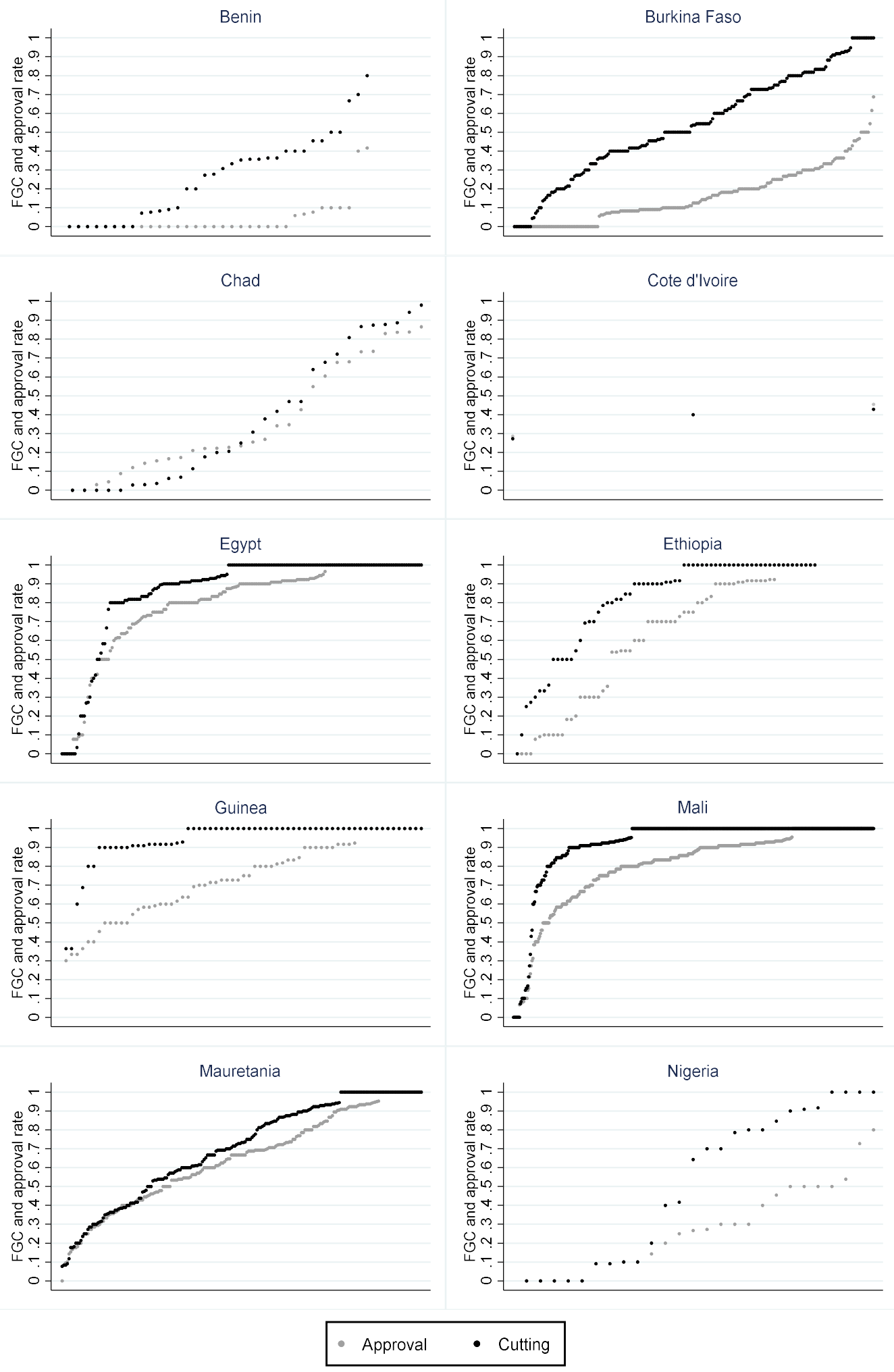

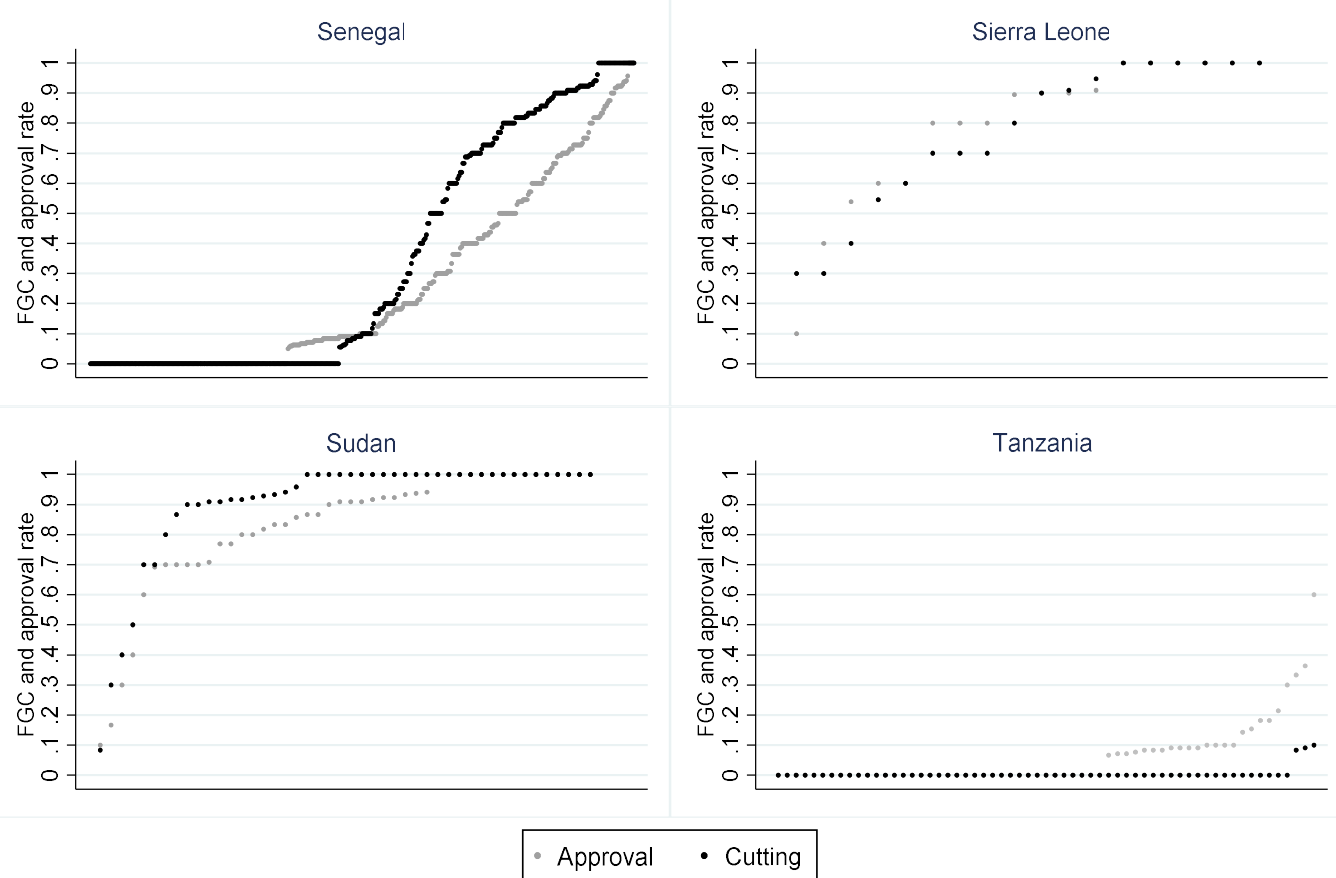

Note: Computed for clusters with a minimum of 10 observations 
Table A12: Testing if the relationship between FGC rate of daughter's and the community cut rate is more concave for mothers who support the practice than for mothers who oppose the practice by country-Community defined by sample cluster

\begin{tabular}{lccc}
\hline & \multicolumn{2}{c}{ Community FGC rate squared*Mother supports FGC } & $N$ \\
\hline Pooled & $-0.965^{* * *}$ & $(0.174)$ & 69,528 \\
\hline Benin & -0.147 & $(0.557)$ & 4,267 \\
Burkina Faso & $-0.321^{*}$ & $(0.137)$ & 6,287 \\
Chad & $-1.603^{* * *}$ & $(0.198)$ & 2,203 \\
Cote d'Ivoire & $-1.307^{* * *}$ & $(0.352)$ & 622 \\
Egypt & -0.486 & $(0.371)$ & 14,533 \\
Ethiopia & -0.315 & $(0.473)$ & 6,391 \\
Guinea & $-3.089^{* * *}$ & $(0.756)$ & 2,802 \\
Kenya & $-0.950^{* *}$ & $(0.359)$ & 2,309 \\
Mali & $-1.892^{* * *}$ & $(0.117)$ & 11,335 \\
Mauretania & $-0.510^{*}$ & $(0.222)$ & 3,324 \\
Nigeria & $-0.752^{*}$ & $(0.313)$ & 3,445 \\
Senegal & $-1.567^{* * *}$ & $(0.116)$ & 12,525 \\
Sierra Leone & $0.194^{* * *}$ & $(0.023)$ & 1,723 \\
Sudan & $-1.289^{* *}$ & $(0.356)$ & 1,799 \\
Tanzania & $-1.476^{* * *}$ & $(0.508)$ & 2,365 \\
\hline
\end{tabular}

Notes: Standard errors clustered at the subnational region in parentheses. ${ }^{* * *} p<0.01,{ }^{* *} p<0.05,{ }^{*} p<0.1$; Social convention theory predicts a more concave relationship between FGC rate of daughters and the community cut rate for mothers who support the practice than for mothers who oppose the practise. If so the coefficient on the 'community $\mathrm{FGC}$ rate squared times support $\mathrm{FGC}^{\prime}$ 'variable should be negative. The community FGC rate refers to girls of the same ethnic-region group who were born 1-6 years earlier than the daughters. The full model also includes the community FGC rate, the community FGC rate squared, a support FGC dummy, the community FGC rate times support FGC, the daughter's year of birth and age, religion, level of education, and urban residence; Religion dummies not in Tanzania and Mauretania. So few Tanzania observations and no Mauretania in the pooled.

Table A13 : Predictive power of the community cut rate and the mother's expressed preference for FGC for daughters' FGC status by country - daughters at most five years older than the $95 \%$ cut-age

\begin{tabular}{llllll}
\hline & \multicolumn{2}{c}{ Community $\mathrm{FGC}$ rate } & \multicolumn{2}{c}{ Mother supports FGC } & $\mathrm{N}$ \\
\hline Pooled sample & $0.677^{* * *}$ & $(0.020)$ & $0.299^{* * *}$ & $(0.021)$ & 32,873 \\
\hline Benin & $0.578^{* * *}$ & $(0.050)$ & $0.151^{*}$ & $(0.082)$ & 2,426 \\
Burkina Faso & $0.537^{* * *}$ & $(0.042)$ & $0.329^{* * *}$ & $(0.021)$ & 4,075 \\
Chad & $0.680^{* * *}$ & $(0.047)$ & $0.330^{* * *}$ & $(0.043)$ & 1,347 \\
Cote d'Ivoire & $0.551^{* * *}$ & $(0.054)$ & $0.263^{* * *}$ & $(0.041)$ & 351 \\
Ethiopia & $0.652^{* * *}$ & $(0.073)$ & $0.210^{* * *}$ & $(0.054)$ & 3,461 \\
Guinea & $1.066^{* * *}$ & $(0.189)$ & $0.076^{* *}$ & $(0.022)$ & 1,819 \\
Kenya & $0.721^{* * *}$ & $(0.083)$ & $0.288^{* * *}$ & $(0.073)$ & 1,367 \\
Mali & $0.768^{* * *}$ & $(0.041)$ & $0.264^{* * *}$ & $(0.043)$ & 6,362 \\
Nigeria & $0.686^{* * *}$ & $(0.057)$ & $0.467^{* * *}$ & $(0.060)$ & 1,772 \\
Senegal & $0.589^{* * *}$ & $(0.033)$ & $0.430^{* * *}$ & $(0.038)$ & 8,220 \\
Sierra Leone & $0.732^{* *}$ & $(0.188)$ & $0.129^{*}$ & $(0.056)$ & 1,673 \\
\hline Notes: Stand
\end{tabular}

Notes: Standard errors clustered at the subnational region in parentheses. ${ }^{* * *} p<0.01,{ }^{* *} p<0.05,{ }^{*} p<0.1$; The community cut rate refers to the FGC rate among women in the same ethnic group and region who were born 1-6 years earlier than the respondent. 
Figure A9: Distribution of support for FGC and cutting of daughters - daughters at most five years older than the $95 \%$ cut-age

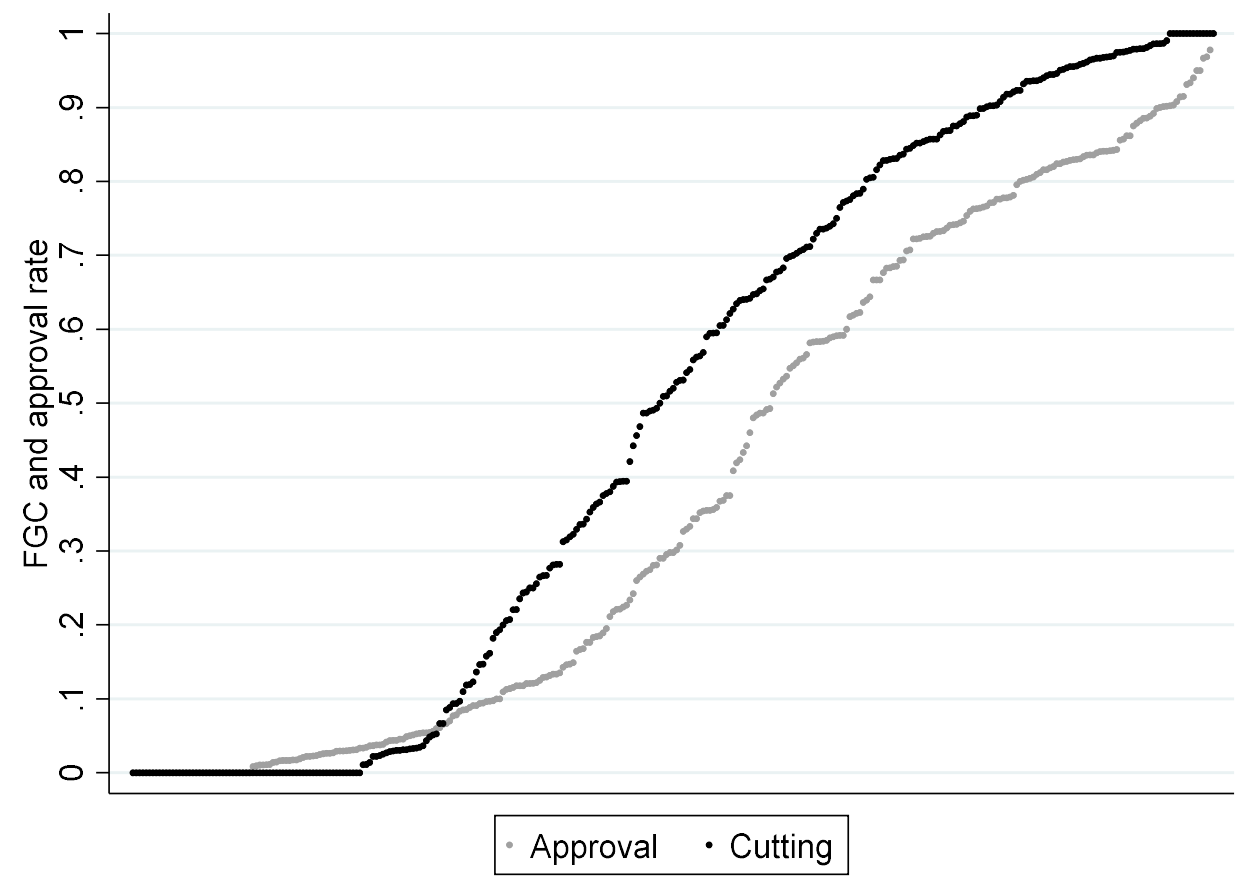


Figure A10: Distribution of support for FGC and cutting of daughters by country - daughters at most five years older than the $95 \%$ cut-age
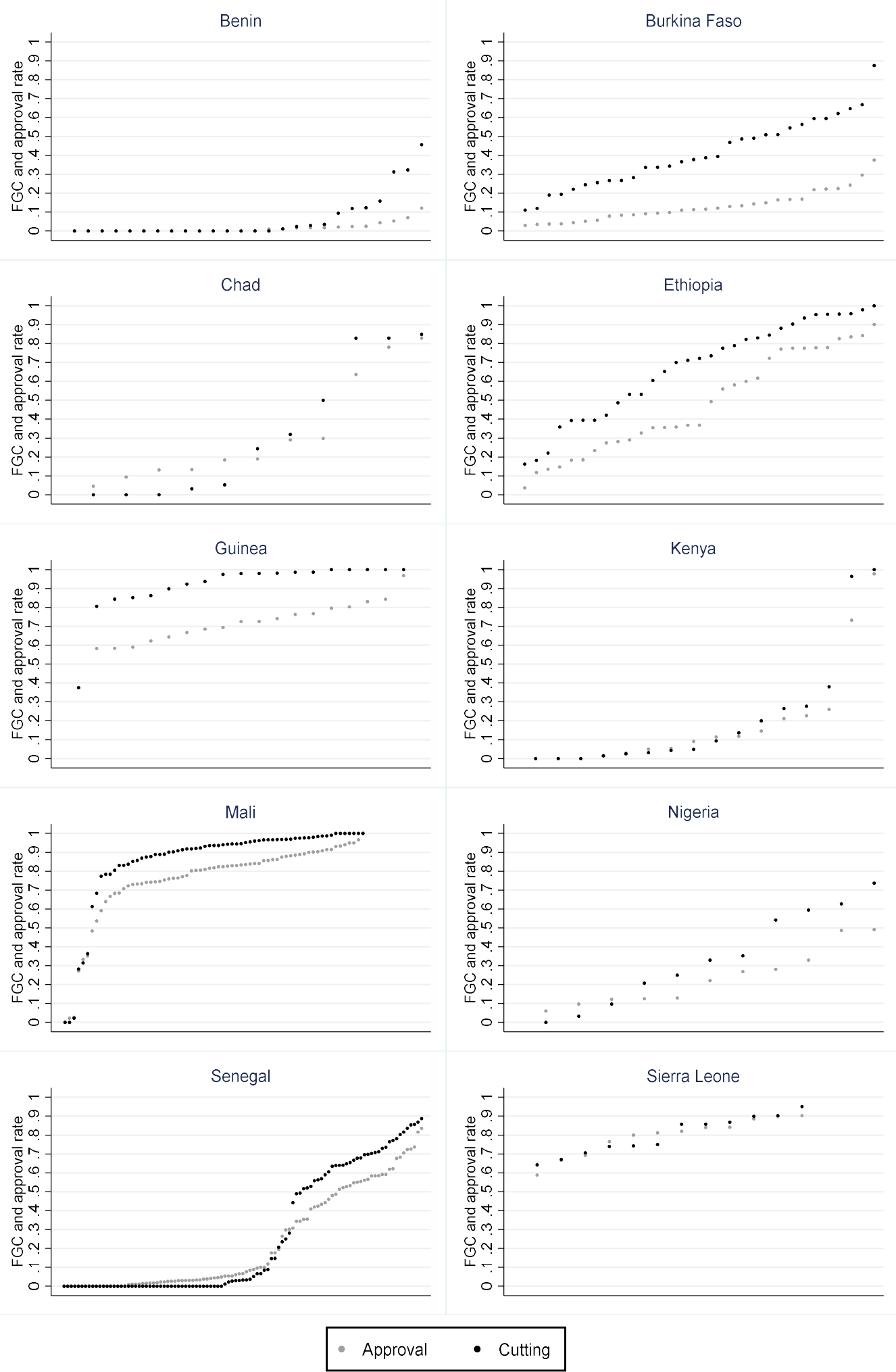
Note: Cote d'Ivoire is excluded in this analysis as the region-ethnic groups are not sufficiently large.

Table A14: Testing if the relationship between FGC rate of daughter's and the community cut rate is more concave for mothers who support the practice than for mothers who oppose the practice by country-daughters at most five years older than the $95 \%$ cut-age

\begin{tabular}{|c|c|c|c|}
\hline & \multicolumn{2}{|c|}{ Community FGC rate squared*Mother supports FGC } & \multirow{2}{*}{$\begin{array}{c}N \\
23,068 \\
\end{array}$} \\
\hline Pooled & $-1.255^{* * *}$ & $(0.192)$ & \\
\hline Benin & 0.370 & $(0.600)$ & 1,478 \\
\hline Burkina Faso & -0.274 & $(0.233)$ & 3,201 \\
\hline Chad & $-1.520 * * *$ & $(0.355)$ & 893 \\
\hline Cote d'Ivoire & $-2.621 * * *$ & $(0.664)$ & 194 \\
\hline Ethiopia & 0.190 & $(0.822)$ & 2,657 \\
\hline Guinea & 0.213 & $(0.651)$ & 1,304 \\
\hline Kenya & $-1.881 * * *$ & $(0.254)$ & 1,128 \\
\hline Mali & $-1.311 * * *$ & $(0.314)$ & 4,693 \\
\hline Nigeria & $-2.781 * *$ & $(0.968)$ & 1,086 \\
\hline Senegal & $-1.812 * * *$ & $(0.319)$ & 5,415 \\
\hline Sierra Leone & -2.172 & $(3.036)$ & 1,019 \\
\hline \multicolumn{4}{|c|}{$\begin{array}{l}\text { Notes: Standard errors clustered at the subnational region in parentheses. }{ }^{* *} \mathrm{p}<0.01,{ }^{*} \mathrm{p}<0.05, * \mathrm{p}<0.1 \text {; } \\
\text { Social convention theory predicts a more concave relationship between FGC rate of daughters and the } \\
\text { community cut rate for mothers who support the practice than for mothers who oppose the practise. If so the } \\
\text { coefficient on the 'community FGC rate squared times support FGC' variable should be negative. The } \\
\text { community FGC rate refers to girls of the same ethnic-region group who were born 1-6 years earlier than the } \\
\text { daughters. The full model also includes the community FGC rate, the community FGC rate squared, a support } \\
\text { FGC dummy, the community FGC rate times support FGC, the daughter's year of birth and age, religion, level }\end{array}$} \\
\hline
\end{tabular}




\section{Appendix III: Complementary analysis on intergenerational transmission and on the distribution of respondents' community cut rates}

Table A15: Predictive power of the community cut rate, the mother's expressed preference for FGC and the mother's FGC status for daughters' FGC status by country

Mother is cut Mother supports FGC Community FGC rate $\mathrm{N}$

\begin{tabular}{|c|c|c|c|c|c|c|c|}
\hline Benin & $0.0992 * * *$ & $(0.0237)$ & $0.570 * * *$ & $(0.0745)$ & 0.155 & (0.0941) & 4094 \\
\hline Burkina Faso & $0.410 * * *$ & $(0.0500)$ & $0.419 * * *$ & $(0.0640)$ & $0.257^{* * *}$ & $(0.0152)$ & 6565 \\
\hline Chad & $0.520 * * *$ & (0.0514) & $0.308 * * *$ & $(0.0496)$ & $0.154 * * *$ & $(0.0273)$ & 2018 \\
\hline Cote d'Ivoire & $0.337 * * *$ & $(0.0730)$ & $0.293^{* *}$ & $(0.0964)$ & $0.203 * * *$ & $(0.0357)$ & 468 \\
\hline Ethiopia & $0.436 * * *$ & $(0.0571)$ & $0.378 * * *$ & (0.0969) & $0.143^{* * *}$ & (0.0326) & 6306 \\
\hline Guinea & $0.353^{* *}$ & $(0.122)$ & $1.108 * * *$ & $(0.127)$ & $0.0573 * *$ & $(0.0187)$ & 2770 \\
\hline Kenya & $0.127^{* *}$ & $(0.0370)$ & $0.631^{* * *}$ & $(0.0864)$ & $0.252^{* * *}$ & (0.0547) & 2225 \\
\hline Mali & $0.563 * * *$ & $(0.0574)$ & $0.324 * * *$ & $(0.0664)$ & $0.145^{* * *}$ & $(0.0172)$ & 10558 \\
\hline Nigeria & $0.449 * * *$ & (0.0708) & $0.289 * *$ & $(0.0746)$ & $0.318 * * *$ & $(0.0241)$ & 3210 \\
\hline Senegal & $0.423 * * *$ & (0.0459) & $0.262 * * *$ & $(0.0464)$ & $0.284 * * *$ & $(0.0273)$ & 11622 \\
\hline Sierra Leone & 0.194 & $(0.140)$ & $0.656^{* *}$ & (0.147) & $0.138^{*}$ & (0.0559) & 2626 \\
\hline
\end{tabular}

Table A16: Comparing the influence of the community cut rate in the mother's previous region to the one in the current region on actual cutting or intentions to cut - community defined by region and birth year.

(1) (3)

\begin{tabular}{lccc}
\hline Cut rate in mother's & -0.050 & -0.158 & -0.095 \\
previous region & $(0.111)$ & $(0.101)$ & $(0.094)$ \\
& $0.444^{* * *}$ & $0.340^{* * *}$ & $0.226^{* *}$ \\
Cut rate in current region & $(0.118)$ & $(0.117)$ & $(0.093)$ \\
& & $0.178^{* * *}$ & $0.118^{* * *}$ \\
Mother is cut & & $(0.040)$ & $(0.030)$ \\
& & & $0.305^{* * *}$ \\
Mother support FGC & & Yes & $(0.042)$ \\
& & Yes & Yes \\
Individual controls & Yes & 0.55 & Yes \\
Country*yob FEs & 0.54 & 2,856 & 0.60 \\
$R^{2}$ & 2,856 & 2,856 \\
$N$ & & & 2,050 \\
\hline
\end{tabular}

Notes: Standard errors clustered at the subnational region in parentheses. ${ }^{* * *} p<0.01,{ }^{* *} p<0.05,{ }^{*} p<0.1$ 
Table A17: Comparing the influence of the community cut rate in the ethnic group in the current region and in the previous region of the mother on daughters' cut status (including intentions to cut)

\begin{tabular}{|c|c|c|c|c|c|c|c|}
\hline & \multicolumn{2}{|c|}{ Previous region } & \multicolumn{2}{|c|}{ Current region } & \multicolumn{2}{|c|}{ Mother is cut } & \multirow[t]{2}{*}{$\mathrm{N}$} \\
\hline Panel A & & & & & & & \\
\hline Ethiopia & -0.051 & $(0.224)$ & -0.010 & $(0.100)$ & 0.116 & $(0.065)$ & 313 \\
\hline Guinea & 0.685 & $(0.382)$ & 0.408 & $(0.231)$ & $0.351 * * *$ & $(0.075)$ & 498 \\
\hline Mali & -0.074 & (0.101) & 0.243 & (0.145) & $0.653^{* * *}$ & $(0.123)$ & 231 \\
\hline Nigeria & $0.240 * * *$ & $(0.045)$ & $-0.313^{*}$ & $(0.124)$ & $0.261^{* *}$ & (0.099) & 163 \\
\hline \multicolumn{8}{|c|}{ Panel B - community defined by region and birth year only } \\
\hline Ethiopia & -0.163 & $(0.273)$ & $0.401^{* *}$ & $(0.131)$ & $0.108^{* *}$ & $(0.041)$ & 363 \\
\hline Guinea & $0.411^{*}$ & $(0.211)$ & $1.170^{* * *}$ & $(0.138)$ & $0.495^{* * *}$ & $(0.083)$ & 511 \\
\hline Mali & 0.036 & $(0.104)$ & $0.193^{*}$ & (0.091) & $0.683 * * *$ & (0.117) & 279 \\
\hline Nigeria & 0.021 & $(0.413)$ & $0.784^{* *}$ & $(0.207)$ & $0.245^{* * *}$ & $(0.042)$ & 323 \\
\hline Tanzania* & -0.038 & $(0.036)$ & $0.075^{* * *}$ & $(0.024)$ & 0.024 & $(0.017)$ & 1,38 \\
\hline
\end{tabular}

Notes: Standard errors clustered at the subnational region in parentheses. ${ }^{* * *} p<0.01,{ }^{* *} p<0.05,{ }^{*} p<0.1 ;$ The regressions also control for individual-level controls and birth-year fixed effects. No control for religion or ethnicity in the Tanzania sample. 
Figure A11: FGC rates in ethnic groups in Benin over time
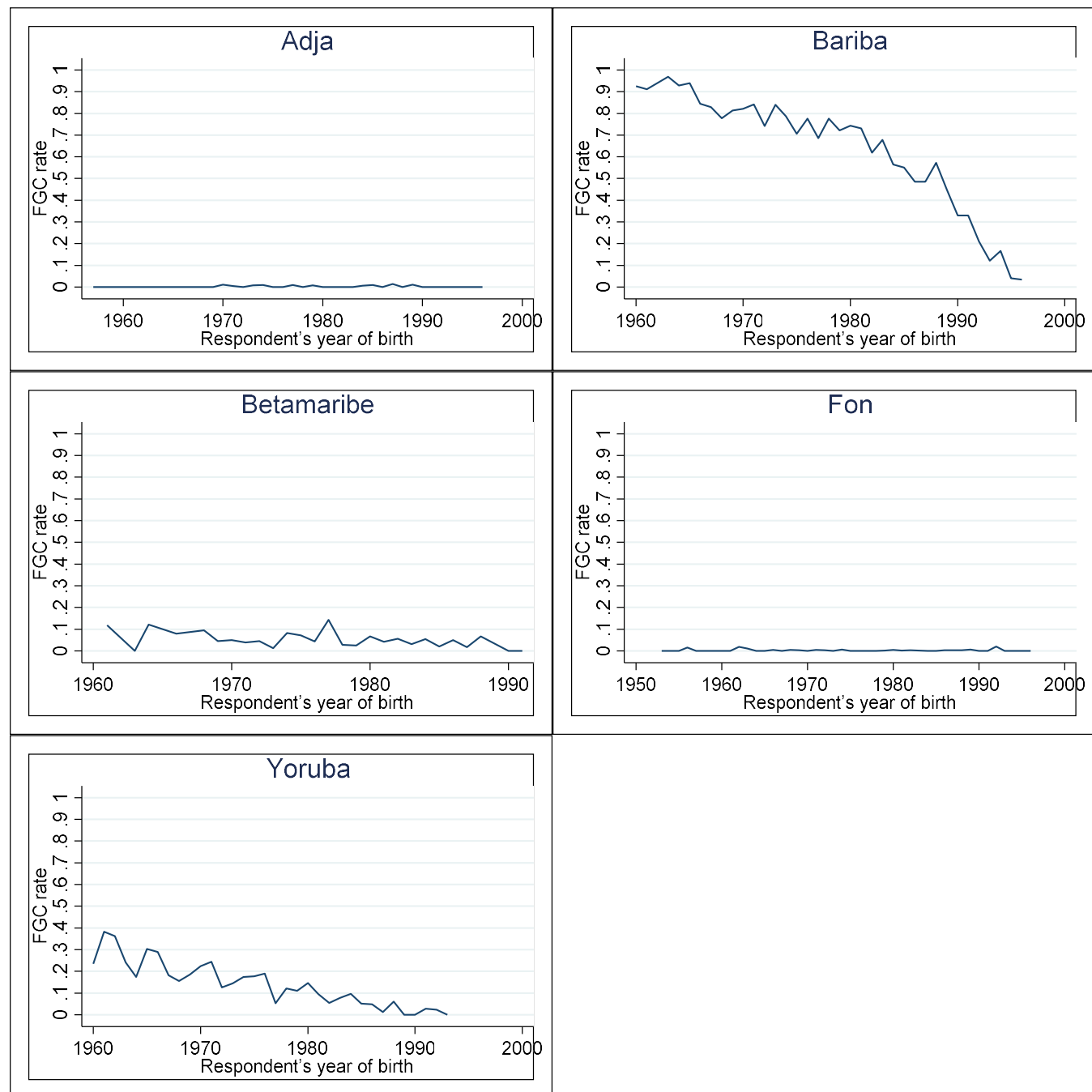
Figure A12: FGC rates in ethnic groups in Burkina Faso over time

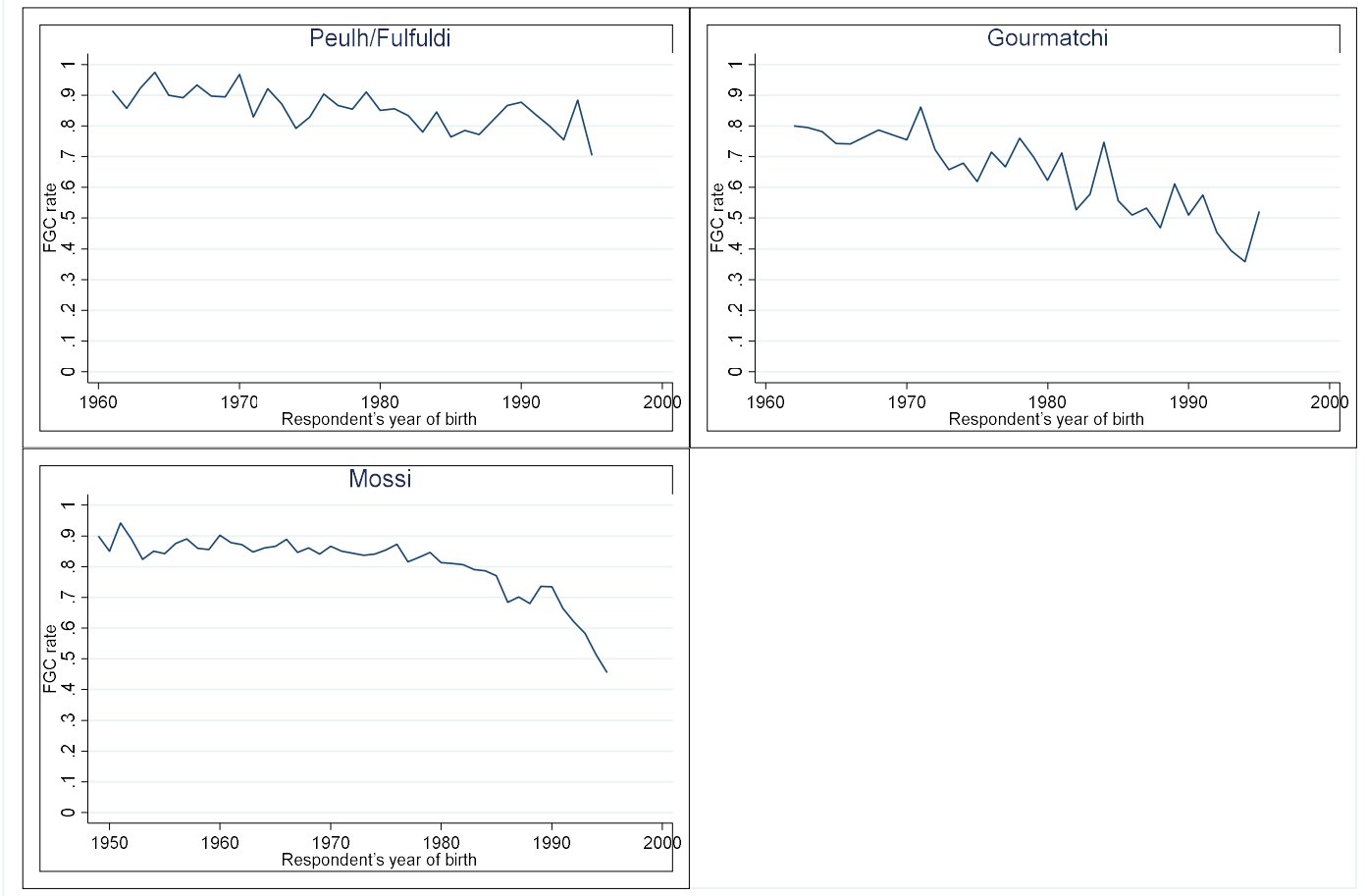

Figure A13: FGC rates in ethnic groups in Chad over time
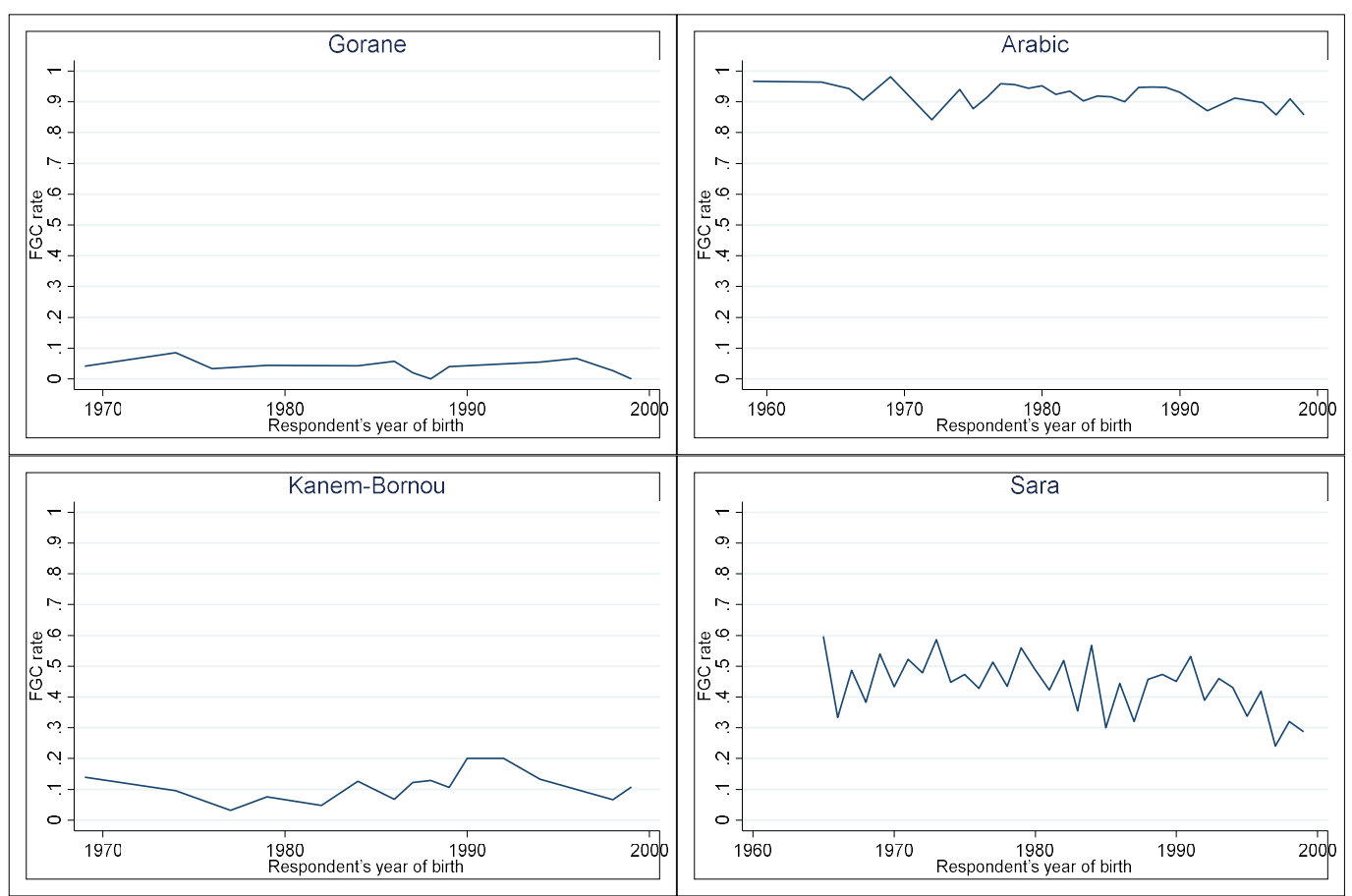
Figure A14: FGC rates in ethnic groups in Cote d'Ivoire over time

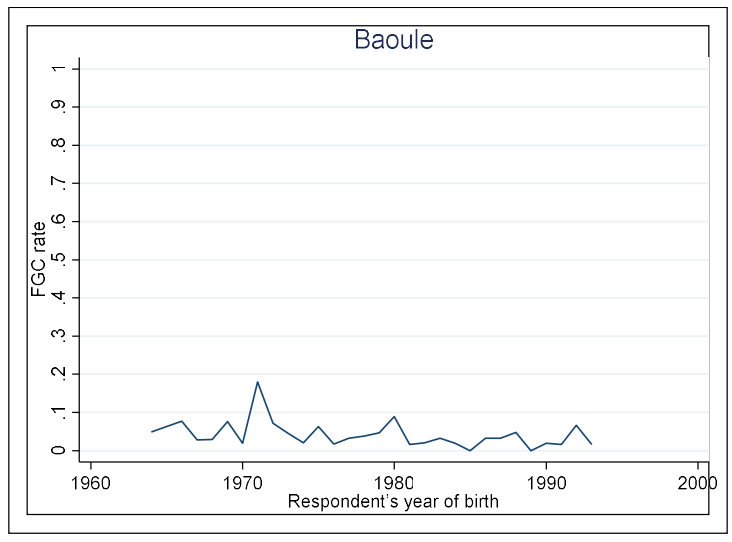

Figure A15: FGC rates in ethnic groups in Ethiopia over time

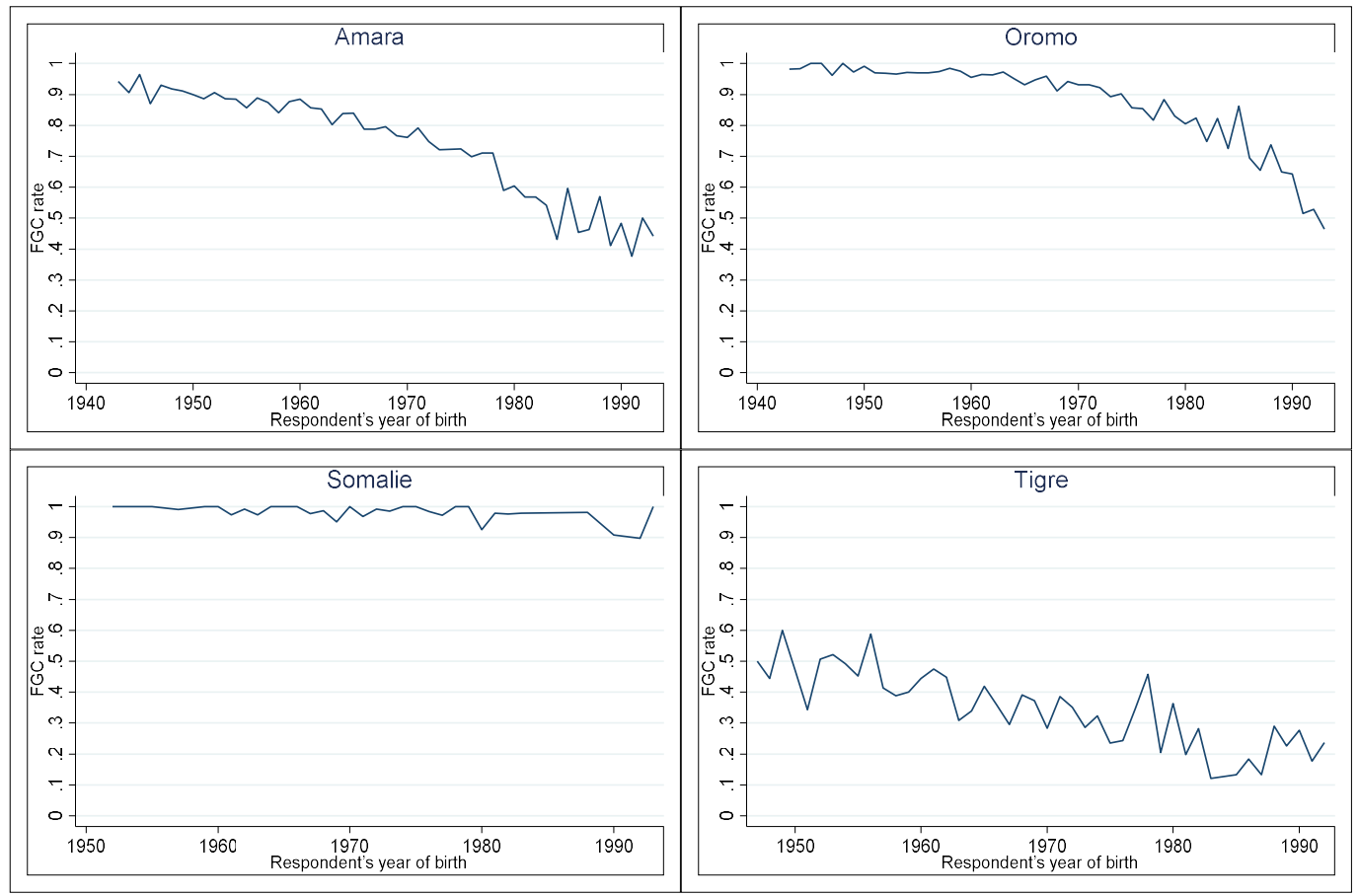

FGC rates in ethnic groups in Liberia over time

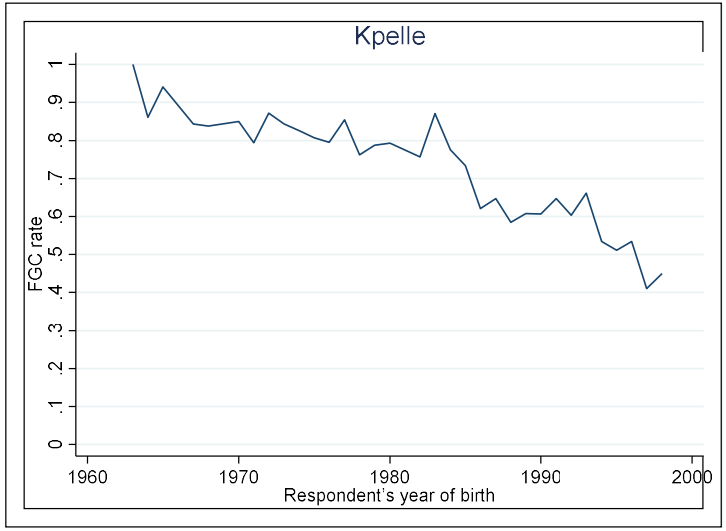


Figure A16: FGC rates in ethnic groups in Gambia over time

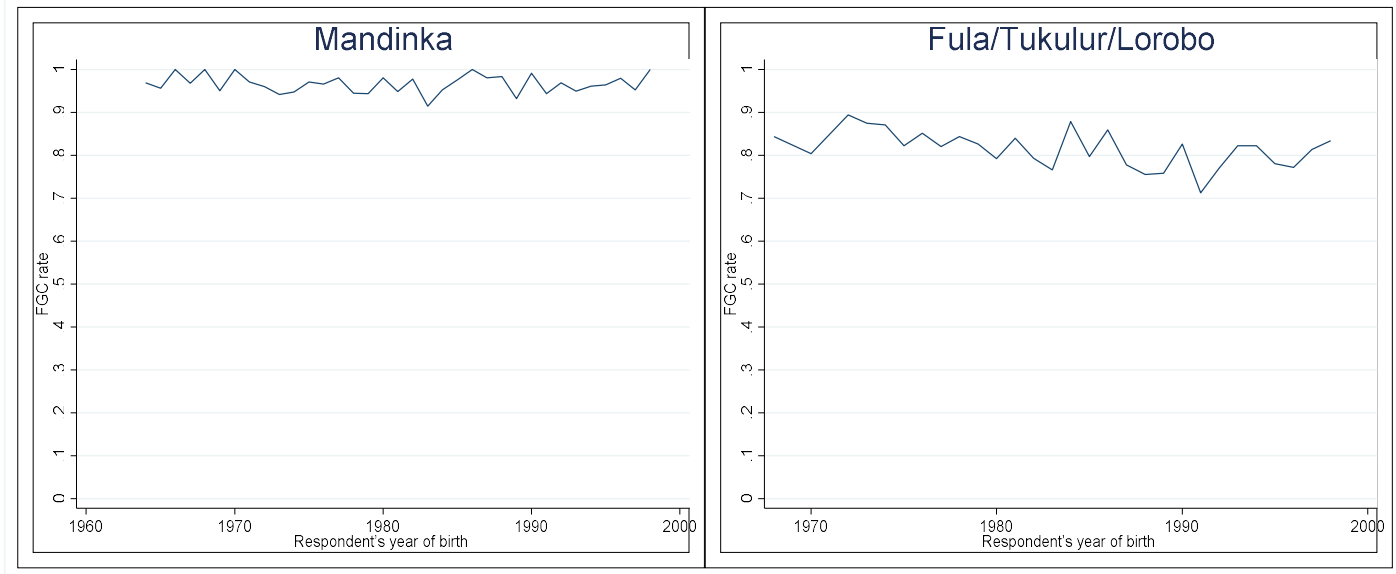

Figure A17: FGC rates in ethnic groups in Guinea over time
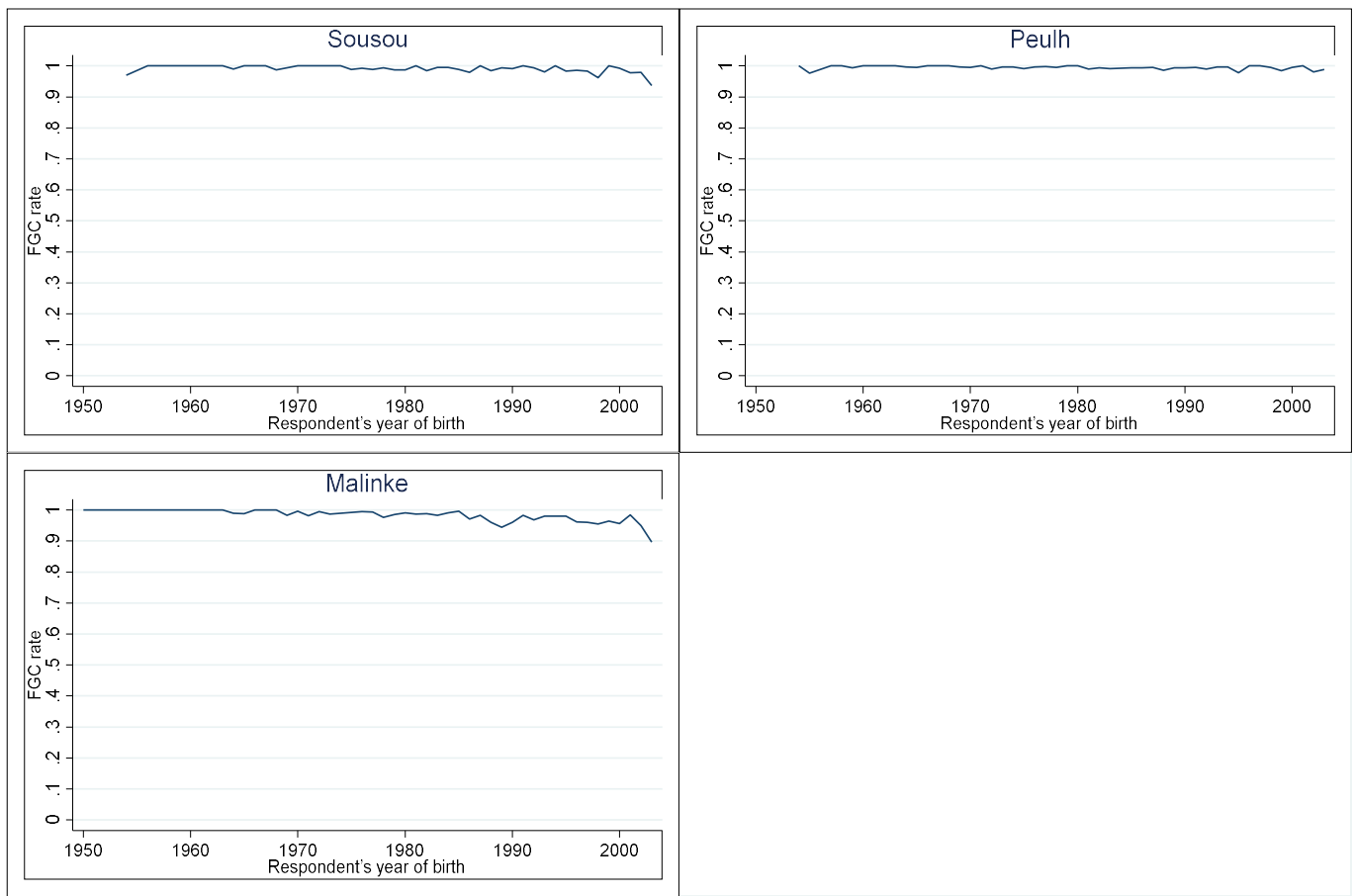
Figure A18: FGC rates in ethnic groups in Kenya over time
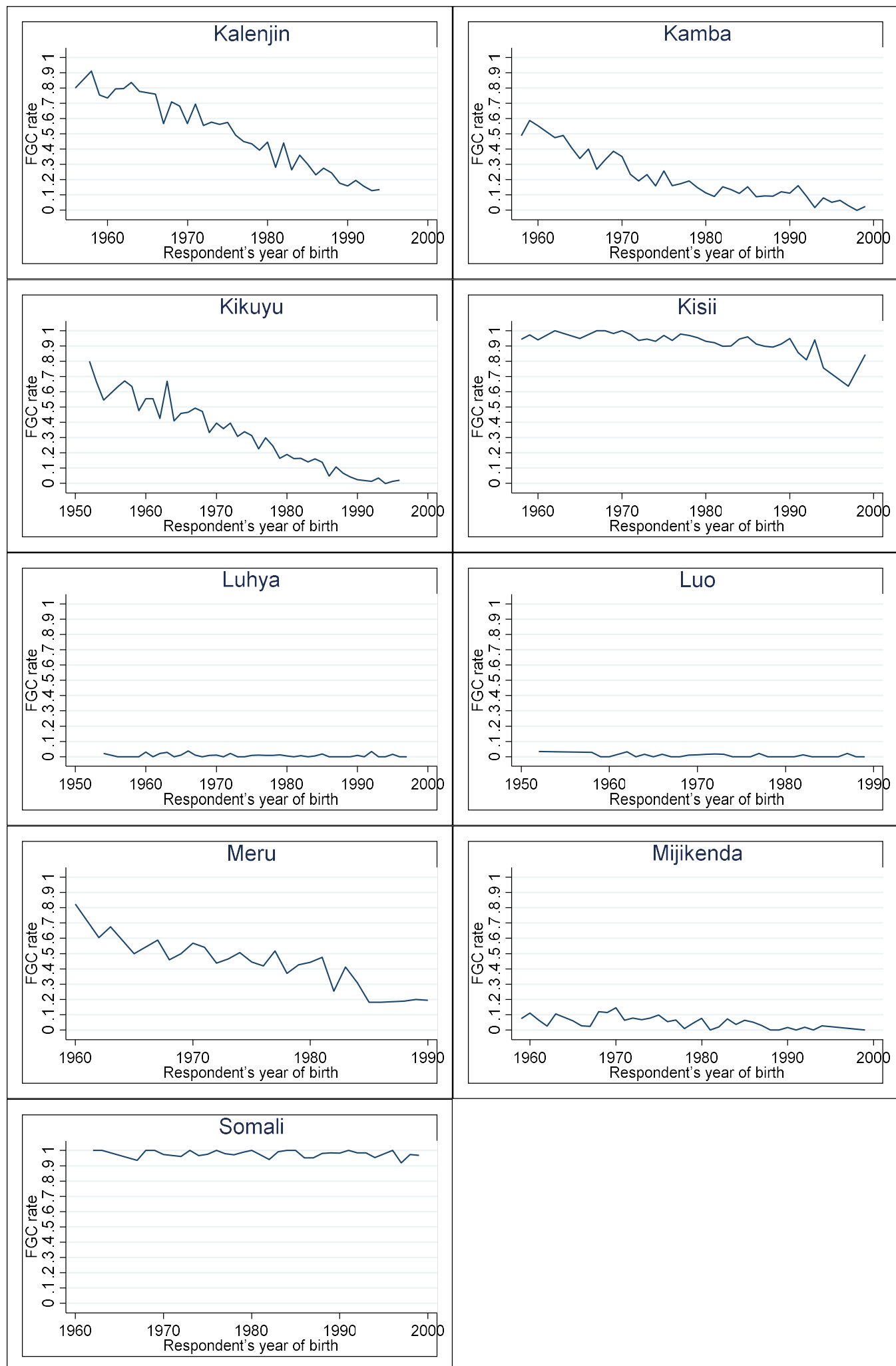
Figure A19: FGC rates in ethnic groups in Mali over time
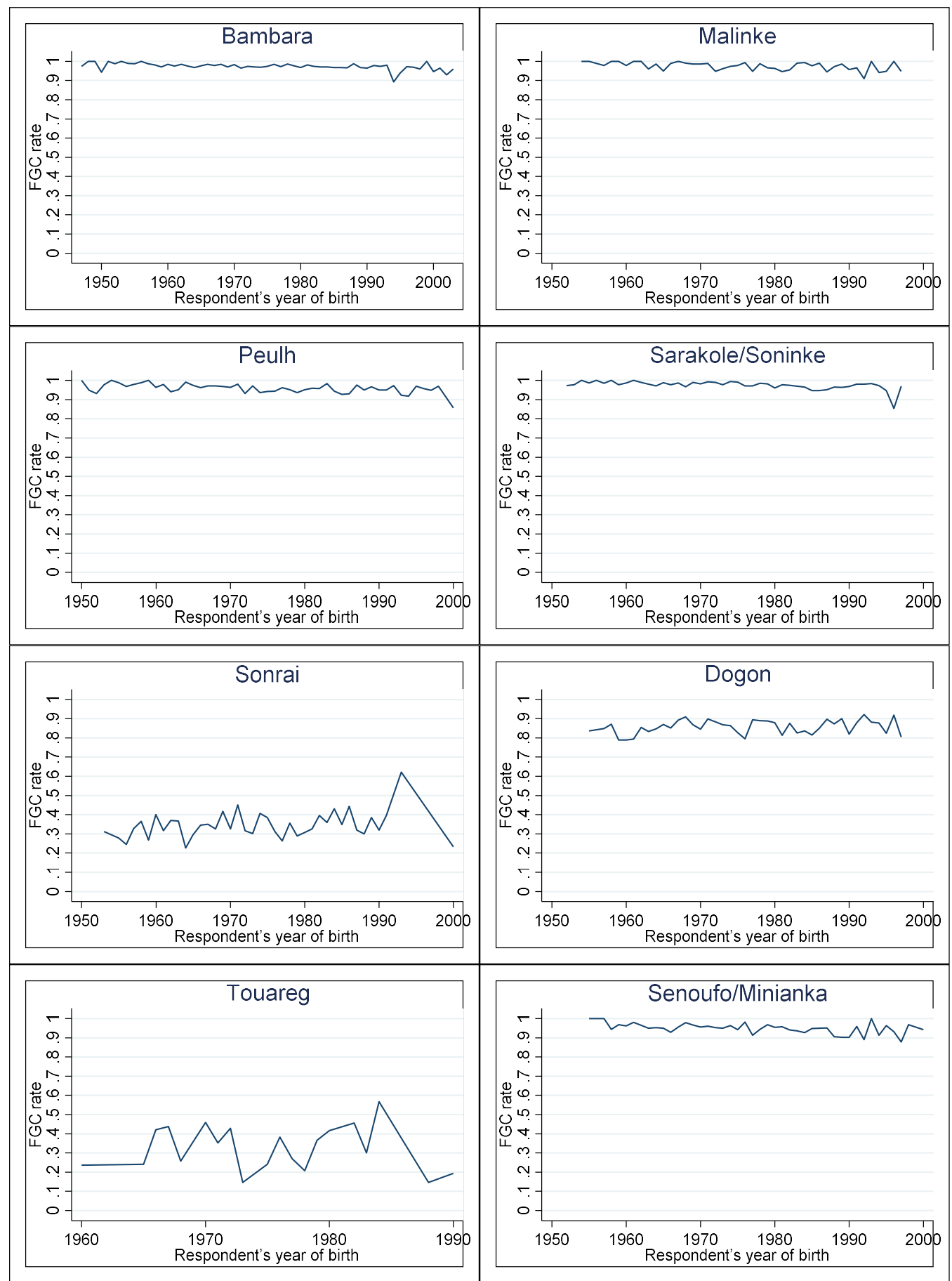
Figure A20: FGC rates in ethnic groups in Nigeria over time

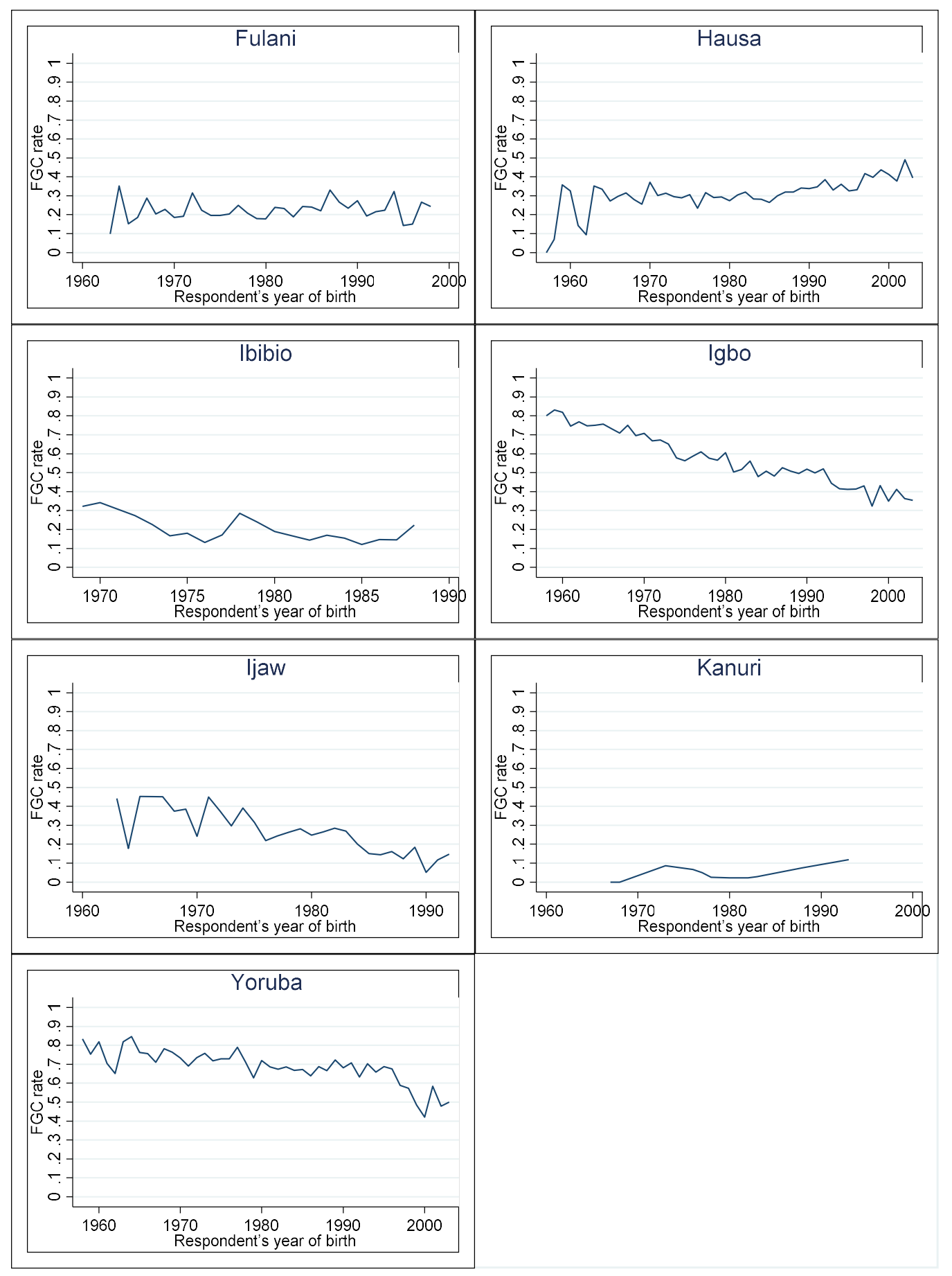


Figure A21: FGC rates in ethnic groups in Senegal over time

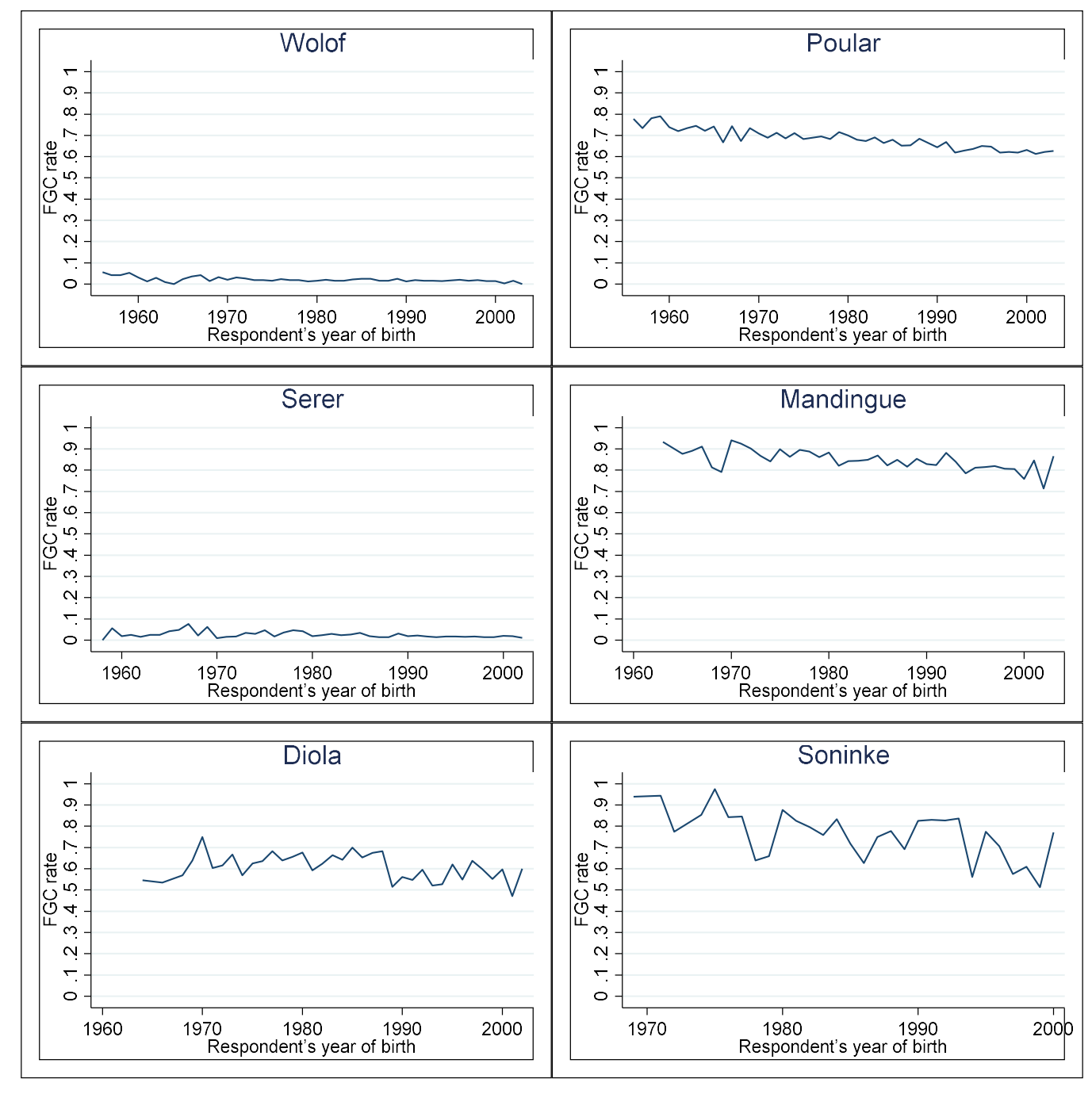

Figure A22: FGC rates in ethnic groups in Sierra Leone over time

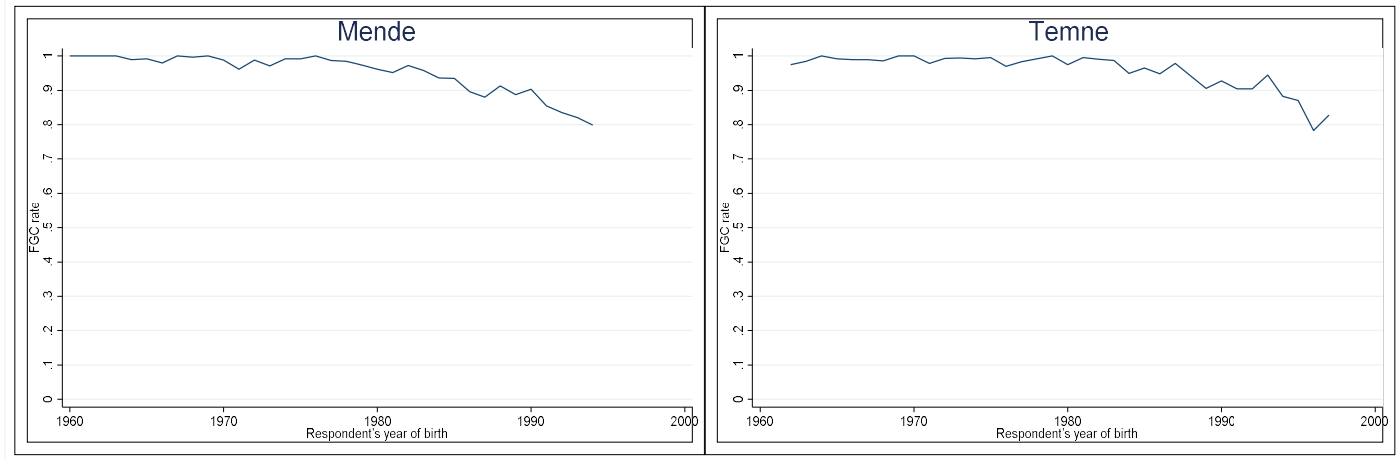


Table A18: Classification of ethnic groups according to pattern of FGC rates over time

\begin{tabular}{|c|c|c|c|c|}
\hline & Stable high & Stable low & Internal & Falling \\
\hline Countries & $\begin{array}{l}\text { Somalie, Ethiopia } \\
\text { Mandinka, Gambia } \\
\text { Sousou, Guinea } \\
\text { Peulh, Guinea } \\
\text { Malinke, Guinea } \\
\text { Somalie, Kenya } \\
\text { Bambara, Mali } \\
\text { Malinke, Mali } \\
\text { Peulh Mali* } \\
\text { Senoufo, Mali }\end{array}$ & $\begin{array}{l}\text { Adja, Benin } \\
\text { Fon, Benin } \\
\text { Betamaribe, Benin* } \\
\text { Gorane, Chad* } \\
\text { Baoule, Cote d'Ivoire } \\
\text { Luhya, Kenya } \\
\text { Luo, Kenya } \\
\text { Mijikenda, Kenya* } \\
\text { Wolof, Senegal } \\
\text { Serer, Senegal }\end{array}$ & $\begin{array}{l}\text { Arabic, Chad* } \\
\text { Kanem-Bomou, Chad } \\
\text { Sara, Chad } \\
\text { Fula, Gambia } \\
\text { Sonrai, Mali } \\
\text { Dogon, Mali } \\
\text { Touareg, Mali } \\
\text { Fulani, Nigeria } \\
\text { Hausa, Nigeria } \\
\text { Kanuri, Nigeria* } \\
\text { Mandinge, Senegal* } \\
\text { Diola, Senegal }\end{array}$ & $\begin{array}{l}\text { Bariba, Benin } \\
\text { Yoruba; Benin } \\
\text { Peulh, Burkina Faso* } \\
\text { Gourmatchi, Burkina } \\
\text { Faso } \\
\text { Mossi, Burkina Faso } \\
\text { Amara, Ethiopia } \\
\text { Oromo, Ethiopia } \\
\text { Tigre, Ethiopia } \\
\text { Kpelle, Liberia } \\
\text { Kalenjin, Kenya } \\
\text { Kamba, Kenya } \\
\text { Kikuyu, Kenya } \\
\text { Kisii, Kenya* } \\
\text { Meru, Kenya } \\
\text { Ibibio, Nigeria* } \\
\text { Igbo, Nigeria } \\
\text { ljaw, Nigeria } \\
\text { Yoruba, Nigeria } \\
\text { Poular, Senegal } \\
\text { Soninke, Senegal* } \\
\text { Mende, Sierra Leone } \\
\text { Temne, Sierra Leone }\end{array}$ \\
\hline Total & 10 & 10 & 12 & 23 \\
\hline Starred & 1 & 3 & 3 & 4 \\
\hline
\end{tabular}

Notes: We consider stable low to be cases where the cut rate is $<10 \%$ and stable high where the cut rate is $>90 \%$. Therefore, some groups will be considered falling if the rate falls under $90 \%$ in consecutive years. A group is starred if it was not completely clear how to classify it.

\section{References}

Efferson,C., Vogt, S., Elhadi, A., Hilal El Fadil, A. and E. Fehr (2015) “Female genital cutting is not a social coordination norm", Science, 349 (6255), pp. 1446-1447.

Orchid Project (2021) "Where does FGC happen", available at: https://www.orchidproject.org/about-fgc/where-does-fgc-happen/

Yoder, PS., Wang, S. and E. Johansen (2013). Estimates of Female Genital Mutilation/Cutting in 27 African Countries and Yemen, Studies in Family Planning, 44(2), pp. 189-204. 